\title{
Aspectos Analítico-Numéricos da Modelagem Matemática da Infecção pelo HIV
}

\author{
Ariovaldo José de Almeida
}

\author{
TESE APRESENTADA \\ AO \\ INSTITUTO DE MATEMÁTICA E ESTATÍSTICA \\ DA \\ UNIVERSIDADE DE SÃO PAULO \\ PARA \\ OBTENÇÃO DO GRAU \\ $\mathrm{DE}$ \\ DOUTOR EM MATEMÁTICA APLICADA
}

Área de Concentração: Sistemas Dinâmicos

Orientador Dr. Luis Carlos de Castro Santos 


\title{
Aspectos Analítico-Numéricos da Modelagem Matemática da Infecção pelo HIV
}

\author{
Este exemplar corresponde à redação final \\ da tese de doutorado devidamente corrigida e \\ defendida por Ariovaldo José de Almeida \\ e aprovada pela comissão julgadora.
}

São Paulo, agosto de 2003.

Banca examinadora:

- Prof. Dr. Luis Carlos de Castro Santos (Orientador) - IME - USP

- Profa. Dra. Élvia Mureb Sallum - IME - USP

- Prof. Dr. José Roberto Castilho Piqueira - EP - USP

- Prof. Dr. Paolo Marinho de Andrade Zanotto - ICB - USP

- Prof. Dr. Laécio Carvalho de Barros - UNICAMP 
Aos meus pais

Ariovaldo e Iracema 


\section{Agradecimentos}

Agradeço e gostaria de manifestar minha gratidão, admiração e respeito ao Prof. Luis Carlos de Castro Santos pela realização e orientação neste trabalho.

À Prof. Élvia Mureb Sallum pela sua experiência acadêmica e pessoal e pelas incontáveis vezes em que contribuiu enormemente para o aprimoramento e aperfeiçoamento em muitas das idéias aqui contidas.

Ao Prof. Antônio Luiz Pereira pelo incentivo e apoio.

Ao pessoal da Comissão de Pós-Graduação, em especial ao Pinho e à Franscisca pela dedicação e atenção sempre dispensadas.

Ao pessoal da Biblioteca, em especial à Sílvia pela simpatia e gentileza.

Ao amigo Joacir pelos comentários e opiniões dadas.

Às minhas queridas amigas Carla Vogel, Isabela de Paula, Regina Marques e Rosimeire Jerônimo pela amizade e companheirismo em todo tipo de situação.

Ao casal de amigos Fernando e Iara pela amizade e disposição em ajudar sempre.

À minha Família pelo suporte, compreensão e incentivo durante todas as etapas de minha jornada.

À Deus, O Senhor fez em mim maravilhas. 


\section{Resumo}

Neste trabalho, foram analisados alguns modelos matemáticos determinísticos que descrevem a interação do vírus HIV com o sistema imune.

A partir deles, foram obtidos resultados da Teoria Qualitativa, tais como, a existência e estabilidade de pontos de equilíbrio e, através da aplicação do Teorema de Bifurcação de Poincaré-Andronov-Hopf, estabeleceu-se a existência de órbitas periódicas e a estabilidade das mesmas.

Neste âmbito, foram sugeridos alguns tipos de variações, em função do tempo, para os parâmetros constantes dos modelos.

\section{Abstract}

This work aimed to analyse some deterministic mathematical models that describe the interaction of HIV virus with the immune system.

It was presented, from their analysis, some results of Qualitative Theory, such as, the existence and stability of critical points and, in relation to it, by application of the PoincareAndronov-Hopf Bifurcation Theorem, it was demonstrated the existence of periodic solutions and the stability of them.

In this scope, it was suggested some types of variation, in function of time, to the constant parameters of models. 


\section{Conteúdo}

Introdução vi

1 Modelos Matemáticos 1

1.1 Modelos Determinísticos . . . . . . . . . . . . . . . . 1

1.1.1 Um Modelo Simples de Dinâmica do HIV . . . . . . . . . 2

1.1.2 Um Modelo que Incorpora Produção Viral . . . . . . . . 2

1.1.3 Modelo com Inibidor de Transcriptase Reversa . . . . . 6

1.1.4 Um Modelo com Inibidor de Protease . . . . . . . . . . 6

1.1.5 Um Modelo com Inibidor de Protease Imperfeito . . . . 7

1.1.6 Combinação de Terapias . . . . . . . . . . . 8

2 Estudos Qualitativos 14

2.1 Análise Qualitativa ... . . . . . . . . . . . . . . . 14

2.1.1 Ponto de Equilíbrio Não Infectado . . . . . . . . . . . . . . . 18

2.1.2 Função de Liapunov . . . . . . . . . . . . . . . . . . . . . . . . 19

2.1.3 Ponto de Equilíbrio Infectado . . . . . . . . . . . . . 21

2.1.4 Bifurcação de Poincaré-Andronov-Hopf . . . . . . . . . 23

2.1.5 Estabilidade das Órbitas Periódicas . . . . . . . . . . 26

3 Alguns Métodos Numéricos em Equações Diferenciais 37

3.1 Considerações Iniciais . . . . . . . . . . . . . . . . . . . . . 37

3.2 Critério de Avaliação dos Métodos . . . . . . . . . . . . . . . . . . 40

3.3 Métodos Numéricos . . . . . . . . . . . . . . . . . . . . . . . . . 42

3.3.1 Método Runge-Kutta-Fehlberg . . . . . . . . . . . . . . 42

3.3.2 Método Obrechkoff . . . . . . . . . . . . . . . . . 45

3.3 .3 Método Gautshi . . . . . . . . . . . . . . . . . . 47

3.3 .4 Método Simos . . . . . . . . . . . . . . 53

3.4 Ilustrações Numéricas. . . . . . . . . . . . . . . . . . . . . 55 
3.4 .1 Oscilador de Van der Pol . . . . . . . . . . . . . 56

3.4 .2 Equações de Lorenz . . . . . . . . . . . . . . . . . . . . . . . . . . 59

3.4.3 O Modelo de Perelson . . . . . . . . . . . . . . . 61

4 Estudo da Variação dos Parâmetros $\quad 66$

4.1 Introdução . . . . . . . . . . . . . . . . . . . . . . . . . . . . . 67

4.2 Parâmetros Variando . . . . . . . . . . . . . . . . 67

4.2.1 Modelo de Perelson [1999] . . . . . . . . . . . . . . . 68

4.2 .2 Modelo de Perelson [1993] . . . . . . . . . . . . . . . 83

4.2 .3 Modelo de Kirschner [1996] . . . . . . . . . . . . . . . 94

5 Considerações Finais 106

$\begin{array}{ll}\text { Apêndice } & 107\end{array}$

A Resultados Técnicos 108

A.1 Critério de Liapunov . . . . . . . . . . . . . . . . . . . . . 108

A.2 Teorema de Routh-Hurwitz . . . . . . . . . . . . . . . . . 109

A.3 Teorema de Poincaré-Andronov-Hopf . . . . . . . . . . . . . 109

$\begin{array}{ll}\text { Referências Bibliográficas } & 110\end{array}$ 


\section{Lista de Figuras}

3.1 Centro . . . . . . . . . . . . . . . . . 41

3.2 Gráfico de Desempenho do Método Runge-Kutta-Fehlberg . . 44

3.3 Gráfico de Desempenho do Método Obrechkoff . . . . . . . . . 47

3.4 Erro no método Gautshi em função da escolha do período $T$. 50

3.5 Gráfico de Desempenho do Método Gautshi . . . . . . . . . 52

3.6 Gráfico de Desempenho do Método Simos . . . . . . . . . 55

3.7 Bifurcação de Poincaré-Andronov-Hopf nas equações de Van

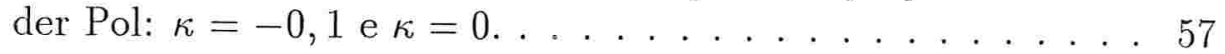

3.8 Bifurcação de Poincaré-Andronov-Hopf nas equações de Van der Pol: $\kappa=0,1$ e $\kappa=0,3 . \ldots \ldots$. . . . . . . . . 58

3.9 Uma órbita não-periódica nas Equações de Lorenz . . . . . . . 60

3.10 Bifurcação de Poincaré-Andronov-Hopf nas equações de Perelson: $s=0.8 \ldots \ldots \ldots \ldots \ldots \ldots \ldots \ldots \ldots \ldots$

3.11 Bifurcação de Poincaré-Andronov-Hopf nas equações de Perelson: $s=0.04 \ldots \ldots \ldots \ldots \ldots \ldots \ldots \ldots$

3.12 Bifurcação de Poincaré-Andronov-Hopf nas equações de Perelson: $s=0.01 \ldots \ldots \ldots \ldots \ldots \ldots \ldots \ldots$

4.1 Modelo de Perelson [1999]: Soluções com parâmetros constantes 69

4.2 Eficácia da droga: Doses tomadas em intervalos de 8 horas. $\beta$ assumido igual a $1 \ldots \ldots \ldots \ldots . \ldots \ldots$

4.3 Modelo de Perelson [1999]: Simulação feita na ausência de terapia . . . . . . . . . . . . . . . . 75

4.4 Modelo de Perelson [1999]: Simulação feita utilizando-se de um inibidores de protease com eficácia máxima $\beta=0,5 . \quad \ldots 76$

4.5 Modelo de Perelson [1999]: Simulação feita utilizando-se de um inibidor de protease com eficácia máxima $\beta=0,7 . \ldots 77$

4.6 Modelo de Perelson [1999]: Simulação feita utilizando-se de um inibidor de protease com eficácia máxima $\beta=0,9 . \quad \ldots 78$ 
4.7 Carga Viral $V$ em função da eficácia de drogas inibidoras da transcriptase reversa . . . . . . . . . . . . 80

4.8 Modelo de Perelson [1999]: Simulação feita utilizando-se inibidores de protease e de transcriptase reversa com eficácia máxima $\beta=0,5$ em ambas as drogas.

4.9 Modelo de Perelson [1999]: Simulação feita utilizando-se inibidores de protease e de transcriptase reversa com eficácia máxima $\beta=0,7$ em ambas as drogas. . . . . . . . . . 82

4.10 Modelo de Perelson [1993]: Soluções com parâmetros constantes 85

4.11 Modelo de Perelson [1993]: Simulação feita na ausência de terapia. . . . . . . . . . . . . . . . 87

4.12 Modelo de Perelson [1993]: Simulação feita utilizando-se um inibidor de protease com eficácia máxima $\beta=0,7 \ldots$. . . 89

4.13 Modelo de Perelson [1993]: Simulação feita utilizando-se um inibidor de protease com eficácia máxima $\beta=0,9 \ldots \ldots 90$

4.14 Modelo de Perelson [1993]: Simulação feita utilizando-se um inibidor de transcriptase reversa com eficácia máxima $\beta=0,7.91$

4.15 Modelo de Perelson [1993]: Simulação feita utilizando-se um inibidor de transcriptase reversa com eficácia máxima $\beta=0,9.92$

4.16 Modelo de Perelson [1993]: Simulação feita utilizando-se de inibidores de protease e inibidores de transcriptase reversa com eficácia máxima $\beta=0,9$ em ambas as drogas. . . . . . . . . . 93

4.17 Modelo de Kirschner [1996]: Soluções com parâmetros constantes, $g_{V}=5 \ldots \ldots \ldots \ldots \ldots \ldots$

4.18 Modelo de Kirschner [1996]: Soluções com parâmetros cons-

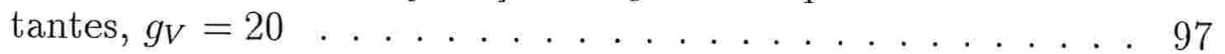

4.19 Modelo de Kirschner [1996]: Simulação feita na ausência de terapia.

4.20 Modelo de Kirschner [1996]: Simulação feita utilizando-se um inibidor de protease com eficácia máxima $\beta=0,5 \ldots$. . . . 100

4.21 Modelo de Kirschner [1996]: Simulação feita utilizando-se um inibidor de protease com eficácia máxima $\beta=0,9 \ldots$. . . . . 101

4.22 Modelo de Kirschner [1996]: Simulação feita utilizando-se um inibidor de transcriptase reversa com eficácia máxima $\beta=0,5.102$

4.23 Modelo de Kirschner [1996]: Simulação feita utilizando-se um inibidor de transcriptase reversa com eficácia máxima $\beta=0,9.103$ 
4.24 Modelo de Kirschner [1996]: Simulação feita utilizando-se um inibidores de protease e de transcriptase reversa com eficácia máxima $\beta=0,5$ em ambas as drogas. . . . . . . . . . . . 104

4.25 Modelo de Kirschner [1996]: Simulação feita utilizando-se um inibidores de protease e de transcriptase reversa com eficácia máxima $\beta=0,9$ em ambas as drogas. . . . . . . . . . 105 


\section{Lista de Tabelas}

3.1 Método Runge-Kutta-Fehlberg. . . . . . . . . . . . . . . 43

3.2 Método Obrechkoff. . . . . . . . . . . . . . . . 46

3.3 Método Gautshi: Erro em função do período. . . . . . . . . . 49

3.4 Método Gautshi. . . . . . . . . . . . . . . . . . 51

3.5 Método Simos. . . . . . . . . . . . . . . . . . . . 54

3.6 Modelo de Perelson [1999]. . . . . . . . . . . . . . . . . . 62

4.1 Modelo de Perelson [1999]: Parâmetros Constantes. . . . . . 68

4.2 Modelo de Perelson [1999]: Parâmetros Variando. . . . . . . . 74

4.3 Modelo de Perelson [1993]: Parâmetros Constantes. . . . . . . 84

4.4 Modelo de Perelson [1993]: Parâmetros Variando. . . . . . . 86

4.5 Modelo de Kirschner [1996]: Parâmetros Constantes. . . . . . 95

4.6 Modelo de Kirschner [1996]: Parâmetros Variando. . . . . . . 98 


\section{Introdução}

O objetivo deste trabalho é estudar e analisar alguns modelos matemáticos que descrevem a interação do vírus HIV-1, o vírus que causa a AIDS, e células do sistema imune que são infectadas pelo vírus. AIDS é a sigla para a Síndrome da Imunodeficiência Adquirida.

Serão analisados modelos que fazem uso de sistemas de equações diferenciais ordinárias.

No Capítulo 1 apresentamos e comentamos vários modelos matemáticos que simulam algumas características da dinâmica HIV/AIDS. Inicialmente é apresentado um modelo básico ao qual vão sendo incorporados mais informações como produção viral, aplicação de monoterapia, combinação de terapias e a utilização de uma ou mais população de células infectadas pelo vírus. Desses modelos foi possível estimar parâmetros que desempenham papel crucial na dinâmica da infecção com o HIV-1. Embora sejam simplificações extremas de um processo complexo, por intermédio deles obtivemos informações importantes como, por exemplo, a produção viral diária. Essa estimativa, da ordem de $10^{10}$ vírus por dia, fez com que a AIDS fosse vista como uma síndrome diferente da herpes, já que no caso da herpes, o vírus fica latente até que, de tempos em tempos, ocorra um recrudescimento na carga viral. Essa característica do HIV-1 direcionou as terapias no sentido de parar a replicação viral e a utilização de uma combinação de drogas antiretrovirais.

Esses modelos, apresentados no Capítulo 1, também sugeriram um tempo médio de duração, da ordem de 2 a 3 anos, para que uma terapia totalmente efetiva ( um objetivo ainda a ser alcançado ) eliminasse completamente o vírus do organismo. Entretanto devido às simplificações e considerações feitas nesses modelos, esta estimativa parece ter sido subestimada. Isso indica que muito ainda precisa ser feito. Alguns modelos incorporaram retardo ( timedelay ) como Nelson [2000] e Culshaw [2000]. Modelos estocásticos como Merrill [1989] e Tan [1997] foram aplicados no estudo da infecção inicial com 
o HIV-1, quando o número de células infectadas e vírus ainda é pequeno.

No Capítulo 2 retomamos as idéias de Nelson [1998] e Perelson [1999] onde foram feitos estudos qualitativos de um modelo matemático de dinâmica HIV/AIDS que é uma síntese dos modelos do Capítulo 1. Entretanto, nessas análises verificamos uma conclusão, sobre a estabilidade local de um determinado ponto de equilíbrio, que julgamos ser incorreta, assim, feita essa correção, foi possível estabelecermos condições suficientes para a existência de órbitas periódicas nesse modelo via Teorema de Bifurcação de PoincaréAndronov-Hopf.

No Capítulo 3 apresentamos vários integradores numéricos com a característica de serem aplicados para o estudo de sistemas de equações diferenciais que apresentem órbitas periódicas. Estabelecemos um critério de escolha dentre esse integradores numéricos e utilizamos o integrador, selecionado por esse critério, para a análise de alguns sistemas de equações diferenciais clássicos, como a Equação de Van der Pol, a Equação de Lorenz e por fim aplicamos esse integrador para verificarmos o comportamento do modelo estudado qualitativamente no Capítulo 2.

No Capítulo 4 são apresentados parâmetros que variem em função do tempo, pois o intervalo de integração numérica é da ordem de alguns anos, visto que o tempo médio decorrido entre a infecção com o HIV-1 e o início da AIDS é em torno de 10 anos. As variações desses parâmetros foram sugeridas ou comentadas por trabalhos anteriores. Analisamos o comportamento das várias populações de células e vírus em diferentes modelos matemáticos sob a influência desses parâmetros. Para esse estudo utilizamos o integrador numérico que foi selecionado no Capítulo 3.

No Capítulo 5 são apresentadas algumas conclusões do trabalho e são feitos comentários acerca de tópicos que poderão ser explorados em trabalhos futuros.

Finalmente, no Apêndice são apresentados os enunciados do Critério de Liapunov, do Teorema de Routh-Hurwitz e do Teorema de Bifurcação de Poincaré-Andronov-Hopf e que foram utilizados neste trabalho. 


\section{Capítulo 1}

\section{Modelos Matemáticos}

Modelos matemáticos são ferramentas que nos auxiliam a compreender os mecanismos de propagação das doenças transmissíveis e a avaliar as diversas formas de intervenção e, talvez o mais importante, predizer o comportamento de uma determinada doença.

Esses modelos são simplificações extremas da realidade e à medida que acrescentamos realismos biológicos, tornam-se matematicamente mais intratáveis. Isto cria uma dificuldade para se atingir um nível ótimo do balanço entre realismo e tratabilidade matemática ( Struchiner [1994] ).

Neste capítulo apresentamos alguns modelos matemáticos determinísticos para a interação do HIV-1, o vírus que causa AIDS, com células do sistema. imune.

\subsection{Modelos Determinísticos}

Modelos determinísticos examinam as mudanças nos números médios das populações e são mais aplicáveis aos estágios avançados do processo quando o número de células e vírus são grandes, segundo Perelson [1999].

Inicialmente apresentaremos algumas idéias propostas por Perelson [1993], Perelson [1996], Perelson [1997] e Perelson [1999] onde são considerados modelos determinísticos de equações diferenciais ordinárias não lineares que descrevem, em função do tempo, a interação entre uma população de células do sistema imune, chamadas de linfócitos auxiliares T-CD4+ (células alvo do vírus HIV-1), e o vírus HIV-1. 


\subsubsection{Um Modelo Simples de Dinâmica do HIV}

Em 1994 potentes drogas antiretrovirais ( inibidores de protease ) estavam sendo desenvolvidas e testadas. Os resultados mostravam que a concentração de vírus caia exponencialmente por um curto período de tempo logo após o paciente utilizar estas drogas. Assim, foi introduzido o seguinte modelo

$$
\frac{d V}{d t}=P-c V
$$

onde $V$ é a concentração de vírus, $P$ é uma função desconhecida representando a taxa de produção viral e $c$ é uma constante chamada taxa de eliminação viral. Se a droga bloqueia completamente a produção viral podemos representar graficamente $\ln V$ em função de $t$.

Usando regressão linear podemos estimar o valor da constante c. Se admitirmos que a concentração viral atinge um valor constante $V_{0}$ antes da terapia iniciar então podemos estimar $P\left(P=c V_{0}\right)$. Medindo $V_{0}$ para cada paciente e multiplicando este valor pelo volume de fluido no qual o vírus é esperado ser encontrado permite-nos avaliar a taxa mínima total de produção viral em cada paciente.

Algumas estimativas iniciais indicaram que este valor é da ordem de $(0,7$ $\pm 0,1) 10^{9}$ vírus por dia ( Ho [1995] ). Modelos posteriores mais refinados e que serão comentados posteriormente alteraram essa estimativa inicial de produção viral para a ordem de $(10,3 \pm 11,7) 10^{9}$ vírus por dia ( Perelson [1996]).

Esses resultados indicam a importância dos dados experimentais na formulação do modelo.

\subsubsection{Um Modelo que Incorpora Produção Viral}

Inicialmente é considerado a dinâmica de crescimento da populacão de células T-CD4 ${ }^{+}$na ausência do vírus HIV-1. O modelo proposto é

$$
\frac{d T}{d t}=s+p T\left(1-\frac{T}{T_{\max }}\right)-d_{T} T .
$$

Neste modelo $T$ representa o número de células T-CD $4^{+}$por milímetros cúbicos de sangue e $s$ representa taxa de fornecimento de células T-CD $4^{+}$de precursores como o timo. Células $\mathrm{T}_{-} \mathrm{CD} 4^{+}$tem um tempo de vida finito, assim, $d_{T}$ representa a taxa média de morte dessas células. 
As células T-CD4 ${ }^{+}$quando estimuladas podem proliferar-se, e essa proliferação é aproximada nesse modelo por uma função logística na qual $p$ é a taxa máxima de proliferação e $T_{\max }$ é a densidade populacional máxima na qual a proliferação deve parar.

Se o contingente populacional de células T-CD4 ${ }^{+}$atingir $T_{\max }$ então a quantidade de células T-CD4+ deve diminuir, logo, é necessário que

$$
d_{T} T_{\max }>s .
$$

A Equação (1.2) tem um ponto de equilíbrio dado por:

$$
T_{0}=\frac{T_{\max }}{2 p}\left[\left(p-d_{T}\right)+\sqrt{\left(p-d_{T}\right)^{2}+\frac{4 s p}{T_{\max }}}\right],
$$

e $0<T_{0}<T_{\max }$. O outro ponto de equilíbrio é negativo, portanto, $T_{0}$ representa o único ponto de equilíbrio fisicamente possível. Pode-se mostrar que esse ponto é globalmente assintoticamente estável.

$\mathrm{O}$ vírus HIV-1 infecta células que carregam em sua superfície uma proteína chamada CD4 bem como outros receptores chamados co-receptores, dentre estas células estão as células T-CD $4^{+}$. Após serem infectadas, tais células podem produzir novos vírus, assim é introduzido no modelo uma população de células $\mathrm{T} \mathrm{CD}^{+}{ }^{+}$não infectadas, $T$, e uma população de células $\mathrm{T}$ $\mathrm{CD} 4^{+}$infectadas produtivamente, $T^{*}$.

Uma aproximação para se modelar essa infecção é considerar que tal infecção é proporcional ao produto entre as concentrações de células T-CD $4^{+} \mathrm{e}$ vírus, $k V T$, esta relação é conhecida como lei de ação de massas e tem sua origem no estudo da cinética química onde se postula que a taxa de formação de um composto é proporcional às concentrações dos reagentes ( Struchiner [1994]).

Com as considerações acima temos o seguinte modelo:

$$
\begin{aligned}
\frac{d T}{d t} & =s+p T\left(1-\frac{T}{T_{\max }}\right)-d_{T} T-k V T \\
\frac{d T^{*}}{d t} & =k V T-\delta T^{*} \\
\frac{d V}{d t} & =N \delta T^{*}-c V
\end{aligned}
$$


onde

$T$ : população de células $\mathrm{T} \mathrm{CD} 4^{+}$,

$T^{*}$ : população de células $\mathrm{T} \mathrm{CD} 4^{+}$infectadas produtivamente,

$V$ : população de vírus,

$s$ : taxa na qual novas células são criadas de fontes dentro do corpo,

$p$ : taxa de crescimento para a população de células T $\mathrm{CD}^{+}$,

$T_{\max }$ : população máxima de células $\mathrm{T} \mathrm{CD} 4^{+}$,

$d_{T}$ : taxa de morte de células $\mathrm{T} \mathrm{CD} 4^{+}$não-infectadas,

$k$ : taxa com que as células $\mathrm{T} \mathrm{CD}^{+}{ }^{+}$tornam-se infectadas por vírus livres,

$\delta$ : taxa de morte de células $\mathrm{T} \mathrm{CD} 4^{+}$infectadas produtivamente,

$N$ : número de vírus produzidos por uma célula T CD $4^{+}$infectada,

$c$ : taxa de eliminação de vírus.

A Equação (1.4) é uma versão da Equação (1.2) com o termo relativo ao efeito do HIV-1.

A Equação (1.5) representa a população de células T-CD4+ infectadas produtivamente, assim, o termo kVT é subtraído da Equação (1.4) e adicionado a Equação (1.5).

O segundo termo $\delta T^{*}$ na Equação (1.5) representa a taxa com que células T-CD4+ infectadas produtivamente estão morrendo.

A Equação (1.6) modela a população de vírus infecciosos livres. É assumido que uma célula T-CD $4^{+}$produz em média $N$ vírus infecciosos durante sua vida. O último termo na Equação (1.6) $c V$ representa a perda de infectividade viral, morte viral e eliminação do vírus do corpo.

Para este modelo pode-se mostrar que existem dois pontos de equilíbrio, que chamaremos de não-infectado e infectado.

\section{Ponto de Equilíbrio Não-Infectado}

O ponto de equilíbrio não-infectado é dado por $\left(T_{s s 1}, 0,0\right)$, onde

$$
T_{s s 1}=\frac{T_{\max }}{2 p}\left[\left(p-d_{T}\right)+\sqrt{\left(p-d_{T}\right)^{2}+\frac{4 s p}{T_{\max }}}\right] .
$$

A matriz Jacobiana, $J$, quando avaliada neste ponto é dada por 


$$
J\left(T_{s s 1}, 0,0\right)=\left(\begin{array}{ccc}
p\left(1-\frac{2 T_{s s 1}}{T_{\max }}\right)-d_{T} & 0 & -k T_{s s 1} \\
0 & -\delta & k T_{s s 1} \\
0 & N \delta & -c
\end{array}\right)
$$

cujos autovalores são

$$
\begin{aligned}
& -\lambda_{1}=p\left(1-\frac{2 T_{s s 1}}{T_{m a x}}\right)-d_{T}, \\
& -\lambda_{2,3}=-\frac{c+\delta}{2} \pm \frac{1}{2} \sqrt{(c+\delta)^{2}-4 \delta\left(c-N k T_{s s 1}\right)},
\end{aligned}
$$

e estão sujeitos as seguintes condições:

$$
\begin{aligned}
& -c>N k T_{s s 1} \Rightarrow\left\{\begin{array}{l}
\lambda_{1}<0 \\
\lambda_{2}<0 \\
\lambda_{3}<0
\end{array}\right. \\
& -c=N k T_{s s 1} \Rightarrow\left\{\begin{array}{l}
\lambda_{1}<0 \\
\lambda_{2}=0 \\
\lambda_{3}<0
\end{array}\right. \\
& -c<N k T_{s s 1} \Rightarrow\left\{\begin{array}{l}
\lambda_{1}<0 \\
\lambda_{2}>0 \\
\lambda_{3}<0
\end{array}\right.
\end{aligned}
$$

\section{Ponto de Equilíbrio Infectado}

O ponto de equilíbrio infectado é dado por $\left(T_{s s 2}, \bar{T}^{*}, \bar{V}\right)$, onde

$$
\begin{aligned}
T_{s s 2} & =\frac{c}{N k}, \\
\bar{T}^{*} & =\frac{s}{\delta}+\frac{p c}{N \delta k}\left(1-\frac{c}{N k T_{\max }}\right)-\frac{c d_{T}}{N \delta k}, \\
\bar{V} & =\frac{N s}{c}+\frac{p}{k}\left(1-\frac{c}{N k T_{\max }}\right)-\frac{d_{T}}{k} .
\end{aligned}
$$

Este ponto de equilíbrio pertence ao octante positivo quando $0<T_{s s 2}<$ $T_{s s 1}$ e dependendo dos valores das constantes desse problema, este ponto pode ser estável ou instável, podendo ter ao seu redor uma órbita periódica. Estes resultados serão considerados no próximo capítulo. 


\subsubsection{Modelo com Inibidor de Transcriptase Reversa}

Um inibidor de transcriptase reversa é uma droga que bloqueia a infecção de células $\mathrm{T} \mathrm{CD}^{+}$e desse modo reduz o valor de $k$. Inibidores de transcriptase reversa, como outras drogas, não são perfeitos, assim, é introduzido no modelo uma constante $\eta_{R T}$ que é a eficácia da droga. Se $\eta_{R T}=1$ então a inibição é $100 \%$ efetiva, entretanto, se $\eta_{R T}=0$, não há inibição.

Um modelo para a ação de um inibidor de transcriptase reversa é

$$
\begin{aligned}
\frac{d T}{d t} & =s+p T\left(1-\frac{T}{T_{\max }}\right)-d_{T} T-\left(1-\eta_{R T}\right) k V T, \\
\frac{d T^{*}}{d t} & =\left(1-\eta_{R T}\right) k V T-\delta T^{*}, \\
\frac{d V}{d t} & =N \delta T^{*}-c V,
\end{aligned}
$$

cuja análise matemática é semelhante à feita anteriormente.

\subsubsection{Um Modelo com Inibidor de Protease}

Inibidores de protease são drogas que inibem a produção de vírus infecciosos, portanto, vamos considerar dois tipos de vírus: vírus infecciosos $V_{I}$ e vírus não-infecciosos $V_{N I}$, de tal forma que a concentração total de vírus $V$ é $V_{I}+V_{N I}$.

Para um inibidor de protease $100 \%$ efetivo temos as seguintes equações

$$
\begin{aligned}
\frac{d T}{d t} & =s+p T\left(1-\frac{T}{T_{\max }}\right)-d_{T} T-k V_{I} T \\
\frac{d T^{*}}{d t} & =k V_{I} T-\delta T^{*}, \\
\frac{d V_{I}}{d t} & =-c V_{I}, \\
\frac{d V_{N I}}{d t} & =N \delta T^{*}-c V_{N I} .
\end{aligned}
$$

Admitindo-se que antes da terapia ser iniciada tenhamos apenas vírus infecciosos, então $V_{N I}(0)=0$ e $V_{I}(0)=V_{0}$, donde $V_{I}(t)=V_{0} e^{-c t}$. Por um curto período de tempo, imediatamente após a terapia ser iniciada, podemos supor que o número de células T-CD $4^{+}$é constante, $T=T_{0}$, donde obtemos

$$
T^{*}(t)=T^{*}(0) e^{-\delta t}+\frac{k T_{0} V_{0}\left(e^{-c t}-e^{\delta T}\right)}{\delta-c}
$$


Assumindo que $T^{*}$ é praticamente constante antes da terapia ser iniciada, então

$$
\frac{d T^{*}}{d t}=0
$$

e

$$
T^{*}(0)=k V_{0} T_{0} / \delta
$$

donde segue que

$$
T^{*}(t)=k V_{0} T_{0}\left[\frac{c e^{-\delta t}-\delta e^{-c t}}{\delta(c-\delta)}\right] .
$$

Substituindo esse valor na equação diferencial para $V_{N I}$ e admitindo-se que antes da terapia ser iniciada a produção viral, $N k T_{0}$, é igual a eliminação viral, $c$, resulta em

$$
V(t)=\frac{c V_{0}}{c-\delta}\left[\frac{c}{c-\delta}\left(e^{-\delta t}-e^{-c t}\right)-\delta t e^{-c t}\right] .
$$

Finalmente, a concentração total de vírus é dada por

$$
V(t)=V_{0} e^{-c t}+\frac{c V_{0}}{c-\delta}\left[\frac{c}{c-\delta}\left(e^{-\delta t}-e^{-c t}\right)-\delta t e^{-c t}\right] .
$$

Através da Equação (1.7), juntamente com técnicas de análise de regressão não-linear, e dados de pacientes foi possível estimar valores para $c$, a taxa de eliminação viral, e $\delta$, a taxa de morte de células T $\mathrm{CD}^{+}{ }^{+}$infectadas produtivamente, conforme Perelson [1996]. De posse desses dados a produção viral foi estimada em aproximadamente $(10,3 \pm 11,7) 10^{9}$ vírus lançados por dia e $\delta=0,5 \pm 0,1$ por dia.

A estimativa da produção viral $c$ é mínima, já que é baseada na hipótese de que a droga bloquearia toda a produção de vírus infecciosos.

\subsubsection{Um Modelo com Inibidor de Protease Imperfeito}

Inibidores de protease não são drogas perfeitas, assim, seja $\eta_{P I}$ a eficácia de um inibidor de protease. Neste caso, as equações passam a ter a seguinte 
forma

$$
\begin{aligned}
\frac{d T}{d t} & =s+p T\left(1-\frac{T}{T_{\max }}\right)-d_{T} T-k V_{I} T \\
\frac{d T^{*}}{d t} & =k V_{I} T-\delta T^{*} \\
\frac{d V_{I}}{d t} & =\left(1-\eta_{P I}\right) N \delta T^{*}-c V_{I}, \\
\frac{d V_{N I}}{d t} & =\eta_{P I} N \delta T^{*}-c V_{N I} .
\end{aligned}
$$

A análise matemática desse sistema de equações diferenciais será feita no capítulo seguinte.

\subsubsection{Combinação de Terapias}

A maioria das terapias atuais empregam mais de uma droga no tratamento de pacientes infectados com vírus HIV-1. Algumas drogas agem no sentido de inibirem a ação da transcriptase reversa ou da protease. Uma outra classe de drogas inibe a fusão do HIV-1 com as células alvo.

Um estudo realizado com um grupo de pacientes infectados com o vírus HIV-1 ( Perelson [1997] ), que utilizaram os inibidores de transcriptase reversa e de protease, verificou que após iniciada a terapia houve uma queda. acentuada da concentração de vírus no plasma durante o período de uma ou duas semanas, entretanto, após esse declínio inicial e ainda sob terapia, a concentração de vírus continuava a cair, mas a uma taxa signicativamente menor. Quando esses dados dos pacientes foram representados graficamente em uma escala logarítmica, verificou-se que ambas as fases de declínio da concentração viral aproximavam-se de um decaimento exponencial.

Uma das explicações para o declínio da carga viral na segunda fase seria a possibilidade de existir grupos de células T-CD $4^{+}$heterogêneas, com uma subpopulação de células T-CD4+infecciosas produzindo menos vírus e tendo um tempo de vida maior.

Uma outra explicação para esse declínio seria um outro tipo de células chamadas de macrófagos que têm subpopulações que são suscetíveis à infecção pelo HIV-1. Esses macrófagos, quando infectados, podem produzir partículas virais por semanas, sendo que o HIV-1 tende a não matar macrófagos em culturas de células. 
$\mathrm{Na}$ presença dos inibidores de transcriptase reversa e de protease e supondo que o número de células $\mathrm{T}$-CD $4^{+}$permaneça constante, $T=T_{0}$, o modelo básico toma a seguinte forma

$$
\begin{aligned}
\frac{d T^{*}}{d t} & =\left(1-\eta_{R T}\right) k V_{I} T_{0}-\delta T^{*} \\
\frac{d V_{I}}{d t} & =\left(1-\eta_{P I}\right) N \delta T^{*}-c V_{I} \\
\frac{d V_{N I}}{d t} & =\eta_{P I} N \delta T^{*}-c V_{N I},
\end{aligned}
$$

onde $\eta_{R T}$ e $\eta_{I P}$ representam a eficácia dos inibidores de transcriptase reversa e de protease, respectivamente. Se ambos os inibidores de transcriptase reversa e de protease são $100 \%$ efetivos, então o modelo anterior torna-se

$$
\begin{aligned}
\frac{d T^{*}}{d t} & =-\delta T^{*} \\
\frac{d V_{I}}{d t} & =-c V_{I}, \\
\frac{d V_{N I}}{d t} & =N \delta T^{*}-c V_{N I} .
\end{aligned}
$$

Se assumirmos que $T^{*}(0)=k V_{0} T_{0} / \delta$ e $N k T_{0}=c$, então

$$
\begin{gathered}
T^{*}(t)=T^{*}(0) e^{-\delta t}=\frac{k V_{0} T_{0}}{\delta} e^{-\delta t}, \\
V(t)=V_{0} e^{-c t},
\end{gathered}
$$

$\mathrm{e}$

$$
V_{N I}(t)=\frac{N \delta T^{*}(0)}{c-\delta}\left[e^{-\delta t}-e^{-c t}\right]
$$

donde,

$$
V(t)=V_{I}(t)+V_{N I}(t)=V_{0}\left[\frac{c e^{-\delta t}-\delta e^{-c t}}{c-\delta}\right] .
$$

Assim, após um rápido transiente da ordem de $1 / \mathrm{c}$, a taxa viral cairia exponencialmente a uma taxa constante caracterizada por $\delta$. Essa queda na carga viral corresponde ao declínio na primeira fase observada nos dados.

Incorporando uma segunda população de células, $M$, suscetíveis à infecção com uma taxa constante $k_{M}$, obtemos o seguinte modelo que podemos 
chamar de modelo com células infectadas de vida longa

$$
\begin{aligned}
\frac{d T}{d t} & =s+p T\left(1-\frac{T}{T_{\text {max }}}\right)-d_{T} T-k V T, \\
\frac{d T^{*}}{d t} & =k V T-\delta T^{*}, \\
\frac{d M}{d t} & =s_{M}-d_{M} M-k_{M} V M, \\
\frac{d M^{*}}{d t} & =k_{M} V M-\mu_{M} M^{*}, \\
\frac{d V}{d t} & =N \delta T^{*}+p_{M} M^{*}-c V,
\end{aligned}
$$

onde $M^{*}$ denota a concentração de células infectadas de vida longa que são assumidas liberando vírus continuamente a uma taxa $p_{M}$ por célula e com uma taxa de morte $\mu_{M}$ por célula. Também é assumido que essas células são criadas por uma fonte a uma taxa constante $s_{M}$ e que morrem a uma taxa constante $d_{M}$.

Se antes que o tratamento seja iniciado supusermos que, no instante inicial $t=0, \frac{d T^{*}}{d t}=0, \frac{d M^{*}}{d t}=0$ e $\frac{d V}{d t}=0$ obtemos

$$
T_{0}^{*}=k V_{0} T_{0} / \delta, \quad M_{0}^{*}=k_{M} V_{0} M_{0} / \mu_{M}, \quad N \delta T_{0}^{*}+p_{M} M_{0}^{*}=c V_{0} .
$$

Se ambos o inibidores de transcriptase reversa e de protease forem $100 \%$ efetivos, então para $t>0, k=k_{M}=0$ e todos os vírus produzidos serão não-infecciosos. Assim, após a terapia ser iniciada, temos o seguinte modelo

$$
\begin{aligned}
\frac{d T}{d t} & =s+p T\left(1-\frac{T}{T_{\max }}\right)-d_{T} T \\
\frac{d T^{*}}{d t} & =-\delta T^{*} \\
\frac{d M}{d t} & =s_{M}-d_{M} M \\
\frac{d M^{*}}{d t} & =-\mu_{M} M^{*} \\
\frac{d V_{I}}{d t} & =-c V_{I} \\
\frac{d V_{N I}}{d t} & =N \delta T^{*}+p_{M} M^{*}-c V_{N I .} .
\end{aligned}
$$


Usando as condições iniciais dadas por (1.8) obtemos:

$$
V(t)=V_{0}\left[\left(1-\frac{N k T_{0}}{c-\delta}-\frac{c-N k T_{0}}{c-\mu_{M}}\right) e^{-c t}+\frac{N k T_{0}}{c-\delta} e^{-\delta t}+\frac{c-N k T_{0}}{c-\mu_{M}} e^{-\mu_{M} t}\right] .
$$

E novamente, utilizando técnicas de regressão não linear, dados de pacientes que utilizaram essa combinação de inibidores e a Equação (1.9) foi possível estimar os parâmetros $\delta$ e $\mu_{M}$. O parâmetro $\mu_{M}$, apresentou um valor médio de $0,07 \pm 0,04$ por dia. A meia-vida da população de células responsáveis pelo decaimento da carga viral na segunda fase, $t_{1 / 2}=\ln 2 / \mu_{M}$, corresponde a $13,3 \pm 7,9$ dias.

O parâmetro $\delta$ apresentou um valor médio de $0,59 \pm 0,15$ por dia. A meia-vida da população de células responsáveis pelo decaimento da carga viral na primeira fase, $t_{1 / 2}=\ln 2 / \delta$, corresponde a $1,25 \pm 0,34$ dias.

$\mathrm{O}$ valor de $\delta$ encontrado na Seção (1.1.4) foi menor possivelmente em virtude de se estar utilizando, naquele modelo, da monoterapia enquanto nesta Seção utilizamos uma combinação de drogas.

Finalmente, Perelson [1997] analisou um modelo que incorpora células infectadas latentes, $L$, e células de vida longa, $M$. Este modelo tem a seguinte forma

$$
\begin{aligned}
\frac{d T}{d t} & =s+p T\left(1-\frac{T}{T_{\max }}\right)-d_{T} T-k V T, \\
\frac{d T^{*}}{d t} & =k V T+a L-\delta T^{*}, \\
\frac{d L}{d t} & =f k V T-\mu_{L} L, \\
\frac{d M}{d t} & =s_{M}-d_{M} M-k_{M} V M, \\
\frac{d M^{*}}{d t} & =k_{M} V M-\mu_{M} M^{*}, \\
\frac{d V}{d t} & =N \delta T^{*}+p_{M} M^{*}-c V,
\end{aligned}
$$

onde é assumido que quando células T-CD4 ${ }^{+}, T$, são infectadas, $T^{*}$ células infectadas produtivamente são geradas a uma taxa $k$ e que células infectadas e latentes, $L$, são produzidas a uma taxa constante $f k$, com $f<1$. Células infectadas latentes são assumidas que morrem a uma taxa $\delta_{L}$ e são ativadas a uma taxa $a$, dando uma taxa total de perda $\mu_{L}=a+\delta_{L}$. 
Assumindo que os inibidores de transcriptase reversa e os inibidores de protease sejam $100 \%$ efetivos, de modo que para $t>0$, tenhamos $k=0$. E, além disso, assumindo que em $t=0, \frac{d T^{*}}{d t}=0, \frac{d L}{d t}=0, \frac{d M^{*}}{d t}=0 \mathrm{e} \frac{d V}{d t}=0$, obtemos

$$
V(t)=V_{0}\left[A e^{-\delta t}+B e^{-\mu_{L} t}+C e^{-\mu_{M} t}+(1-A-B-C) e^{-c t}\right],
$$

onde

$$
\begin{aligned}
A & =\frac{N k T_{0}}{c-\delta}\left(1-\frac{a f}{\delta-\mu_{L}}\right), \\
B & =\frac{a f \delta N k T_{0}}{\mu_{L}\left(c-\mu_{L}\right)\left(\delta-\mu_{L}\right)}, \\
C & =\frac{c-N k T_{0}\left(1+\frac{a f}{\mu_{L}}\right)}{c-\mu_{M}} .
\end{aligned}
$$

Admitindo que o número de células infectadas seja proporcional a

$$
I(t)=T^{*}(t)+L(t)
$$

segue que

$$
I(t)=\frac{k V_{0} T_{0}}{\delta}\left[\left(1-\frac{a f}{\delta-\mu_{L}}\right) e^{-\delta t}+\frac{f \delta}{\mu_{L}}\left(1+\frac{a}{\delta-\mu_{L}}\right) e^{-\mu_{L} t}\right] .
$$

Ajustando-se parâmetros desse modelo à Equação (1.10) e a dados experimentais foi verificado que em média levaria entre dois anos e meio e três anos de tratamento perfeitamente efetivo para que as células responsáveis pela segunda fase fossem totalmente eliminadas e $V$ se aproximasse do valor zero. Detalhes podem ser encontrados em Perelson [1997]. Essas estimativas quando apresentadas na XI Conferência Internacional sobre AIDS em Vancouver em 1996, geraram grande entusiasmo e otimismo. Entretanto, como assinalado em Perelson [1997], esses modelos apresentados até aqui seriam caricaturas simplificadas da realidade não incluindo aspectos espaciais e compartimentais do corpo. Além disso, existem locais no corpo onde as drogas têm acesso limitado, como cérebro e sistema nervoso central, assim nesses locais a concentração de drogas seria menor do que a concentração encontrada na circulação. Dessa maneira, esses locais poderiam agir como 
santuários para o vírus HIV-1. Em modelos matemáticos com santuários para os vírus é possível gerar resistência as drogas e assim a replicação viral pode permanecer um problema até que novas gerações de drogas se tornem disponíveis ( Kepler [1998], Callaway [2002] ).

Em um artigo publicado em 1999, Finzi et al. apresenta resultados obtidos a partir de um estudo feito com pacientes sob uma combinação de terapias para o tratamento da infecção com o HIV-1 mostrando que, apesar do tratamento reduzir a carga viral a níveis indetectáveis, indicando que um tratamento prolongado poderia erradicar a infecção, a meia-vida das células infectadas latentes seria de 43,9 meses e uma erradicação levaria em torno de 60 anos.

Outros trabalhos, ( Chun [1999], Sharkey [2000] ), verificaram que a população viral não foi extinta em nenhum dos pacientes infectados e que estavam sob terapia antiretroviral. 


\section{Capítulo 2}

\section{Estudos Qualitativos}

Neste capítulo é feito um estudo qualitativo do sistema de equações diferenciais não lineares dado pelas Equações (2.1), (2.2), (2.3) e (2.4) descritas abaixo. Análises desse sistema, publicadas em Nelson [1998] e Perelson [1999], mostraram a existência de 3 pontos de equilíbrio e foram também apresentados estudos sobre a estabilidade local e global desses pontos. No entanto, esses trabalhos apresentam uma demonstração incorreta da estabilidade local de um dos pontos de equilíbrio. Assim, neste capítulo, é feita uma correção sobre o comportamento dinâmico de um dos pontos de equilíbrio e é enunciado e provado um resultado que estabelece condições suficientes sobre a existência de uma órbita periódica em torno desse ponto de equilíbrio via Teorema de Bifurcação de Poincaré-Andronov-Hopf.

\subsection{Análise Qualitativa}

Começamos analisando o seguinte sistema de equações diferenciais

$$
\begin{aligned}
\frac{d T}{d t} & =s+p T\left(1-\frac{T}{T_{\max }}\right)-d_{T} T-\mu k V_{I} T \\
\frac{d T^{*}}{d t} & =\mu k V_{I} T-\delta T^{*} \\
\frac{d V_{I}}{d t} & =\varepsilon N \delta T^{*}-c V_{I}, \\
\frac{d V_{N I}}{d t} & =\eta_{P I} N \delta T^{*}-c V_{N I},
\end{aligned}
$$


definido no conjunto

$$
\begin{aligned}
\Delta= & \left\{\left(T, T^{*}, V_{I}, V_{N I}\right) \in \mathbb{R}^{4} / T \geq 0, T^{*} \geq 0, V_{I} \geq 0, V_{N I} \geq 0,\right. \\
& \left.T+T^{*} \leq T_{\text {max }}, V_{I} \leq \frac{N \delta \varepsilon T_{\max }}{c}, V_{N I} \leq \frac{N \delta \eta_{P I} T_{\text {max }}}{c}\right\},
\end{aligned}
$$

sendo que os parâmetros envolvidos são todos positivos e $\varepsilon=\left(1-\eta_{P I}\right)$ e $\mu=\left(1-\eta_{R T}\right)$ representam os tratamentos terapêuticos.

Mostraremos inicialmente que nenhuma das populações fica negativa, mais que isso, uma trajetória que comece em $\Delta$ permanecerá sempre em $\Delta$. Dizemos, então, que $\Delta$ é positivamente invariante. Para isso, devemos mostrar que em cada hiperplano que limita $\Delta$ o campo vetorial, dado pelas Equações (2.1), (2.2), (2.3) e (2.4), aponta para o interior ou é tangente a $\Delta$.

Assim,

$$
\begin{aligned}
\left.\frac{d T}{d t}\right|_{T=0} & =s>0, & \left.\frac{d T^{*}}{d t}\right|_{T^{*}=0} & =k V_{I} T \mu>0 \\
\left.\frac{d V_{I}}{d t}\right|_{V_{I}=0} & =N \delta T^{*} \varepsilon>0, & \left.\frac{d V_{N I}}{d t}\right|_{V_{N I}=0} & =N \delta T^{*} \eta_{P I}>0 .
\end{aligned}
$$

Além disso, notemos que

$$
\left.\frac{d V_{I}}{d t}\right|_{V_{I}=\frac{N \delta \varepsilon T_{\max }}{c}}=N \delta \varepsilon\left(T^{*}-T_{\max }\right) \leq 0,
$$

e

$$
\left.\frac{d V_{N I}}{d t}\right|_{V_{N I}=\frac{N \delta \eta_{P I} T_{\max }}{c}}=N \delta \eta_{P I}\left(T^{*}-T_{\max }\right) \leq 0 .
$$

Segundo Perelson [1999], na presença de HIV-1, existem dois tipos de células T-CD4 ${ }^{+}$: células não infectadas e células infectadas produtivamente, portanto seria razoável mudar o termo referente a proliferação logística para

$$
p T\left(1-\frac{T+T^{*}}{T_{\max }}\right)
$$

conforme Perelson [1993]. Entretanto, como a proporção de células infectadas produtivamente é muito pequena, ainda segundo Perelson [1999], pode-se ignorar essa correção.

Essa consideração, no entanto, faz com que surja uma limitação entre alguns parâmetros para que o modelo possa descrever com mais fidelidade 
uma condição que do ponto de vista biológico é bastante razoável, que é a seguinte condição:

$$
T+T^{*} \leq T_{\max }
$$

Observemos que se na. Equação (2.1) o termo referente a proliferação logística fosse $p T\left(1-\frac{T+T^{*}}{T_{m a x}}\right)$ e se tomarmos $T_{t o t}=T+T^{*}$ então, juntamente com a Equação (2.2), teríamos:

$$
\begin{aligned}
\frac{d T_{t o t}}{d t} & =s+p T\left(1-\frac{T_{t o t}}{T_{\text {max }}}\right)-d_{T} T-\delta T^{*} \\
& <s+p T\left(1-\frac{T_{t o t}}{T_{\text {max }}}\right)-d_{T} T_{t o t},
\end{aligned}
$$

já que $d_{T}<\delta$, pois morte por citopaticidade viral ocorre com maior intensidade do que morte por meios naturais.

Portanto, quando $T_{\text {tot }}=T_{\max }$,

$$
\left.\frac{d T_{\text {tot }}}{d t}\right|_{T_{\text {tot }=T_{\max }}}<s-d_{T} T_{\max }<0 .
$$

A última desigualdade, já vista no Capítulo 1, conforme Equação (1.3), segue de Perelson [1993]. Assim, teríamos a população total de células TCD $4^{+}$e portanto as populações $T$ e $T^{*}$ limitadas por $T_{\max }$.

Ao tomarmos o termo referente a proliferação logística como $p T\left(1-\frac{T}{T_{\max }}\right)$ temos:

$$
\begin{aligned}
& \frac{d T_{\text {tot }}}{d t}=s+p T\left(1-\frac{T}{T_{\max }}\right)-d_{T} T-\delta T^{*} \\
& <s+p T\left(1-\frac{T}{T_{\max }}\right)-d_{T} T_{t o t},
\end{aligned}
$$

$\mathrm{e}$

$$
\left.\frac{d T_{t o t}}{d t}\right|_{T_{t o t}=T_{\max }}<s+p T\left(1-\frac{T}{T_{\max }}\right)-d_{T} T_{\max } .
$$

Uma condição necessária e suficiente para que

$$
\left.\frac{d T_{t o t}}{d t}\right|_{T_{t o t}=T_{\max }}<0
$$

é que

$$
s+p T\left(1-\frac{T}{T_{\max }}\right)-d_{T} T_{\max }<0
$$


para $T \in\left[0, T_{\max }\right]$, ou equivalentemente,

$$
\frac{p T^{2}}{T_{\max }}-p T+d_{T} T_{\max }-s>0
$$

para $T \in\left[0, T_{\max }\right]$. Essa última desigualdade é satisfeita se, e somente se,

$$
\frac{s}{T_{\max }}+\frac{p}{4}<d_{T}
$$

Assim, para obtermos a condição (2.5) para as Equações (2.1) e (2.2), os parâmetros devem satisfazer (2.6). Nas simulações que serão feitas nos próximos capítulos esta condição será satisfeita.

Portanto acabamos de mostrar que o conjunto $\Delta$ é positivamente invariante se $c \neq 0$ e se for satisfeita a condição (2.6). Como $\Delta$ é um conjunto compacto ( fechado e limitado em $\mathbb{R}^{4}$ ), então todas as soluções que comecem em $\Delta$ serão definidas e limitadas em $[0, \infty[$, se $c \neq 0$ e se for satisfeita a condição (2.6).

Mostraremos agora que, no conjunto $\Delta$, existem dois pontos de equilíbrio, um na ausência de vírus, chamado equilíbrio não infectado, e outro com a presença de vírus, chamado equilíbrio infectado.

Igualando as Equações (2.1), (2.2), (2.3) e (2.4) a zero obtemos o equilíbrio não infectado dado por $\left(T_{s s 1}, 0,0,0\right)$, onde:

$$
T_{s s 1}=\frac{T_{\max }}{2 p}\left[\left(p-d_{T}\right)+\sqrt{\left(p-d_{T}\right)^{2}+\frac{4 s p}{T_{\max }}}\right]
$$

e o equilíbrio infectado dado por $\left(T_{s s 2}, \bar{T}^{*}, \bar{V}_{I}, \bar{V}_{N I}\right)$, onde:

$$
\begin{aligned}
T_{s s 2} & =\frac{c}{N k \varepsilon \mu}, \\
\bar{T}^{*} & =\frac{c \bar{V}_{I}}{N \delta \varepsilon} \\
\bar{V}_{I} & =\frac{s}{k T_{s s 2} \mu}+\frac{p}{k \mu}\left(1-\frac{T_{s s 2}}{T_{\max }}\right)-\frac{d_{T}}{k \mu}, \\
& =\frac{s N \varepsilon}{c}+\frac{p-d_{T}}{k \mu}-\frac{p c}{N k^{2} T_{\max } \varepsilon \mu^{2}} \\
\bar{V}_{N I} & =\frac{\eta_{P I} \bar{V}_{I}}{\varepsilon} .
\end{aligned}
$$


É interessante notar que existe um outro ponto de equilíbrio $\left(T_{N}, 0,0,0\right)$, onde $T_{N}=\frac{T_{\max }}{2 p}\left[\left(p-d_{T}\right)-\sqrt{\left(p-d_{T}\right)^{2}+\frac{4 s p}{T_{\max }}}\right]$ e $-T_{\max }<T_{N}<0$, que não pertence ao conjunto $\Delta$, não tendo, portanto, uma associação com o processo biológico em estudo.

\subsubsection{Ponto de Equilíbrio Não Infectado}

O ponto de equilíbrio não infectado é dado por $\left(T_{s s 1}, 0,0,0\right)$, onde

$$
T_{s s 1}=\frac{T_{\max }}{2 p}\left[\left(p-d_{T}\right)+\sqrt{\left(p-d_{T}\right)^{2}+\frac{4 s p}{T_{\max }}}\right] .
$$

Notemos, a partir da expressão acima, que $0 \leq T_{s s 1}$ e pela condição (2.6) temos que $s<d_{T} T_{\max }$ e então $T_{s s 1}<T_{\max }$.

A matriz Jacobiana quando avaliada no ponto de equilíbrio não infectado é dada por

$$
\boldsymbol{J}\left(T_{s s 1}, 0,0,0\right)=\left(\begin{array}{cccc}
a & 0 & -k \mu T_{s s 1} & 0 \\
0 & -\delta & k \mu T_{s s 1} & 0 \\
0 & N \delta \varepsilon & -c & 0 \\
0 & N \delta \eta_{P I} & 0 & -c
\end{array}\right)
$$

onde

$$
a=p\left(1-\frac{2 T_{s s 1}}{T_{\max }}\right)-d_{T} .
$$

Da Equação (2.7) temos que:

$$
-\left(p-d_{T}\right)+\frac{2 p T_{s s 1}}{T_{\max }}=\sqrt{\left(p-d_{T}\right)^{2}+\frac{4 s p}{T_{\max }}} .
$$

Logo,

$$
-p\left(1-\frac{2 T_{s s 1}}{T_{\max }}\right)+d_{T}=\sqrt{\left(p-d_{T}\right)^{2}+\frac{4 s p}{T_{\max }}}
$$

e portanto $a<0$.

O ponto de equilíbrio não infectado é assintóticamente estável se, e somente se, todos os autovalores da matriz Jacobiana $\boldsymbol{J}\left(T_{s s 1}, 0,0,0\right)$ têm parte real negativa.

Os autovalores podem ser determinados resolvendo a equação característica em $\lambda$, $\operatorname{det}\left[\boldsymbol{J}\left(T_{s s 1}, 0,0,0\right)-\lambda \boldsymbol{I}_{4}\right]=0$, onde $\boldsymbol{I}_{4}$ é a matriz identidade de ordem 4. 
Para a matriz Jacobiana $\boldsymbol{J}\left(T_{s s 1}, 0,0,0\right)$, dada pela Equação (2.8), temos

$$
(\lambda-a)(\lambda+c)\left[\lambda^{2}+(c+\delta) \lambda+c \delta-N k \delta T_{s s 1} \varepsilon \mu\right]=0,
$$

cujos autovalores são

$$
\begin{aligned}
& \lambda_{1}=a \\
& \lambda_{2}=-\frac{c+\delta}{2}+\frac{1}{2} \sqrt{(c+\delta)^{2}-4 c \delta+4 N k \delta T_{s s 1} \varepsilon \mu} \\
& \lambda_{3}=-\frac{c+\delta}{2}-\frac{1}{2} \sqrt{(c+\delta)^{2}-4 c \delta+4 N k \delta T_{s s 1} \varepsilon \mu} \\
& \lambda_{4}=-c
\end{aligned}
$$

Observemos que $(c+\delta)^{2}-4 c \delta=(c-\delta)^{2}$ e assim, o radicando em $\lambda_{2}$ e $\lambda_{3}$ são positivos. Observemos também que $\lambda_{1}<0, \lambda_{3}<0$ e $\lambda_{4}<0$.

Para a estabilidade local do ponto de equilíbrio não infectado, necessitamos ainda que $\lambda_{2}<0$, que é satisfeito se:

$$
c+\delta>\sqrt{(c+\delta)^{2}-4 c \delta+4 N k \delta T_{s s 1} \varepsilon \mu},
$$

ou seja,

$$
N<N_{c r i t}=\frac{c}{k T_{s s 1} \varepsilon \mu}
$$

Portanto, se $N<N_{\text {crit }}$, o ponto de equilíbrio não infectado é assintoticamente estável, se $N=N_{\text {crit }}$ o ponto de equilíbrio não infectado é neutramente estável e, finalmente, se $N>N_{\text {crit }}$ o ponto de equilíbrio não infectado é instável.

\subsubsection{Função de Liapunov}

Conjecturamos que o ponto de equilíbrio não infectado seja globalmente assintoticamente estável no conjunto $\Delta$ se $N<N_{\text {crit }}$.

Para

$$
0<N<N_{L}=\frac{c}{k T_{\max } \mu}
$$

podemos mostrar que a conjectura é verdadeira.

Consideremos a função

$$
L(t)=N T^{*}(t)+V_{I}(t)+V_{N I}(t), \quad \forall t \geq 0 .
$$


Mostraremos que $L=N T^{*}+V_{I}+V_{N I}$ é uma função de Liapunov ( ver Apêndice ).

Observemos que $L(0,0,0)=0$ e que $L(t)>0, \forall t>0$.

Da expressão (2.12) temos,

$$
\begin{aligned}
\frac{d L}{d t} & =N \mu k V_{I} T-N \delta T^{*}+\varepsilon N \delta T^{*}-c V_{I}+\eta_{P I} N \delta T^{*}-c V_{N I} \\
& =N \mu k V_{I} T-c V_{I}-c V_{N I} \\
& =[N \mu k T-c] V_{I}-c V_{N I} .
\end{aligned}
$$

Portanto, se a condição (2.11) for satisfeita temos que $\frac{d L}{d t}<0$ em $\Delta$.

Logo $L(t) \rightarrow 0$, quando $t \rightarrow \infty$. Portanto, $T^{*}, V_{I}$ e $V_{N I}$ tendem para 0 e $T \rightarrow T_{0}$.

A título de menção, notemos que para o ponto de equilíbrio $\left(T_{N}, 0,0,0\right)$ os autovalores são:

$$
\begin{aligned}
& \lambda_{1}=p\left(1-\frac{2 T_{N}}{T_{\max }}\right)-d_{T} \\
& \lambda_{2}=-\frac{c+\delta}{2}+\frac{1}{2} \sqrt{(c+\delta)^{2}-4 c \delta+4 N k \delta T_{N} \varepsilon \mu} \\
& \lambda_{3}=-\frac{c+\delta}{2}-\frac{1}{2} \sqrt{(c+\delta)^{2}-4 c \delta+4 N k \delta T_{N} \varepsilon \mu} \\
& \lambda_{4}=-c,
\end{aligned}
$$

sendo que $\lambda_{2}$ e $\lambda_{3}$ têm parte real negativa e $\lambda_{4}$ é negativo. Como $\lambda_{1}$ é positivo se $p-d_{T}>0$, então o ponto de equilíbrio $\left(T_{N}, 0,0,0\right)$ é instável se $p-d_{T}>0$. Além disso, podemos observar que o ponto de equilíbrio $\left(T_{N}, 0,0,0\right)$ é neutramente estável se $p-d_{T}=0$ e assintoticamente estável se $p-d_{T}<0$. 


\subsubsection{Ponto de Equilíbrio Infectado}

$\mathrm{O}$ ponto de equilíbrio infectado pertence ao conjunto $\Delta$ se, e somente se, $\bar{V}_{I}>0$, ou seja,

$$
\begin{aligned}
\bar{V}_{I} & =\frac{s N \varepsilon}{c}+\frac{p-d_{T}}{k \mu}-\frac{p c}{N k^{2} T_{\max } \varepsilon \mu^{2}}>0 \\
& \Leftrightarrow \frac{s}{k T_{s s 2} \mu}+\frac{p}{k \mu}\left(1-\frac{T_{s s 2}}{T_{\max }}\right)-\frac{d_{T}}{k \mu}>0 \\
& \Leftrightarrow s+p T_{s s 2}\left(1-\frac{T_{s s 2}}{T_{\text {max }}}\right)-d_{T} T_{s s 2}>0 \\
& \Leftrightarrow T_{s s 2}^{2}+\left(d_{T}-p\right) \frac{T_{\text {max }}}{p} T_{s s 2}-\frac{s T_{\text {max }}}{p}<0
\end{aligned}
$$

Portanto,

$$
\bar{V}_{I}>0 \Leftrightarrow 0<T_{s s 2}=\frac{c}{N k \varepsilon \mu}<T_{s s 1}
$$

ou seja,

$$
\bar{V}_{I}>0 \Leftrightarrow N>N_{c r i t}=\frac{c}{k T_{s s 1} \varepsilon \mu},
$$

Assim, resumindo os resultados obtidos, temos: se $N<N_{\text {crit }}$, então o ponto de equilíbrio não infectado é assintoticamente estável. Em particular, se $N<N_{L}<N_{c r i t}$, então o ponto de equilíbrio não infectado é globalmente assintoticamente estável em $\Delta$.

Quando $N<N_{\text {crit }}$ o ponto de equilíbrio infectado não pertence ao conjunto $\Delta$. Se $N=N_{\text {crit }}$, então os pontos de equilíbrio coincidem e ocorre uma bifurcação transcrítica $\left(\lambda_{1}<0, \quad \lambda_{2}=0, \quad \lambda_{3}<0\right.$ e $\left.\lambda_{4}<0\right)$. Quando $N>N_{\text {crit }}$ então o ponto de equilíbrio não infectado é instável e o ponto de equilíbrio infectado imerge no conjunto $\Delta$.

Estudaremos agora a estabilidade do ponto de equilíbrio infectado para $N>N_{\text {crit }}$. Nos trabalhos de Nelson [1998] e Perelson [1999] é mostrado que esse ponto de equilíbrio é estável se $N>N_{c r i t}$, o que julgamos ser incorreto. Mostraremos que esse ponto de equilíbrio pode ser estável ou instável e pode também surgir uma órbita periódica circundando-o, via Teorema de Bifurcação de Poincaré-Andronov-Hopf.

A matriz Jacobiana $\boldsymbol{J}$ quando avaliada no ponto de equilíbrio infectado 
$\left(\bar{T}_{s s 2}, \bar{T}^{*}, \bar{V}_{I}, \bar{V}_{N I}\right)$ é dada por

$$
\left(\begin{array}{cccc}
p\left(1-\frac{2 \bar{T}_{s s 2}}{T_{\text {max }}}\right)-d_{T}-k \mu \bar{V}_{I} & 0 & -k \mu \bar{T}_{s s 2} & 0 \\
k \mu \bar{V}_{I} & -\delta & k \mu \bar{T}_{s s 2} & 0 \\
0 & N \delta \varepsilon & -c & 0 \\
0 & N \delta \eta_{P I} & 0 & -c
\end{array}\right),
$$

ou ainda,

$$
\left(\begin{array}{cccc}
-T-s Q & 0 & \frac{-c}{N \varepsilon} & 0 \\
p-d_{T}+s Q-T & -\delta & \frac{c}{N \varepsilon} & 0 \\
0 & N \delta \varepsilon & -c & 0 \\
0 & N \delta \eta_{P I} & 0 & -c
\end{array}\right)
$$

onde $Q=\frac{N k \varepsilon \mu}{c}$ e $T=\frac{p c}{N k T_{\max } \varepsilon \mu}$.

A equação característica tem um fator $\lambda+c$, implicando que um autovalor é $\lambda_{4}=-c$.

Os outros autovalores são raízes da equação

$$
\begin{aligned}
\operatorname{det}\left(\boldsymbol{J}-\lambda \boldsymbol{I}_{3}\right)= & \lambda^{3}+\left(c+\delta+\frac{p c}{N k T_{\max } \varepsilon \mu}+\frac{s N k \varepsilon \mu}{c}\right) \lambda^{2} \\
& +\left(\frac{p c^{2}}{N k T_{\max } \varepsilon \mu}+\frac{p c \delta}{N k T_{\max } \varepsilon \mu}\right. \\
& \left.+s N k \varepsilon \mu+\frac{s N k \delta \varepsilon \mu}{c}\right) \lambda \\
& +\left(s N k \delta \varepsilon \mu+c \delta\left(p-d_{T}\right)-\frac{p c^{2} \delta}{N k T_{\max } \varepsilon \mu}\right) \\
= & 0,
\end{aligned}
$$

ou seja,

$$
\operatorname{det}\left(\boldsymbol{J}-\lambda \boldsymbol{I}_{3}\right)=\lambda^{3}+A \lambda^{2}+B \lambda+C=0,
$$

onde,

$$
\begin{aligned}
& \boldsymbol{A}=(c+\delta+T+s Q)>0 \\
& B=(c+\delta)(T+s Q)>0 \\
& C=c \delta\left(p-d_{T}-T+s Q\right)
\end{aligned}
$$


e $C$ é positivo se $N>N_{\text {crit }}$, pois $C=c \delta k \mu \bar{V}_{I}$.

Pelo Critério de Routh-Hurwitz ( ver Apêndice), as três raízes da equação característica (2.13) terão parte real negativa se, e somente se,

$$
A>0, C>0 \text { e } A B-C>0 .
$$

O coeficiente $A$ é a soma de termos positivos e é positivo. Sob a condição de $N>N_{\text {crit }}$ temos que $C>0$.

Mostraremos agora que existe um $s=s_{c}>0$ tal que

$$
\boldsymbol{A}\left(s_{c}\right) \boldsymbol{B}\left(s_{c}\right)-\boldsymbol{C}\left(s_{c}\right)=0,
$$

se $s>s_{c}$ então

$$
\boldsymbol{A}(s) \boldsymbol{B}(s)-\boldsymbol{C}(s)>0
$$

e se $0 \leq s<s_{c}$ então

$$
\boldsymbol{A}(s) \boldsymbol{B}(s)-\boldsymbol{C}(s)<0 .
$$

Assim, se $s>s_{c}$ o ponto de equilíbrio infectado é assintoticamente estável, se $s<s_{c}$ o ponto de equilíbrio infectado é instável e quando $s=s_{c}$ mostraremos que temos uma Bifurcação de Poincaré-Andronov-Hopf.

\subsubsection{Bifurcação de Poincaré-Andronov-Hopf}

Observemos que $\boldsymbol{A}(s) \boldsymbol{B}(s)-\boldsymbol{C}(s)=0$ é equivalente a

$$
(c+\delta)^{2}(T+s Q)+(c+\delta)(T+s Q)^{2}+c \delta\left(-s Q-p+d_{T}+T\right)=0,
$$

ou seja,

$$
\begin{aligned}
(\boldsymbol{A B}-\boldsymbol{C})(s) & =(c+\delta) Q^{2} s^{2}+\left[c^{2}+\delta^{2}+c \delta+2(c+\delta) T\right] Q s \\
& +(c+\delta) T^{2}+\left(c^{2}+\delta^{2}+3 c \delta\right) T+c \delta\left(-p+d_{T}\right) \\
& =0
\end{aligned}
$$

que é uma equação polinomial do segundo grau em $s$.

O coeficiente que está multiplicando o termo quadrático $(c+\delta) Q^{2}$ é positivo, logo o gráfico dessa função polinomial tem concavidade voltada para cima, portanto se o termo independente de $s, T I s$, for negativo existirá uma raiz real positiva $s_{c}$ satisfazendo $(2.14),(2.15)$ e $(2.16)$.

Estudaremos agora a condição para que o TIs seja negativo. 
TIs é negativo se, e somente se,

$$
(c+\delta) T^{2}+\left(c^{2}+\delta^{2}+3 c \delta\right) T+c \delta\left(-p+d_{T}\right)<0,
$$

ou seja,

$$
\text { TIs }<0 \Leftrightarrow 0<T<T_{1}
$$

onde

$$
T_{1}=\frac{-\left(c^{2}+\delta^{2}+3 c \delta\right)+\sqrt{\left(c^{2}+\delta^{2}+3 c \delta\right)^{2}-4 c \delta(c+\delta)\left(-p+d_{T}\right)}}{2(c+\delta)} .
$$

Para que $T<T_{1}$ devemos ter

$$
0<\frac{p^{2} c(c+\delta)}{\left(N k T_{\max } \varepsilon \mu\right)^{2}}+\frac{p\left(c^{2}+\delta^{2}+3 c \delta\right)}{N k T_{\max } \varepsilon \mu}<\delta\left(p-d_{T}\right)
$$

que é equivalente a

$$
0<T\left(\beta^{2}+\beta T+c \delta\right)<c \delta\left(p-d_{T}\right)
$$

onde $\beta=c+\delta$.

Notemos que se a condição (2.19) for satisfeita, então $0<T<T_{1}$ e assim, $T I s<0$ e a equação polinomial do segundo grau terá uma raiz real positiva $s_{c}$ dada por

$$
\frac{-\left(\beta^{2}-c \delta+2 \beta T\right)+\sqrt{\left(\beta^{2}-c \delta+2 \beta T\right)^{2}-4 \beta\left[\beta T^{2}+\left(\beta^{2}+c \delta\right) T+c \delta\left(-p+d_{T}\right)\right]}}{2 \beta Q} .
$$

Notemos ainda que se $\boldsymbol{A} B=\boldsymbol{C}$ então $-\boldsymbol{A}$ é raíz de (2.13) e assim podemos escrever

$$
\operatorname{det}\left(\boldsymbol{J}-\lambda \boldsymbol{I}_{3}\right)=(\lambda+\boldsymbol{A})\left(\lambda^{2}+\boldsymbol{B}\right)
$$

Portanto se $s=s_{c}$, por (2.14) e por (2.21) podemos escrever

$$
\begin{aligned}
\operatorname{det}\left(\boldsymbol{J}-\lambda \boldsymbol{I}_{3}\right) & =(\lambda+\boldsymbol{A})\left(\lambda^{2}+\boldsymbol{B}\right) \\
& =(\lambda+\boldsymbol{A})(\lambda+i \sqrt{\boldsymbol{B}})(\lambda-i \sqrt{\boldsymbol{B}}),
\end{aligned}
$$

pois $B>0$, ou ainda,

$$
\operatorname{det}\left(\boldsymbol{J}-\lambda \boldsymbol{I}_{3}\right)=(\lambda+\boldsymbol{A})(\lambda+i \sqrt{\alpha \beta})(\lambda-i \sqrt{\alpha \beta}),
$$


onde $\alpha=T+s Q$ e $\beta=c+\delta$.

Logo, se $s=s_{c}$, então os autovalores da matriz Jacobiana $\boldsymbol{J}\left(\bar{T}_{s s 2}, \bar{T}^{*}, \bar{V}_{I}, \bar{V}_{N I}\right)$ são

$$
\begin{aligned}
& \lambda_{1}=-A=-(\alpha+\beta), \\
& \lambda_{2}=i \sqrt{B}=i \sqrt{\alpha \beta}, \\
& \lambda_{3}=-i \sqrt{B}=-i \sqrt{\alpha \beta}, \\
& \lambda_{4}=-c .
\end{aligned}
$$

Para encontrarmos os autovetores $\boldsymbol{v}_{i}$ associados aos autovalores $\lambda_{i}$, devemos resolver o sistema de equações lineares

$$
\left(J\left(s_{c}\right)-\lambda_{i} I_{4}\right) v_{i}=0
$$

para cada $i=1, \ldots, 4$.

Assim, os autovetores $\boldsymbol{v}_{i}$ associados aos autovalores $\lambda_{i}, i=1, \ldots 4$, são

$$
\begin{aligned}
& v_{1}=\left(1,-\frac{\beta(\alpha+\delta)}{c \delta}, \frac{N \beta \varepsilon}{c}, \frac{N \beta \eta_{P I}}{c}\right), \\
& v_{2}=\left(1, \frac{\alpha}{c}-\frac{(\alpha+c) \sqrt{\alpha \beta}}{c \delta} i,-\frac{N \alpha \varepsilon}{c}-\frac{N \varepsilon \sqrt{\alpha \beta}}{c} i,-\frac{N \alpha \eta_{P I}}{c}-\frac{N \eta_{P I} \sqrt{\alpha \beta}}{c} i\right), \\
& v_{3}=\left(1, \frac{\alpha}{c}+\frac{(\alpha+c) \sqrt{\alpha \beta}}{c \delta} i,-\frac{N \alpha \varepsilon}{c}+\frac{N \varepsilon \sqrt{\alpha \beta}}{c} i,-\frac{N \alpha \eta_{P I}}{c}+\frac{N \eta_{P I} \sqrt{\alpha \beta}}{c} i\right), \\
& \boldsymbol{v}_{4}=(0,0,0,1) .
\end{aligned}
$$

Diferenciando (2.13) em relação a $s$, temos

$$
\lambda^{\prime}(s)=-\frac{\boldsymbol{A}^{\prime}(s) \lambda^{2}(s)+\boldsymbol{B}^{\prime}(s) \lambda(s)+\boldsymbol{C}^{\prime}(s)}{3 \lambda^{2}(s)+2 \boldsymbol{A}(s) \lambda(s)+\boldsymbol{B}(s)} .
$$

Tomando-se $s=s_{c}$ e $\lambda=\lambda_{2}$, temos

$$
\lambda_{2}^{\prime}\left(s_{c}\right)=\frac{\left(\boldsymbol{A}^{\prime}\left(s_{c}\right) \boldsymbol{B}\left(s_{c}\right)-C^{\prime}\left(s_{c}\right)-\boldsymbol{B}^{\prime}\left(s_{c}\right) \sqrt{\boldsymbol{B}\left(s_{c}\right)} i\right.}{-2 \boldsymbol{B}\left(s_{c}\right)+2 \boldsymbol{A}\left(s_{c}\right) \sqrt{\boldsymbol{B}\left(s_{c}\right)} i},
$$

ou seja,

$$
\lambda_{2}^{\prime}\left(s_{c}\right)=-\frac{(\boldsymbol{A} B-C)^{\prime}\left(s_{c}\right)}{2\left[\boldsymbol{A}^{2}\left(s_{c}\right)+B\left(s_{c}\right)\right]}+\frac{\boldsymbol{B}^{\prime}\left(s_{c}\right)}{2 \sqrt{\boldsymbol{B}\left(s_{c}\right)}} i
$$

Mostraremos agora que

$$
(A B-C)^{\prime}\left(s_{c}\right)>0
$$


De fato, derivando a Equação (2.17) em relação a $s$ temos

$$
(\boldsymbol{A B}-\boldsymbol{C})^{\prime}(s)=2(c+\delta) Q^{2} s+\left[c^{2}+\delta^{2}+c \delta+2(c+\delta) T\right] Q>0, \quad \forall s \geq 0,
$$

e portanto

$$
\frac{d}{d s} \Re\left(\lambda_{2}\left(s_{c}\right)\right)=-\frac{(A B-C)^{\prime}\left(s_{c}\right)}{2\left(A^{2}\left(s_{c}\right)+B\left(s_{c}\right)\right)}<0,
$$

que é equivalente a

$$
\frac{d}{d s} \Re\left(\lambda_{2}\left(s_{c}\right)\right)=-\frac{Q[\beta(2 \alpha+\beta)-c \delta]}{2\left[(\alpha+\beta)^{2}+\alpha \beta\right]}<0,
$$

onde $\Re$ é a parte real de um número complexo e $B\left(s_{c}\right)>0$.

Portanto, pelo Teorema de Bifurcação de Poincaré-Andronov-Hopf ( ver Apêndice ), existe uma órbita periódica para cada $s$ próximo de $s_{c}$ quando $s>s_{c}$ ou $s<s_{c}$ e cujo período é aproximadamente $2 \pi / \omega_{0}$, onde $\omega_{0}=$ $\Im\left(\lambda_{2}\left(s_{c}\right)\right)=\sqrt{\boldsymbol{B}\left(s_{c}\right)}$ e $\Im$ é a parte imaginária de um número complexo.

\subsubsection{Estabilidade das Örbitas Periódicas}

Estudaremos agora a estabilidade ou não das órbitas periódicas, usaremos técnicas desenvolvidas em Hassard [1981], páginas 86 a 91.

Seja $P$ a seguinte matriz

$$
\boldsymbol{P}=\left(\Re\left[\boldsymbol{v}_{2}\left(s_{c}\right)\right],-\Im\left[\boldsymbol{v}_{2}\left(s_{c}\right)\right], \boldsymbol{v}_{\mathbf{1}}\left(s_{c}\right), \boldsymbol{v}_{4}\left(s_{c}\right)\right),
$$

ou seja,

$$
P=\left(\begin{array}{cccc}
1 & 0 & 1 & 0 \\
\frac{\alpha}{c} & \frac{(\alpha+c) \sqrt{\alpha \beta}}{c \delta} & -\frac{\beta(\alpha+\delta)}{c \delta} & 0 \\
-\frac{N \alpha \varepsilon}{c} & \frac{N \varepsilon \sqrt{\alpha \beta}}{c} & \frac{N \beta \varepsilon}{c} & 0 \\
-\frac{N \alpha \eta_{P I}}{c} & \frac{N \eta_{P I} \sqrt{\alpha \beta}}{c} & \frac{N \beta \eta_{P I}}{c} & 1
\end{array}\right)
$$

$\mathrm{e}$

$$
P^{-1}=\left(\begin{array}{cccc}
\frac{\beta(2 \alpha+\beta)}{\alpha^{2}+\beta^{2}+3 \alpha \beta} & \frac{c \delta}{\alpha^{2}+\beta^{2}+3 \alpha \beta} & -\frac{c(\alpha+c)}{N \varepsilon\left(\alpha^{2}+\beta^{2}+3 \alpha \beta\right)} & 0 \\
\frac{\alpha \sqrt{\alpha \beta}}{\alpha^{2}+\beta^{2}+3 \alpha \beta} & \frac{c \delta(\alpha+\beta)}{\sqrt{\alpha \beta}\left(\alpha^{2}+\beta^{2}+3 \alpha \beta\right)} & \frac{c[\alpha \delta+\beta(\alpha+\delta)]}{N \varepsilon \sqrt{\alpha \beta}\left(\alpha^{2}+\beta^{2}+3 \alpha \beta\right.} & 0 \\
\frac{\alpha(\alpha+\beta)}{\alpha^{2}+\beta^{2}+3 \alpha \beta} & -\frac{c \delta}{\alpha^{2}+\beta^{2}+3 \alpha \beta} & \frac{c(\alpha+c)}{N \varepsilon\left(\alpha^{2}+\beta^{2}+3 \alpha \beta\right)} & 0 \\
0 & 0 & -\frac{\eta_{P I}}{\varepsilon} & 1
\end{array}\right)
$$

a matriz inversa de $P$. 
Tomando-se

$$
\begin{aligned}
x & =T-\bar{T}_{s s 2}, \\
y & =T^{*}-\bar{T}^{*}, \\
z & =V_{I}-\bar{V}_{I} \\
w & =V_{N I}-\bar{V}_{N I}
\end{aligned}
$$

o sistema de equações diferenciais dado por (2.1), (2.2), (2.3) e (2.4) definido em $\Delta$ fica

$$
\begin{aligned}
\frac{d x}{d t} & =-T Q x^{2}-k \mu x z-\alpha x-\frac{c}{N \varepsilon} z \\
\frac{d y}{d t} & =k \mu x z+\frac{\alpha \beta(\alpha+\beta)}{c \delta} x-\delta y+\frac{c}{N \varepsilon} z \\
\frac{d z}{d t} & =N \varepsilon \delta y-c z \\
\frac{d w}{d t} & =N \delta \eta_{P I} y-c w
\end{aligned}
$$

Façamos agora a seguinte mudança de variáveis

$$
\boldsymbol{x}=\boldsymbol{P y}
$$

e seja

$$
\dot{\boldsymbol{y}}=D(\boldsymbol{y}),
$$

onde $D=P^{-1} \boldsymbol{J}\left(s_{c}\right) \boldsymbol{P}$ e $\boldsymbol{y}=\left(y_{1}, y_{2}, y_{3}, y_{4}\right)=(\tilde{x}, \tilde{y}, \tilde{z}, \tilde{w})$.

Sejam

$$
\begin{aligned}
& F(\tilde{x}, \tilde{y}, \tilde{z}, \tilde{w})=D^{1}(\tilde{x}, \tilde{y}, \tilde{z}, \tilde{w})=\frac{d \tilde{x}}{d t}(\tilde{x}, \tilde{y}, \tilde{z}, \tilde{w}), \\
& G(\tilde{x}, \tilde{y}, \tilde{z}, \tilde{w})=D^{2}(\tilde{x}, \tilde{y}, \tilde{z}, \tilde{w})=\frac{d \tilde{y}}{d t}(\tilde{x}, \tilde{y}, \tilde{z}, \tilde{w}), \\
& H(\tilde{x}, \tilde{y}, \tilde{z}, \tilde{w})=D^{3}(\tilde{x}, \tilde{y}, \tilde{z}, \tilde{w})=\frac{d \tilde{z}}{d t}(\tilde{x}, \tilde{y}, \tilde{z}, \tilde{w}), \\
& L(\tilde{x}, \tilde{y}, \tilde{z}, \tilde{w})=D^{4}(\tilde{x}, \tilde{y}, \tilde{z}, \tilde{w})=\frac{d \tilde{w}}{d t}(\tilde{x}, \tilde{y}, \tilde{z}, \tilde{w}) .
\end{aligned}
$$

A partir desse momento, os cálculos foram feito utilizando-se do pacote matemático Maple 6 ( Maple é uma marca registrada da Waterloo Maple Software ). Assim, 


$$
\begin{aligned}
\frac{d \tilde{x}}{d t}= & \frac{\left(2 \beta k \mu N \varepsilon \alpha^{2}-2 \beta \alpha T Q c-\beta^{2} T Q c-c k \mu N \varepsilon \alpha \delta+\beta^{2} k \mu N \varepsilon \alpha\right)}{c\left(\alpha^{2}+\beta^{2}+3 \alpha \beta\right)} \tilde{x}^{2} \\
- & \frac{\left(\beta^{2} T Q c+2 \beta^{2} k \mu N \varepsilon \alpha+2 \beta \alpha T Q c+k \mu N \varepsilon \beta^{3}-c k \mu N \varepsilon \beta \delta\right)}{c\left(\alpha^{2}+\beta^{2}+3 \alpha \beta\right)} \tilde{z}^{2} \\
- & \frac{k \mu N \varepsilon \sqrt{\alpha \beta}\left(2 \alpha \beta+\beta^{2}-c \delta\right)}{c\left(\alpha^{2}+\beta^{2}+3 \alpha \beta\right)} \tilde{x} \tilde{y} \\
- & \left(\frac{c k \mu N \varepsilon \alpha \delta+k \mu N \varepsilon \beta^{3}+2 \beta^{2} T Q c-c k \mu N \varepsilon \beta \delta+4 \beta \alpha T Q c}{c\left(\alpha^{2}+\beta^{2}+3 \alpha \beta\right)}\right. \\
& \left.+\frac{\beta^{2} k \mu N \varepsilon \alpha-2 \beta k \mu N \varepsilon \alpha^{2}}{c\left(\alpha^{2}+\beta^{2}+3 \alpha \beta\right)}\right) \tilde{x} \tilde{z} \\
& -\frac{k \mu N \varepsilon \sqrt{\alpha \beta}\left(2 \alpha \beta+\beta^{2}-c \delta\right)}{c\left(\alpha^{2}+\beta^{2}+3 \alpha \beta\right)} \tilde{y} \tilde{z} \\
- & \sqrt{\alpha \beta} \tilde{y}
\end{aligned}
$$




$$
\begin{aligned}
& \frac{d \tilde{y}}{d t}=\frac{\left(\alpha^{3} \beta k \mu N \varepsilon-\alpha^{2} \beta T Q c-c \beta k \mu N \varepsilon \alpha \delta-c k \mu N \varepsilon \alpha^{2} \delta\right)}{c \sqrt{\alpha \beta}\left(\alpha^{2}+\beta^{2}+3 \alpha \beta\right)} \tilde{x}^{2} \\
& +\frac{\left(-\alpha^{2} \beta^{2} k \mu N \varepsilon-\alpha^{2} \beta T Q c+c \beta^{2} k \mu N \varepsilon \delta+c \beta k \mu N \varepsilon \alpha \delta\right)}{c \sqrt{\alpha \beta}\left(\alpha^{2}+\beta^{2}+3 \alpha \beta\right)} \tilde{z}^{2} \\
& +\frac{k \mu N \varepsilon\left(c \alpha \delta-\alpha^{2} \beta+c \beta \delta\right)}{c\left(\alpha^{2}+\beta^{2}+3 \alpha \beta\right)} \tilde{x} \tilde{y} \\
& +\frac{\left(-\alpha^{2} \beta^{2} k \mu N \varepsilon+\alpha^{3} \beta k \mu N \varepsilon-c k \mu N \varepsilon \alpha^{2} \delta+c \beta^{2} k \mu N \varepsilon \delta-2 \alpha^{2} \beta T Q c\right)}{c \sqrt{\alpha \beta}\left(\alpha^{2}+\beta^{2}+3 \alpha \beta\right)} \tilde{x} \tilde{z} \\
& +\frac{k \mu N \varepsilon\left(c \alpha \delta-\alpha^{2} \beta+c \beta \delta\right)}{c\left(\alpha^{2}+\beta^{2}+3 \alpha \beta\right)} \tilde{y} \tilde{z} \\
& +\sqrt{\alpha \beta} \tilde{x} \\
& \frac{d \tilde{z}}{d t}=\frac{\left(k \mu N \varepsilon \alpha^{3}-\beta \alpha T Q c+c k \mu N \varepsilon \alpha \delta+\beta k \mu N \varepsilon \alpha^{2}-\alpha^{2} T Q c\right)}{c\left(\alpha^{2}+\beta^{2}+3 \alpha \beta\right)} \tilde{x}^{2} \\
& +\frac{\left(-\beta k \mu N \varepsilon \alpha^{2}-\beta^{2} k \mu N \varepsilon \alpha-\beta \alpha T Q c-c k \mu N \varepsilon \beta \delta-\alpha^{2} T Q c\right)}{c\left(\alpha^{2}+\beta^{2}+3 \alpha \beta\right)} \tilde{z}^{2} \\
& +\frac{k \mu N \varepsilon \sqrt{\alpha \beta}\left(-\alpha^{2}-\alpha \beta-c \delta\right)}{c\left(\alpha^{2}+\beta^{2}+3 \alpha \beta\right)} \tilde{x} \tilde{y} \\
& +\left(\frac{-\beta^{2} k \mu N \varepsilon \alpha+k \mu N \varepsilon \alpha^{3}+c k \mu N \varepsilon \alpha \delta-2 \alpha^{2} T Q c}{c\left(\alpha^{2}+\beta^{2}+3 \alpha \beta\right)}\right. \\
& \left.+\frac{-c k \mu N \varepsilon \beta \delta-2 \beta \alpha T Q c}{c\left(\alpha^{2}+\beta^{2}+3 \alpha \beta\right)}\right) \tilde{x} \tilde{z} \\
& +\frac{k \mu N \varepsilon \sqrt{\alpha \beta}\left(-\alpha^{2}-\alpha \beta-c \delta\right)}{c\left(\alpha^{2}+\beta^{2}+3 \alpha \beta\right)} \tilde{y} \tilde{z} \\
& -(\alpha+\beta) \tilde{z} \\
& \frac{d \tilde{w}}{d t}=-c \tilde{w}
\end{aligned}
$$

A matriz Jacobiana

$$
\frac{\partial D^{i}(0)}{\partial y_{j}}, \quad i=1, \ldots, 4, j=1, \ldots, 4,
$$


tem a seguinte forma canônica real

$$
\frac{\partial D}{\partial y}(0)=\left(\begin{array}{cccc}
0 & -\omega_{0} & 0 & 0 \\
\omega_{0} & 0 & 0 & 0 \\
0 & 0 & -(\alpha+\beta) & 0 \\
0 & 0 & 0 & -c
\end{array}\right) \text {, }
$$

onde $\omega_{0}=\sqrt{B\left(s_{c}\right)}=\sqrt{\alpha \beta}$.

As quantidades a seguir serão calculadas em $s=s_{c}$ e $\boldsymbol{y}=0$.

$$
\text { - } g_{11}=\frac{1}{4}\left[\frac{\partial^{2} F}{\partial \tilde{x}^{2}}+\frac{\partial^{2} F}{\partial \tilde{y}^{2}}+i\left[\frac{\partial^{2} G}{\partial \tilde{x}^{2}}+\frac{\partial^{2} G}{\partial \tilde{y}^{2}}\right]\right]
$$

ou seja,

$$
\begin{aligned}
g_{11} & =\frac{2 \beta k \mu N \varepsilon \alpha^{2}-2 \beta \alpha T Q c-c k \mu N \varepsilon \alpha \delta-\beta^{2} T Q c+\beta^{2} k \mu N \varepsilon \alpha}{2 c\left(\alpha^{2}+\beta^{2}+3 \alpha \beta\right)} \\
& +\frac{\alpha\left(-c k \mu N \varepsilon \alpha \delta-c k \mu N \varepsilon \beta \delta-\beta \alpha T Q c+\beta k \mu N \varepsilon \alpha^{2}\right)}{2 c \sqrt{\alpha \beta}\left(\alpha^{2}+\beta^{2}+3 \alpha \beta\right)} i .
\end{aligned}
$$

- $g_{02}=\frac{1}{4}\left[\frac{\partial^{2} F}{\partial \tilde{x}^{2}}-\frac{\partial^{2} F}{\partial \tilde{y}^{2}}-2 \frac{\partial^{2} G}{\partial \tilde{x} \partial \tilde{y}}+i\left[\frac{\partial^{2} G}{\partial \tilde{x}^{2}}-\frac{\partial^{2} G}{\partial \tilde{y}^{2}}+2 \frac{\partial^{2} F}{\partial \tilde{x} \partial \tilde{y}}\right]\right]$

ou seja,

$$
\begin{aligned}
g_{02} & =\frac{3 \beta k \mu N \varepsilon \alpha^{2}-2 \beta \alpha T Q c-2 c k \mu N \varepsilon \alpha \delta-\beta^{2} T Q c}{2 c\left(\alpha^{2}+\beta^{2}+3 \alpha \beta\right)} \\
& +\frac{\beta^{2} k \mu N \varepsilon \alpha-c k \mu N \varepsilon \beta \delta}{2 c\left(\alpha^{2}+\beta^{2}+3 \alpha \beta\right)} \\
& +\left(\frac{\alpha\left(\beta k \mu N \varepsilon \alpha^{2}-c k \mu N \varepsilon \alpha \delta-\beta \alpha T Q c-k \mu N \varepsilon \beta^{3}-2 \beta^{2} k \mu N \varepsilon \alpha\right)}{2 c \sqrt{\alpha \beta}\left(\alpha^{2}+\beta^{2}+3 \alpha \beta\right)}\right) i . \\
& \quad g_{20}=\frac{1}{4}\left[\frac{\partial^{2} F}{\partial \tilde{x}^{2}}-\frac{\partial^{2} F}{\partial \tilde{y}^{2}}+2 \frac{\partial^{2} G}{\partial \tilde{x} \partial \tilde{y}}+i\left[\frac{\partial^{2} G}{\partial \tilde{x}^{2}}-\frac{\partial^{2} G}{\partial \tilde{y}^{2}}-2 \frac{\partial^{2} F}{\partial \tilde{x} \partial \tilde{y}}\right]\right],
\end{aligned}
$$


ou seja,

$$
\begin{aligned}
g_{20}= & \frac{\beta\left(k \mu N \varepsilon \alpha^{2}-2 \alpha T Q c-\beta T Q c+\beta k \mu N \varepsilon \alpha+c k \mu N \varepsilon \delta\right)}{2 c\left(\alpha^{2}+\beta^{2}+3 \alpha \beta\right)} \\
+ & \left(\frac{\alpha\left(k \mu N \varepsilon \beta^{3}-2 c k \mu N \varepsilon \beta \delta-\beta \alpha T Q c+\beta k \mu N \varepsilon \alpha^{2}\right)}{2 c \sqrt{\alpha \beta}\left(\alpha^{2}+\beta^{2}+3 \alpha \beta\right)}\right. \\
& \left.+\frac{\alpha\left(2 \beta^{2} k \mu N \varepsilon \alpha-c k \mu N \varepsilon \alpha \delta\right)}{2 c \sqrt{\alpha \beta}\left(\alpha^{2}+\beta^{2}+3 \alpha \beta\right)}\right) i . \\
\bullet \quad G_{21}= & \frac{1}{8}\left[\frac{\partial^{3} F}{\partial \tilde{x}^{3}}-\frac{\partial^{3} F}{\partial \tilde{x} \partial \tilde{y}^{2}}+\frac{\partial^{3} G}{\partial \tilde{x}^{2} \partial \tilde{y}}+\frac{\partial^{3} G}{\partial \tilde{y}^{3}}\right. \\
+ & \left.i\left[\frac{\partial^{3} G}{\partial \tilde{x}^{3}}-\frac{\partial^{3} G}{\partial \tilde{x} \partial \tilde{y}^{2}}-\frac{\partial^{3} F}{\partial \tilde{x}^{2} \partial \tilde{y}}-\frac{\partial^{3} F}{\partial \tilde{y}^{3}}\right]\right],
\end{aligned}
$$

ou seja,

$$
\begin{gathered}
G_{21}=0 . \\
\text { - } h_{11}^{k-2}=\frac{1}{4}\left[\frac{\partial^{2} D^{k}}{\partial \tilde{x}^{2}}+\frac{\partial^{2} D^{k}}{\partial \tilde{y}^{2}}\right],
\end{gathered}
$$

onde $k=3,4$, ou seja,

$$
\begin{aligned}
& h_{11}^{1}=\frac{\alpha\left(k \mu N \varepsilon \alpha^{2}-\beta T Q c+\beta k \mu N \varepsilon \alpha+c k \mu N \varepsilon \delta-\alpha T Q c\right)}{2 c\left(\alpha^{2}+\beta^{2}+3 \alpha \beta\right)}, \\
& h_{11}^{2}=0 .
\end{aligned}
$$

$$
h_{20}^{k-2}=\frac{1}{4}\left[\frac{\partial^{2} D^{k}}{\partial \tilde{x}^{2}}-\frac{\partial^{2} D^{k}}{\partial \tilde{y}^{2}}-2 i \frac{\partial^{2} D^{k}}{\partial \tilde{x} \partial \tilde{y}}\right],
$$

onde $k=3,4$, ou seja,

$$
\begin{aligned}
h_{20}^{1} & =\frac{\alpha\left(c k \mu N \varepsilon \delta-\alpha T Q c+k \mu N \varepsilon \alpha^{2}-\beta T Q c-\beta k \mu N \varepsilon \alpha\right)}{2 c\left(\alpha^{2}+\beta^{2}+3 \alpha \beta\right)} \\
& +\frac{k \mu N \varepsilon \sqrt{\alpha \beta}\left(\alpha^{2}+\alpha \beta+c \delta\right)}{2 c\left(\alpha^{2}+\beta^{2}+3 \alpha \beta\right)} i, \\
h_{20}^{2} & =0 .
\end{aligned}
$$


Resolvendo os seguintes sistemas lineares

$$
\begin{aligned}
\boldsymbol{E} w_{11} & =-h_{11}=-\left(h_{11}^{1}, h_{11}^{2}\right), \\
\left(\boldsymbol{E}-2 i \omega_{0} \boldsymbol{I}_{2}\right) w_{20} & =-h_{20}=-\left(h_{20}^{1}, h_{20}^{2}\right),
\end{aligned}
$$

em termos de $w_{11}=\left(w_{11}^{1}, w_{11}^{2}\right)$ e $w_{20}=\left(w_{20}^{1}, w_{20}^{2}\right)$, onde

$$
E=\left(\begin{array}{cc}
-(\alpha+\beta) & 0 \\
0 & -c
\end{array}\right)
$$

obtemos

$$
\begin{gathered}
w_{11}^{1}=\frac{h_{11}^{1}}{\alpha+\beta}, \quad w_{11}^{2}=0, \text { e } \quad w_{20}^{1}=\frac{h_{20}^{1}}{\alpha+\beta+2 i \sqrt{\alpha \beta}}, \quad w_{20}^{2}=0 \\
\quad G_{110}^{k-2}=\frac{1}{2}\left[\frac{\partial^{2} F}{\partial \tilde{x} \partial y_{k}}+\frac{\partial^{2} G}{\partial \tilde{y} \partial y_{k}}+i\left[\frac{\partial^{2} G}{\partial \tilde{x} \partial y_{k}}-\frac{\partial^{2} F}{\partial \tilde{y} \partial y_{k}}\right]\right],
\end{gathered}
$$

onde $k=3,4$, ou seja,

$$
\begin{aligned}
G_{110}^{1}= & \frac{\beta\left(k \mu N \varepsilon \alpha^{2}-2 \beta T Q c-\beta^{2} k \mu N \varepsilon-\beta k \mu N \varepsilon \alpha-4 \alpha T Q c+2 c k \mu N \varepsilon \delta\right)}{2 c\left(\alpha^{2}+\beta^{2}+3 \alpha \beta\right)} \\
+ & \left(\frac{c k \mu N \varepsilon \beta^{2} \delta-c k \mu N \varepsilon \alpha^{2} \delta+\alpha^{2} \beta^{2} k \mu N \varepsilon+\alpha^{3} \beta k \mu N \varepsilon-2 \alpha^{2} \beta T Q c}{c \sqrt{\alpha \beta}\left(\alpha^{2}+\beta^{2}+3 \alpha \beta\right)}\right. \\
& \left.+\frac{k \mu N \varepsilon \alpha \beta^{3}-c \alpha k \mu N \varepsilon \beta \delta}{c \sqrt{\alpha \beta}\left(\alpha^{2}+\beta^{2}+3 \alpha \beta\right)}\right) i, \\
G_{110}^{2}= & 0 .
\end{aligned}
$$

- $G_{101}^{k-2}=\frac{1}{2}\left[\frac{\partial^{2} F}{\partial \tilde{x} \partial y_{k}}-\frac{\partial^{2} G}{\partial \tilde{y} \partial y_{k}}+i\left[\frac{\partial^{2} F}{\partial \tilde{y} \partial y_{k}}+\frac{\partial^{2} G}{\partial \tilde{x} \partial y_{k}}\right]\right]$, 
onde $k=3,4$, ou seja,

$$
\begin{aligned}
G_{101}^{1}= & \frac{3 \beta k \mu N \varepsilon \alpha^{2}-2 \beta^{2} T Q c-k \mu N \varepsilon \beta^{3}-\beta^{2} k \mu N \varepsilon \alpha}{2 c\left(\alpha^{2}-\beta^{2}+3 \alpha \beta\right)} \\
- & \frac{4 \beta \alpha T Q c+2 c k \mu N \varepsilon \alpha \delta}{2 c\left(\alpha^{2}+\beta^{2}+3 \alpha \beta\right)} \\
+ & \left(\frac{c \alpha k \mu N \varepsilon \beta \delta-k \mu N \varepsilon \alpha \beta^{3}-3 \alpha^{2} \beta^{2} k \mu N \varepsilon-c k \mu N \varepsilon \alpha^{2} \delta}{2 c \sqrt{\alpha \beta}\left(\alpha^{2}+\beta^{2}+3 \alpha \beta\right)}\right. \\
& \left.+\frac{c k \mu N \varepsilon \beta^{2} \delta+\alpha^{3} \beta k \mu N \varepsilon-2 \alpha^{2} \beta T Q c}{2 c \sqrt{\alpha \beta}\left(\alpha^{2}+\beta^{2}+3 \alpha \beta\right)}\right) i \\
G_{101}^{2}= & 0 . \\
& \bullet \quad G_{21}+\sum_{k=1}^{2}\left(2 G_{110}^{k} w_{11}^{k}+G_{101}^{k} w_{20}^{k}\right) \\
= & 2 G_{110}^{1} w_{11}^{1}+G_{101}^{1} w_{20}^{1} .
\end{aligned}
$$

Antes de prosseguirmos com os cálculos, faremos algumas considerações. Após calcular $g_{21}$, calcularemos ainda

$$
\begin{aligned}
c_{1}(0) & =\frac{i}{2 \omega_{0}}\left[g_{20} g_{11}-2\left\|g_{11}\right\|^{2}-\frac{1}{3}\left\|g_{02}\right\|^{2}\right]+\frac{g_{21}}{2}, \\
\text { - } \mu_{2} & =-\frac{\Re\left(c_{1}(0)\right)}{\gamma^{\prime}(0)} \\
\mathrm{e} & \text { - } \beta_{2}=2 \Re\left(c_{1}(0)\right),
\end{aligned}
$$

onde

$$
\gamma^{\prime}(0)=\frac{d}{d s} \Re\left(\lambda_{2}\left(s_{c}\right)\right),
$$

e é negativo por (2.26). O sinal de $\mu_{2}$ informa se as órbitas periódicas ocorrem para $s>s_{c}$ ou para $s<s_{c}$. Quando $\mu_{2}>0$ as órbitas ocorrem para $s>s_{c}$ e quando $\mu_{2}<0$ as órbitas ocorrem para $s<s_{c}$.

$\mathrm{O}$ sinal de $\beta_{2}$ informa sobre a estabilidade ou não das órbitas periódicas. Se $\beta_{2}>0$, então as órbitas são instáveis e se $\beta_{2}<0$, então as órbitas periódicas são atratoras. 
Se $\mu_{2}=0$ ou se $\beta_{2}=0$, então haverá necessidade de se calcular outros termos.

Observemos que no cálculo de $\mu_{2}$ e de $\beta_{2}$ basta, agora, calcular a parte real de $c_{1}(0)$, e no cálculo da parte real de $c_{1}(0)$ necessitamos da parte real de $g_{21}$ e da parte imaginária de $g_{20} g_{11}$. Assim, concentraremos esforços agora para o cálculo da parte real de $g_{21}$ e da parte imaginária de $g_{20} g_{11}$ e aí então calcularemos a parte real de $c_{1}(0)$. É importante notar também que estamos interessados apenas no sinal de $\mu_{2}$ e $\beta_{2}$ e esses sinais são iguais ao sinal da parte real de $c_{1}(0)$, não havendo portanto necessidade de se calcular explicitamente os parâmetros $\mu_{2}$ e $\beta_{2}$, contanto que eles não se anulem.

- Parte Real de $g_{21}, \Re\left(g_{21}\right)$

Observemos que

$$
G_{110}^{1}=\frac{F_{\tilde{x} \bar{z}}+G_{\tilde{y} \tilde{z}}}{2}+i \Im\left(G_{110}^{1}\right)
$$

e

$$
w_{11}^{1}=\frac{H_{\tilde{x} \tilde{x}}}{4(\alpha+\beta)}
$$

onde $f_{\tilde{p} \tilde{q}}=\frac{\partial^{2} f}{\partial \tilde{q} \partial \tilde{p}}$ e se $f \in \mathcal{C}^{2}$, então $f_{\tilde{p} \tilde{q}}=f_{\tilde{q} \tilde{p}}$, assim

$$
2 G_{110}^{1} w_{11}^{1}=\frac{H_{\tilde{x} \tilde{x}}\left(F_{\tilde{x} \tilde{z}}+G_{\tilde{y} \tilde{z}}\right)}{4(\alpha+\beta)}+i \Im\left(2 G_{110}^{1} w_{11}^{1}\right) .
$$

Observemos também que

$$
G_{101}^{1}=\frac{F_{\tilde{x} \tilde{z}}-G_{\tilde{y} \tilde{z}}+i\left(F_{\tilde{y} \tilde{z}}+G_{\tilde{x} \tilde{z}}\right)}{2}
$$

e

$$
\begin{aligned}
w_{20}^{1} & =\frac{h_{20}^{1}}{\alpha+\beta+2 i \sqrt{\alpha \beta}} \\
& =\frac{H_{\tilde{x} \tilde{x}}-2 i H_{\tilde{x} \tilde{y}}}{4\left[(\alpha+\beta)+2 i \omega_{0}\right]} \\
& =\frac{(\alpha+\beta) H_{\tilde{x} \tilde{x}}-4 \omega_{0} H_{\tilde{x} \tilde{y}}}{4\left[(\alpha+\beta)^{2}+4 \omega_{0}^{2}\right]}-\frac{i\left[\omega_{0} H_{\tilde{x} \tilde{x}}+(\alpha+\beta) H_{\tilde{x} \tilde{y}}\right]}{2\left[(\alpha+\beta)^{2}+4 \omega_{0}^{2}\right]}
\end{aligned}
$$


e portanto

$$
\begin{aligned}
G_{101}^{1} w_{20}^{1} & =\frac{\left(F_{\tilde{x} \tilde{z}}-G_{\tilde{y} \tilde{z}}\right)\left[(\alpha+\beta) H_{\tilde{x} \tilde{x}}-4 \omega_{0} H_{\tilde{x} \tilde{y}}\right]}{8\left[(\alpha+\beta)^{2}+4 \omega_{0}^{2}\right]} \\
& +\frac{\left(F_{\tilde{y} \tilde{z}}+G_{\tilde{x} \tilde{z}}\right)\left[\omega_{0} H_{\tilde{x} \tilde{x}}+(\alpha+\beta) H_{\tilde{x} \tilde{y}}\right]}{4\left[(\alpha+\beta)^{2}+4 \omega_{0}^{2}\right]}+i \Im\left(G_{101}^{1} w_{20}^{1}\right) .
\end{aligned}
$$

Como, por (2.32) temos

$$
g_{21}=2 G_{110}^{1} w_{11}^{1}+G_{101}^{1} w_{20}^{1}
$$

então por (2.36) e por (2.37) temos que a parte real de $g_{21}$ é dada por

$$
\begin{aligned}
& \Re\left(g_{21}\right)=\frac{H_{\tilde{x} \tilde{x}}\left(F_{\tilde{x} \tilde{z}}+G_{\tilde{y} \tilde{z}}\right)}{4(\alpha+\beta)}+\frac{\left(F_{\tilde{x} \tilde{z}}-G_{\tilde{y} \tilde{z}}\right)\left[(\alpha+\beta) H_{\tilde{x} \tilde{x}}-4 \omega_{0} H_{\tilde{x} \tilde{y}}\right]}{8\left[(\alpha+\beta)^{2}+4 \omega_{0}^{2}\right]} \\
& +\frac{\left(F_{\tilde{y} \tilde{z}}+G_{\tilde{x} \tilde{z}}\right)\left[\omega_{0} H_{\tilde{x} \tilde{x}}+(\alpha+\beta) H_{\tilde{x} \tilde{y}}\right]}{4\left[(\alpha+\beta)^{2}+4 \omega_{0}^{2}\right]} .
\end{aligned}
$$

- Parte Imaginária de $g_{20} g_{11}, \Im\left(g_{20} g_{11}\right)$

Observemos que

$$
g_{20}=\frac{F_{\tilde{x} \tilde{x}}+2 G_{\tilde{x} \tilde{y}}+i\left(G_{\tilde{x} \tilde{x}}-2 F_{\tilde{x} \tilde{y}}\right)}{4}
$$

e

$$
g_{11}=\frac{F_{\tilde{x} \tilde{x}}+i G_{\tilde{x} \tilde{x}}}{4}
$$

e portanto

$$
\Im\left(g_{20} g_{11}\right)=\frac{F_{\tilde{x} \tilde{x}} G_{\tilde{x} \tilde{x}}-F_{\tilde{x} \tilde{x}} F_{\tilde{x} \tilde{y}}+G_{\tilde{x} \tilde{x}} G_{\tilde{x} \tilde{y}}}{8} .
$$

- Parte Real de $c_{1}(0), \Re\left(c_{1}(0)\right)$

De (2.33) concluímos que a parte real de $c_{1}(0)$ é dada por

$$
\Re\left(c_{1}(0)\right)=\frac{-\Im\left(g_{20} g_{11}\right)}{2 \omega_{0}}+\frac{\Re\left(g_{21}\right)}{2},
$$


assim, por (2.38) e (2.39) temos

$$
\begin{aligned}
\Re\left(c_{1}(0)\right) & =-\frac{F_{\tilde{x} \tilde{x}} G_{\tilde{x} \tilde{x}}-F_{\tilde{x} \tilde{x}} F_{\tilde{x} \tilde{y}}+G_{\tilde{x} \tilde{x}} G_{\tilde{x} \tilde{y}}}{16 \omega_{0}}+\frac{H_{\tilde{x} \tilde{x}}\left(F_{\tilde{x} \tilde{z}}+G_{\tilde{y} \tilde{z}}\right)}{8(\alpha+\beta)} \\
& +\frac{\left(F_{\tilde{x} \tilde{z}}-G_{\tilde{y} \tilde{z}}\right)\left[(\alpha+\beta) H_{\tilde{x} \tilde{x}}-4 \omega_{0} H_{\tilde{x} \tilde{y}}\right]}{16\left[(\alpha+\beta)^{2}+4 \omega_{0}^{2}\right]} \\
& +\frac{\left(F_{\tilde{y} \tilde{z}}+G_{\tilde{x} \tilde{z}}\right)\left[\omega_{0} H_{\tilde{x} \tilde{x}}+(\alpha+\beta) H_{\tilde{x} \tilde{y}}\right]}{8\left[(\alpha+\beta)^{2}+4 \omega_{0}^{2}\right]},
\end{aligned}
$$

ou seja,

$$
\begin{aligned}
\Re\left(c_{1}(0)\right) & =\frac{3 \beta^{2} k^{2} \mu^{2} N^{2} \varepsilon^{2} \alpha^{5}-14 \beta^{2} k \mu N \varepsilon \alpha^{4} T Q c-12 \beta^{3} k^{2} \mu^{2} N^{2} \varepsilon^{2} \alpha^{4}}{\psi} \\
& +\frac{\beta k^{2} \mu^{2} N^{2} \varepsilon^{2} \alpha^{4} c \delta-\beta \alpha^{3} T Q c^{2} k \mu N \varepsilon \delta+12 \beta^{2} \alpha^{3} T^{2} Q^{2} c^{2}}{\psi} \\
& +\frac{33 \beta^{2} k^{2} \mu^{2} N^{2} \varepsilon^{2} \alpha^{3} c \delta-c^{2} k^{2} \mu^{2} N^{2} \varepsilon^{2} \alpha^{3} \delta^{2}-3 \beta^{3} T Q c k \mu N \varepsilon \alpha^{3}}{\psi} \\
& +\frac{23 \beta^{3} k^{2} \mu^{2} N^{2} \varepsilon^{2} \alpha^{2} c \delta-26 k^{2} \mu^{2} N^{2} \varepsilon^{2} \beta^{4} \alpha^{3}-8 c^{2} k^{2} \mu^{2} N^{2} \varepsilon^{2} \alpha^{2} \delta^{2} \beta}{\psi} \\
& +\frac{21 \beta^{4} T Q c k \mu N \varepsilon \alpha^{2}-49 \beta^{2} \alpha^{2} T Q c^{2} k \mu N \varepsilon \delta+16 \beta^{3} T^{2} Q^{2} c^{2} \alpha^{2}}{\psi} \\
& +\frac{4 \alpha \beta^{4} T^{2} Q^{2} c^{2}-12 k^{2} \mu^{2} N^{2} \varepsilon^{2} \beta^{5} \alpha^{2}+9 \alpha k^{2} \mu^{2} N^{2} \varepsilon^{2} c^{2} \beta^{2} \delta^{2}}{\psi} \\
& +\frac{11 \alpha k \mu N \varepsilon \beta^{5} T Q c-\alpha k^{2} \mu^{2} N^{2} \varepsilon^{2} \beta^{4} c \delta-35 \alpha \beta^{3} T Q c^{2} k \mu N \varepsilon \delta}{\psi} \\
& +\frac{k \mu N \varepsilon \beta^{6} T Q c-\alpha \beta^{6} k^{2} \mu^{2} N^{2} \varepsilon^{2}-3 c^{2} k \mu N \varepsilon \beta^{4} \delta T Q}{\psi},
\end{aligned}
$$

onde $\psi=8 c^{2} \beta(\alpha+\beta)\left(\alpha^{2}+\beta^{2}+3 \alpha \beta\right)\left(\alpha^{2}+\beta^{2}+6 \alpha \beta\right)$.

Finalmente estamos em condições de enunciar o seguinte Teorema que acabamos de demonstrar

Teorema 1 Para o sistema de equações diferenciais (2.1), (2.2), (2.3) e (2.4) definido em $\Delta$ se as desigualdades (2.6) e (2.18) forem satisfeitas, então $s_{c}$ dado por (2.20) é estritamente positivo e existe uma órbita periódica em $\Delta$ para cada s próximo de $s_{c}$ quando $s>s_{c}$ ou $s<s_{c}$. Além disso, se $\Re\left(c_{1}(0)\right)$ dado por (2.41) for positivo, então a orbita periódica será instável para $s>s_{c}$ e se $\Re\left(c_{1}(0)\right)$ for negativo, então a órbita será atratora para $s<s_{c}$. 


\section{Capítulo 3}

\section{Alguns Métodos Numéricos em Equações Diferenciais}

Na maioria das vezes é difícil, ou até mesmo impossível, obter uma solução explícita ou analítica de um sistema de equações diferenciais, especialmente os sistemas não-lineares. A Teoria Qualitativa das Equações Diferenciais, como discutida em capítulo anterior, proporciona meios de se abordar estas equações e é utilizada para obter informações sobre o comportamento das soluções.

Uma outra abordagem, apresentada neste capítulo, enfatiza o emprego de métodos numéricos a fim de se obter uma aproximação da solução exata de uma equação diferencial. É necessário ter em mente que quando tais soluções aproximadas convergem para as soluções exatas, tal convergência se dá em intervalos finitos, sendo a convergência tanto mais lenta quanto maior for o intervalo, ou maior a quantidade de pontos considerados neste intervalo.

\subsection{Considerações Iniciais}

Consideremos o seguinte problema de valor inicial:

$$
\left\{\begin{aligned}
x^{\prime} & =f(t, x) \\
x\left(t_{0}\right) & =x_{0}
\end{aligned}\right.
$$

para $t_{0} \in[a, b]$ onde $a, b \in \mathbb{R}$ e $f$ é uma função com alguma propriedade que garanta que o problema (3.1) tenha uma única solução diferenciável $x=x(t)$, por exemplo, $f \in \mathcal{C}^{1}[a, b]$. Seja a seqüência de pontos $\left\{t_{n}\right\}$ definida por $t_{n}=$ 
$a+n h, n=0,1,2, \ldots$ onde o parâmetro $h>0$ é tomado constante e é chamado de tamanho do passo. A maioria dos métodos computacionais para solução de (3.1) são discretos, ou seja, esses métodos fornecem uma solução aproximada não no intervalo contínuo $a \leq t \leq b$ mas, em um conjunto discreto de pontos $\left\{t_{n}: n=0,1,2, \ldots,(b-a) / h\right.$ e $\left.a \leq t_{n} \leq b\right\}$. Seja $x_{n}$ uma aproximação para a solução teórica em $t_{n}$, ou seja, $x_{n}$ é uma aproximação para $x\left(t_{n}\right)$, e seja também, $f_{n}=f\left(t_{n}, x_{n}\right)$. Se um dado método computacional para determinar $\left\{x_{n}\right\}$ apresenta uma relação linear entre $x_{n+j}, f_{n+j}, j=0,1, \ldots, k$, então temos um método linear multipassos com $k$ passos, Lambert [1973].

Um método geral linear multipassos pode ser escrito como

$$
\sum_{j=0}^{k} \alpha_{j} x_{n+j}=h \sum_{j=0}^{k} \beta_{j} f_{n+j}
$$

onde $\alpha_{j}$ e $\beta_{j}$ são constantes, $\alpha_{k} \neq 0$ e $\alpha_{0}^{2}+\beta_{0}^{2} \neq 0$. Por conveniência tomamos $\alpha_{k}=1$. Para obtermos a seqüência $\left\{x_{n}\right\}$ numericamente devemos fornecer um conjunto de valores iniciais $x_{0}, x_{1}, \ldots, x_{k-1}$ (para métodos de passo único, $k=1$, tomamos $\left.x\left(t_{0}\right)=x_{0}\right)$.

$\mathrm{O}$ método (3.2) é explícito se $\beta_{k}=0$ e implícito se $\beta_{k} \neq 0$. Para um método explícito, obtemos o valor de $x_{n+k}$ diretamente em termos de $x_{n+j}, f_{n+j}, \quad j=0,1, \ldots, k-1$, já calculados. Em um método implícito utilizamos uma equação da forma

$$
x_{n+k}=h \beta_{k} f\left(t_{n+k}, x_{n+k}\right)+g,
$$

onde $g$ é uma função conhecida de valores $x_{n+j}, f_{n+j}, \quad j=0,1, \ldots, k-1$, previamente calculados.

Existem diferentes maneiras de se obter os coeficientes $\alpha_{j}$ e $\beta_{j}$ que aparecem em (3.2), abaixo segue uma abordagem utilizando expansão em série de Taylor para a obtenção desses coeficientes.

Ao método linear multipassos associamos o operador linear de diferenças $\mathcal{L}$ definido por

$$
\mathcal{L}[x(t) ; h]=\sum_{j=0}^{k}\left[\alpha_{j} x(t+j h)-h \beta_{j} x^{\prime}(t+j h)\right],
$$

onde $x=x(t)$ é uma função arbitrária que assumiremos ser de uma classe suficiente para que possamos efetuar a expansão em série de Taylor. Expandindo a função teste $x(t+j h)$ e sua derivada $x^{\prime}(t+j h)$ em série de Taylor 
em torno de $t$, e agrupando os termos em (3.3) obtemos

$$
\mathcal{L}[x(t) ; h]=C_{0} x(t)+C_{1} h x^{(1)}(t)+\cdots+C_{q} h^{q} x^{(q)}(t)+\cdots,
$$

onde os $C_{q}$ são constantes.

Definição 10 método linear multipassos (3.2) e o operador de diferenças associado (3.3) são ditos de ordem $p$ se, em (3.4), $C_{0}=C_{1}=\cdots=C_{p}=0$ $e C_{p+1} \neq 0$.

As constantes $C_{q}$ em termos de $\alpha_{j}$ e $\beta_{j}$ são dadas por

$$
\begin{aligned}
C_{0}= & \alpha_{0}+\alpha_{1}+\alpha_{2}+\cdots+\alpha_{k}, \\
C_{1}= & \alpha_{1}+2 \alpha_{2}+\cdots+k \alpha_{k}-\left(\beta_{0}+\beta_{1}+\beta_{2}+\cdots+\beta_{k}\right), \\
C_{q}= & \frac{1}{q}\left(\alpha_{1}+2^{q} \alpha_{2}+\cdots+k^{q} \alpha_{k}\right) \\
& -\frac{1}{(q-1) !}\left(\beta_{1}+2^{q-1} \beta_{2}+\cdots+k^{q-1} \beta_{k}\right), \quad q=2,3, \ldots
\end{aligned}
$$

Essas expressões são usadas para se obterem métodos lineares múltipassos com uma determinada estrutura ou ordem.

Definição $2 O$ erro de truncamento local $\mathrm{em} t_{n+k}$ do método (3.2) é definido pela expressão $\mathcal{L}\left[x\left(t_{n}\right) ; h\right]$, dada em (3.3), quando $x\left(t_{n}\right)$ é a solução teórica do problema de valor inicial (3.1).

Usamos a notação $T_{n+k}$ para denotarmos o erro de truncamento local em $t_{n+k}$. O erro de truncamento $T_{n+k}$ é local no sentido de que não tenha ocorrido nenhum erro de truncamento prévio, ou seja, é assumido que

$$
x_{n+j}=x\left(t_{n+j}\right), \quad j=0,1, \ldots, k-1 .
$$

Sob a hipótese adicional que $x=x(t)$ tenha derivadas contínuas de ordem suficientemente altas, pode-se deduzir que

$$
\begin{aligned}
T_{n+k} & =x\left(t_{n+k}\right)-x_{n+k} \\
& =C_{p+1} h^{p+1} x^{p+1}\left(t_{n}\right)+O\left(h^{p+2}\right),
\end{aligned}
$$

onde $p$ é a ordem do método. O termo $C_{p+1} h^{p+1} x^{(p+1)}$, freqüentemente chamado de erro de truncamento local principal, é conhecido se a ordem $p$, e a constante de erro $C_{p+1}$ do método (3.2) são conhecidos. 
É importante salientar que sem a hipótese de que não tenha ocorrido nenhum erro de truncamento prévio, então o erro

$$
e_{n+k}=x\left(t_{n+k}\right)-x_{n+k}
$$

é chamado de erro de truncamento global. Este erro envolve todos os erros de truncamento produzidos em cada aplicação do método. Uma estimativa desse erro global é dada por

$$
e_{n+k}=C h^{p+1},
$$

onde $C$ é uma constante. Esta estimativa será utilizada para um cálculo aproximado da ordem de cada um dos métodos que serão analisados na seção seguinte.

\subsection{Critério de Avaliação dos Métodos}

Se dada uma equação diferencial soubermos a priori que sua solução possui alguma propriedade especial ou alguma característica relevante, como por exemplo ser periódica, é natural utilizarmos algum método numérico especial que faça uso desta propriedade ou característica. Foi mostrado no Capítulo 2 que, sob determinadas condições, o problema de valor inicial proposto por Perelson [1999] possui órbitas periódicas, então, neste capítulo, são apresentados métodos numéricos para problemas especiais, no caso problemas cuja solução seja periódica. Em seguida, analisamos o desempenho de cada um deles baseado na solução do seguinte problema,

$$
\begin{cases}x^{\prime}=y, & x(0)=0, \\ y^{\prime}=-x, & y(0)=1,\end{cases}
$$

dada por

$$
\left\{\begin{array}{l}
x(t)=\operatorname{sen}(t) \\
y(t)=\cos (t)
\end{array}\right.
$$

que representa um centro, conforme Figura (3.1).

O intervalo de integração considerado foi compreendido entre $[0,3650]$, o que corresponde a um período de 10 anos ( $t$ em dias). Foram utilizados vários tamanhos de passos fixos e uniformes e o critério para avaliar cada um desses métodos se baseou em três aspectos: o erro global, ordem do método e tempo de processamento. 


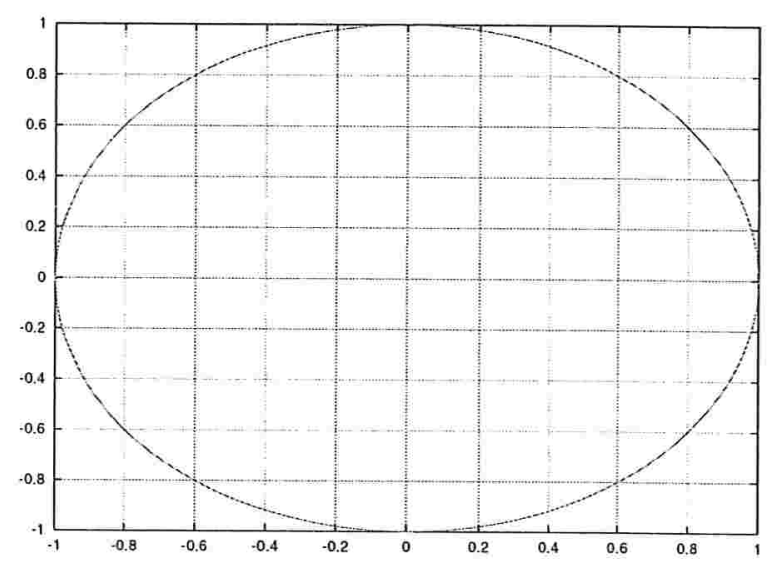

Figura 3.1: Centro

O erro global $e$ foi calculado utilizando a norma 2 de distância entre a solução exata e a aproximada $e=\left\|\bar{x}_{e x}-\bar{x}_{a p}\right\|_{2}$.

Assim,

$$
e(h)=\sqrt{\left[\operatorname{sen}(3650)-x_{3650}(h)\right]^{2}+\left[\cos (3650)-y_{3650}(h)\right]^{2}},
$$

onde $x_{3650}(h)$ e $y_{3650}(h)$ representam o resultado final do método para um passo fixo e uniforme $h$.

Podemos obter uma estimativa da ordem de um método computacional calculando a expressão (3.7) em $h$ e em $k h, 0<k<1$. Assim,

$$
e(h)=C h^{p+1} \text { e } e(k h)=C(k h)^{p+1}
$$

donde segue que

$$
\frac{e(k h)}{e(h)}=k^{p+1}
$$

Portanto

$$
\log _{k}\left(\frac{e(k h)}{e(h)}\right)=p+1,
$$

e como $p$ é um número inteiro, então

$$
p=\left\lfloor\log _{k}\left(\frac{e(k h)}{e(h)}\right)\right\rfloor-1,
$$


onde $\lfloor x\rfloor, x \in \mathbb{R}$, é o maior inteiro que não supera $x$, se $x>0$, e é o menor inteiro que supera $x$, se $x<0$.

Se tomarmos $k=1 / 2$ obtemos

$$
p=\left\lfloor\log _{2}\left(\frac{e(h)}{e(k h)}\right)\right\rfloor-1 .
$$

O tempo de processamento foi estimado utilizando-se um cronômetro digital e os métodos numéricos a seguir foram implementados em um computador pessoal com um processador K6-II $500 \mathrm{MgHertz}$.

\subsection{Métodos Numéricos}

A baixo, segue uma descrição suscinta dos métodos numéricos que foram utilizados para resolver o problema de valor inicial (3.8).

\subsubsection{Método Runge-Kutta-Fehlberg}

Os métodos de Runge-Kutta foram concebidos para evitar o cálculo das derivadas exigidas pelo método da série de Taylor. Em lugar destas derivadas usam-se vários valores da função $f$.

Segue abaixo o método Runge-Kutta-Fehlberg de ordem 5 e passo simples:

$$
\begin{aligned}
s 1 & =h f\left(t_{k}, x_{k}\right) \\
s 2 & =h f\left(t_{k}+\frac{1}{4} h, x_{k}+\frac{1}{4} s_{1}\right) \\
s 3 & =h f\left(t_{k}+\frac{3}{8} h, x_{k}+\frac{3}{32} s_{1}+\frac{9}{32} s_{2}\right), \\
s 4 & =h f\left(t_{k}+\frac{12}{13} h, x_{k}+\frac{1932}{2197} s_{1}-\frac{7200}{2197} s_{2}+\frac{7296}{2197} s_{3}\right), \\
s 5 & =h f\left(t_{k}+h, x_{k}+\frac{439}{216} s_{1}-8 s_{2}+\frac{3680}{513} s_{3}-\frac{845}{4104} s_{4}\right), \\
s 6 & =h f\left(t_{k}+\frac{1}{2} h, x_{k}-\frac{8}{27} s_{1}+2 s_{2}-\frac{3544}{2565} s_{3}+\frac{1859}{4104} s_{4}-\frac{11}{40} s_{5}\right), \\
\widehat{x}_{k+1} & =x_{k}+\frac{25}{216} s_{1}+\frac{1408}{2565} s_{3}+\frac{2197}{4104} s_{4}-\frac{1}{5} s_{5}, \\
x_{k+1} & =x_{k}+\frac{16}{135} s_{1}+\frac{6656}{12825} s_{3}+\frac{28561}{56430} s_{4}-\frac{9}{50} s_{5}+\frac{2}{55} s_{6} .
\end{aligned}
$$


Essas fórmulas são determinadas de modo que as inclinações $s_{i}$ possam ser combinadas em duas diferentes maneiras: uma para dar uma estimativa $\widehat{x}_{k+1}$ de ordem 4 e outra para dar uma estimativa $x_{k+1}$ de ordem 5 . O ponto é que $\widehat{x}_{k+1}-x_{k+1}$ pode ser usado como uma estimativa do erro em $x_{k+1}$, conforme Rice [1993].

O erro de truncamento global é dado por ( Gerald [1994] )

$$
e=\frac{1}{360} s_{1}-\frac{128}{4275} s_{3}-\frac{2197}{75240} s_{4}+\frac{1}{50} s_{5}+\frac{2}{55} s_{6} .
$$

A Tabela (3.1) e a Figura (3.2) mostram o desempenho do Método RungeKutta-Fehlberg.

Tabela 3.1: Método Runge-Kutta-Fehlberg.

\begin{tabular}{|r|c|c|c|c|}
\hline \multicolumn{5}{|c|}{ Método Runge-Kutta-Fehlberg } \\
\hline \hline \multicolumn{1}{|c|}{$\boldsymbol{h}$} & sen(3650) & cos(3650) & Erro & Tempo \\
& $-0,50610567511$ & 0,86247147525 & & \\
\hline 1 & $-1330,70656760$ & $-316,97921555$ & $1,368 \mathrm{E}+03$ & - \\
0,5 & $-0,44270812840$ & 1,25249753920 & $3,951 \mathrm{E}-01$ & - \\
0,2 & $-0,50154835340$ & 0,86869958180 & $7,717 \mathrm{E}-03$ & - \\
0,1 & $-0,50575696847$ & 0,86278870607 & $4,714 \mathrm{E}-04$ & - \\
0,08 & $-0,50595800435$ & 0,86259508568 & $1,926 \mathrm{E}-04$ & - \\
0,05 & $-0,50608208397$ & 0,86248885040 & $2,930 \mathrm{E}-05$ & - \\
0,04 & $-0,50609587390$ & 0,86247838625 & $1,200 \mathrm{E}-05$ & - \\
0,02 & $-0,50610504753$ & 0,86247188230 & $7,510 \mathrm{E}-07$ & - \\
0,01 & $-0,50610563785$ & 0,86247150226 & $4,896 \mathrm{E}-08$ & - \\
0,008 & $-0,50610566515$ & 0,86247148619 & $1,764 \mathrm{E}-08$ & $35^{\prime \prime}$ \\
0,005 & $-0,50610567735$ & 0,86247148154 & $7,791 \mathrm{E}-09$ & $1^{\prime} 05^{\prime \prime}$ \\
0,004 & $-0,50610568389$ & 0,86247147970 & $8,612 \mathrm{E}-09$ & $2^{\prime} 10^{\prime \prime}$ \\
0,002 & $-0,50610569026$ & 0,86247148479 & $1,675 \mathrm{E}-08$ & $5^{\prime} 25^{\prime \prime}$ \\
0,001 & $-0,50610570132$ & 0,86247149618 & $3,260 \mathrm{E}-08$ & $11^{\prime} 45^{\prime \prime}$ \\
0,0005 & $-0,50610567735$ & 0,86247151477 & $4,102 \mathrm{E}-08$ & $21^{\prime} 35^{\prime \prime}$ \\
0,0002 & $-0,50610580097$ & 0,86247157909 & $1,622 \mathrm{E}-07$ & $53^{\prime} 45^{\prime \prime}$ \\
0,0001 & $-0,50610592855$ & 0,86247168531 & $3,282 \mathrm{E}-07$ & $1 h 47^{\prime} 30^{\prime \prime}$ \\
\hline
\end{tabular}




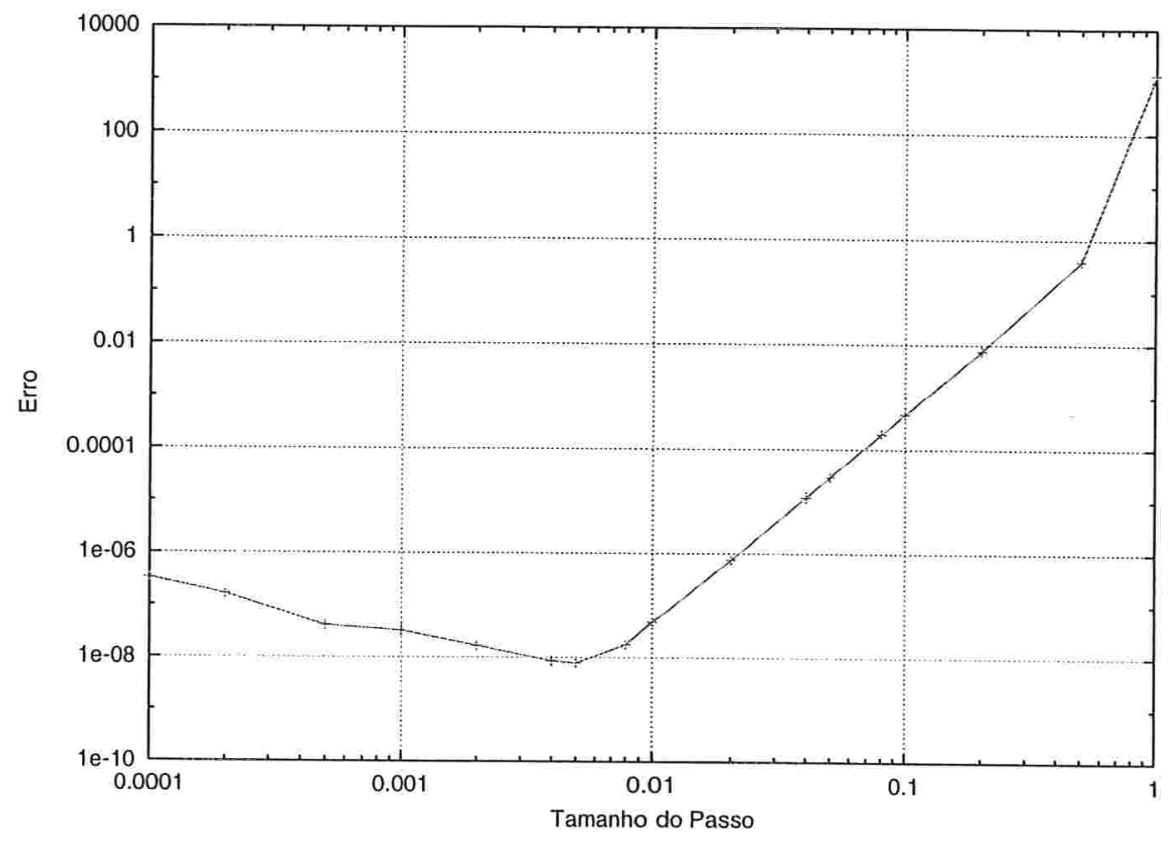

Figura 3.2: Gráfico de Desempenho do Método Runge-Kutta-Fehlberg

Esse método tem a grande vantagem de ser o mais simples no sentido de que não há necessidade de nada mais elaborado além do que avaliar a função $f$ em pontos do intervalo considerado.

Neste teste a grande desvantagem foi o tempo de processamento que foi bastante longo. O erro fica abaixo de $10^{-7}$ para tamanhos de passo $h$ compreendidos entre $h=0,0005$ e $h=0,01$. 


\subsubsection{Método Obrechkoff}

Dado o problema de valor inicial

$$
\left\{\begin{aligned}
x^{\prime} & =f(t, x), \\
x\left(t_{0}\right) & =x_{0},
\end{aligned}\right.
$$

podemos incorporar mais informações analíticas em um método numérico ao utilizarmos as derivadas totais com respeito a $t$, de $f(t, x)$. Assim, temos

$$
\begin{aligned}
& x^{(1)}=f(t, x)=f \\
& x^{(2)}=f_{t}+f f_{x} \\
& x^{(3)}=f_{t t}+2 f f_{t x}+f^{2} f_{x x}+f_{x}\left(f_{t}+f f_{x}\right)
\end{aligned}
$$

Para muitos problemas, tal diferenciação explícita pode ser extremamente complicada, mas quando é exequível avaliar tais derivadas totais de $x$, então métodos que empregam tais derivadas podem ser bastante eficientes. Tais métodos são chamados Métodos Obrechkoff.

O $k$-ésimo passo do Método Obrechkoff usando as primeiras $l$ derivadas de $x$ é dado por

$$
\sum_{j=0}^{k} \alpha_{j} x_{n+j}=\sum_{i=1}^{l} h^{i} \sum_{j=0}^{k} \beta_{i j} x_{n+j}^{(i)} ; \quad \alpha_{k}=1 .
$$

Os coeficientes $\alpha_{j}, \beta_{i j} i=0,1, \ldots l ; j=0,1, \ldots, k$ são apresentados em Lambert [1962].

Segue abaixo o Método Obrechkoff explícito do tipo Adams com $k=2$ e $l=3$

$$
x_{n+2}-x_{n+1}=\frac{h}{2}\left(15 x_{n+1}^{(1)}-13 x_{n}^{(1)}\right)-\frac{h^{2}}{10}\left(31 x_{n+1}^{(2)}+29 x_{n}^{(2)}\right)+\frac{h^{3}}{120}\left(111 x_{n+1}^{(3)}-49 x_{n}^{(3)}\right) .
$$

Esse é um método de ordem $p=6$, cuja constante de erro é $C_{7}=+\frac{209}{100800}$ e é multipassos havendo, assim, necessidade de se fornecer um ponto adicional, além da condição inicial. Este ponto adicional foi calculado utilizando-se o Método Runge-Kutta-Fehlberg com um tamanho de passo $h_{0}=h / 10$, onde $h$ é o tamanho do passo do método Obrechkoff.

A Tabela (3.2) e a Figura (3.3) mostram o desempenho do Método Obrechkoff. 
Tabela 3.2: Método Obrechkoff.

\begin{tabular}{|r|c|c|c|c|}
\hline \multicolumn{5}{|c|}{ Método Obrechkoff } \\
\hline \hline \multicolumn{6}{|c|}{$\boldsymbol{h}$} & sen(3650) & cos(3650) & Erro & Tempo \\
& $-0,50610567511$ & 0,86247147525 & & \\
\hline 1 & Diverge & Diverge & - & - \\
0,5 & Diverge & Diverge & - & - \\
0,2 & Diverge & Diverge & - & - \\
0,1 & $-0,50609883767$ & 0,86247176078 & $6,846 \mathrm{E}-06$ & - \\
0,08 & $-0,50610383174$ & 0,86247172345 & $1,863 \mathrm{E}-06$ & - \\
0,05 & $-0,50610556710$ & 0,86247150820 & $1,158 \mathrm{E}-07$ & - \\
0,04 & $-0,50610564340$ & 0,86247148942 & $3,767 \mathrm{E}-08$ & - \\
0,02 & $-0,50610567194$ & 0,86247148017 & $8,595 \mathrm{E}-09$ & - \\
0,01 & $-0,50610567345$ & 0,86247147901 & $6,733 \mathrm{E}-09$ & - \\
0,005 & $-0,50610567384$ & 0,86247148050 & $7,751 \mathrm{E}-09$ & - \\
0,002 & $-0,50610567946$ & 0,86247147941 & $5,935 \mathrm{E}-09$ & $40^{\prime \prime}$ \\
0,001 & $-0,50610568370$ & 0,86247148580 & $1,347 \mathrm{E}-08$ & $1^{\prime} 20^{\prime \prime}$ \\
0,0005 & $-0,50610566286$ & 0,86247151351 & $4,242 \mathrm{E}-08$ & $2^{\prime} 30^{\prime \prime}$ \\
0,0002 & $-0,50610610875$ & 0,86247130956 & $4,613 \mathrm{E}-07$ & $6^{\prime} 00^{\prime \prime}$ \\
0,0001 & $-0,50609903705$ & 0,86247546474 & $7,748 \mathrm{E}-06$ & $12^{\prime} 00^{\prime \prime}$ \\
\hline
\end{tabular}

Esse método tem a grande vantagem de que o erro se mantém abaixo de $10^{-7}$ ao longo de um intervalo grande compreendido entre $h=0,0005$ e $h=0,04$. O tempo de processamento é curto, é o segundo método mais rápido em relação aos outros métodos.

As desvantagens são a necessidade de se calcular as derivadas totais, o que em alguns casos pode ser bastante complicado ou impossível, e a incapacidade de se obter resultados neste teste com um tamanho de passo $h$ maior ou igual a 0,2 . 


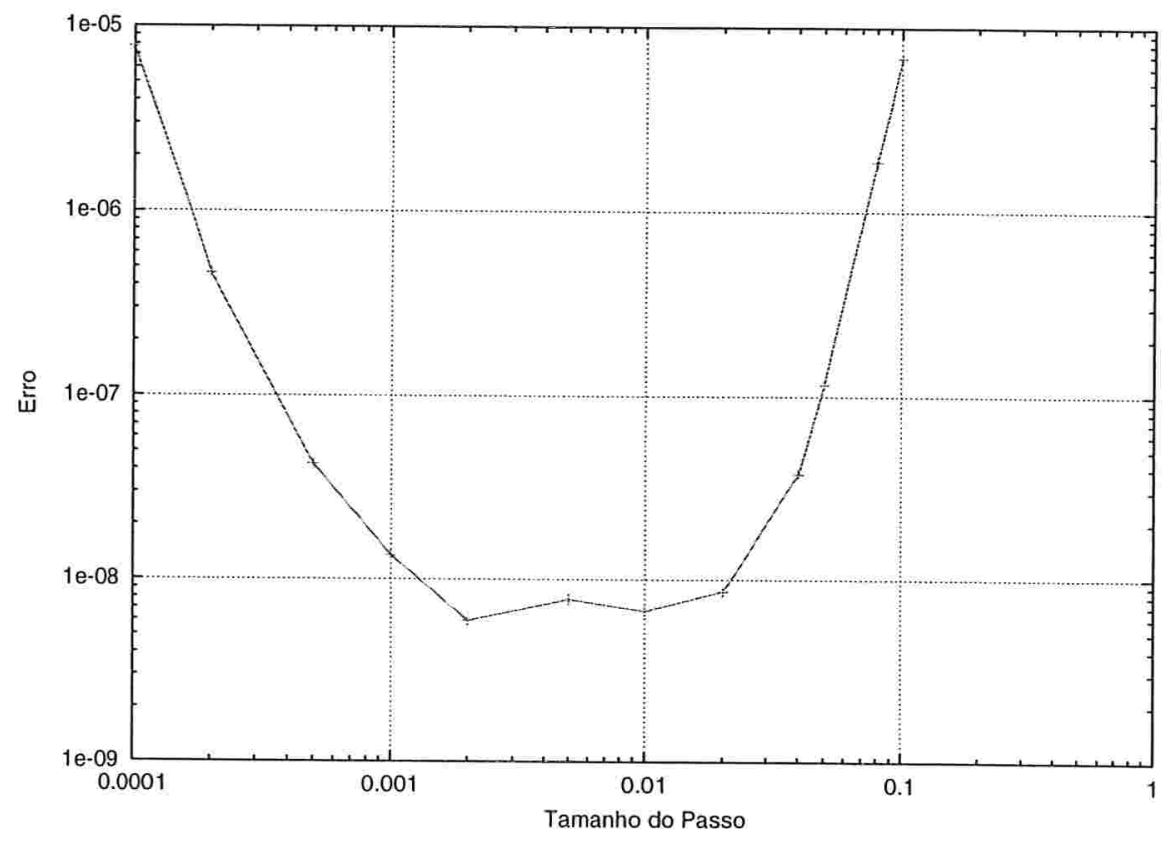

Figura 3.3: Gráfico de Desempenho do Método Obrechkoff

\subsubsection{Método Gautshi}

Os métodos desenvolvidos por Gautshi ( Gautshi [1961] ), baseados em polinômios trigonométricos, são particularmente apropriados para o estudo de problemas de valores iniciais cujas soluções sabemos a priori serem periódicas ou possuírem oscilações com freqüência conhecida.

Se o período $T$ ou a freqüência $\omega=2 \pi / T$ ou uma estimativa razoável deles é conhecida então podemos usar o seguintes método do tipo Adams

$$
\sum_{j=0}^{k} \alpha_{j} x_{n+j}=h \sum_{j=0}^{k} \beta_{j}(\nu) f_{n+j} ; \quad \nu=\omega h, \quad \alpha_{k}=1,
$$

chamado de método trigonométrico de ordem q relativa a freqüência $\omega$. 
Segue abaixo o Método Gautshi explícito $\operatorname{com} k=4$ :

$$
\begin{aligned}
x_{n+4}-x_{n+3} & =h\left(\beta_{3} f_{n+3}+\beta_{2} f_{n+2}+\beta_{1} f_{n+1}+\beta_{0} f_{n}\right) \\
\beta_{3} & =\frac{55}{24}\left(1-\frac{95}{132} \nu^{2}+\frac{79}{792} \nu^{4}+\ldots\right), \\
\beta_{2} & =-\frac{59}{24}\left(1-\frac{923}{708} \nu^{2}+\frac{15647}{21240} \nu^{4}+\ldots\right), \\
\beta_{1} & =\frac{37}{24}\left(1-\frac{421}{444} \nu^{2}+\frac{1921}{13320} \nu^{4}+\ldots\right), \\
\beta_{0} & =-\frac{9}{24}\left(1+\frac{1}{4} \nu^{2}+\frac{11}{120} \nu^{4}+\ldots\right) .
\end{aligned}
$$

Esse método tem ordem 4 e erro de truncamento local dado por:

$$
T(h)=\frac{251}{720} h^{5}\left[x^{(5)}+5 \omega^{2} x^{(3)}+4 \omega^{4} x^{(1)}\right]+O\left(h^{6}\right) .
$$

Se compararmos esse método com o método de Adams convencional percebemos que os coeficientes do método trigonométrico são perturbações proporcionais à freqüência $\omega$. Segundo Gautshi [1961], se $\omega=2 \pi / T$ não é conhecido precisamente parece mais adequado subestimar seu valor, e o problema de valor inicial (3.8) parece confirmar essa observação, conforme Tabela (3.3) e a Figura (3.4). 
Tabela 3.3: Método Gautshi: Erro em função do período.

\begin{tabular}{|c|c|c|c|}
\hline \multicolumn{4}{|c|}{ Método Gautshi } \\
\hline \hline Período & sen(3650) & $\cos (3650)$ & Erro \\
$T$ & $-0,50610567511$ & 0,86247147525 & \\
\hline 1 & $-0,50621149949$ & 0,86240892925 & $1,229 \mathrm{E}-04$ \\
2 & $-0,50611165709$ & 0,86246794412 & $6,943 \mathrm{E}-06$ \\
3 & $-0,50610664756$ & 0,86247090529 & $1,124 \mathrm{E}-06$ \\
4 & $-0,50610591362$ & 0,86247133759 & $2,724 \mathrm{E}-07$ \\
5 & $-0,50610572156$ & 0,86247145204 & $4,898 \mathrm{E}-08$ \\
6 & $-0,50610568014$ & 0,86247147656 & $3,745 \mathrm{E}-09$ \\
6,28 & $-0,50610567606$ & 0,86247147971 & $6,166 \mathrm{E}-09$ \\
7 & $-0,50610566582$ & 0,86247148610 & $1,710 \mathrm{E}-08$ \\
8 & $-0,50610566800$ & 0,86247148420 & $1,423 \mathrm{E}-08$ \\
9 & $-0,50610566832$ & 0,86247148423 & $1,403 \mathrm{E}-08$ \\
10 & $-0,50610567741$ & 0,86247147811 & $4,362 \mathrm{E}-09$ \\
11 & $-0,50610567614$ & 0,86247147901 & $5,470 \mathrm{E}-09$ \\
12 & $-0,50610567372$ & 0,86247147998 & $7,367 \mathrm{E}-09$ \\
13 & $-0,50610567720$ & 0,86247147828 & $4,548 \mathrm{E}-09$ \\
20 & $-0,50610569754$ & 0,86247146576 & $2,143 \mathrm{E}-08$ \\
\hline
\end{tabular}




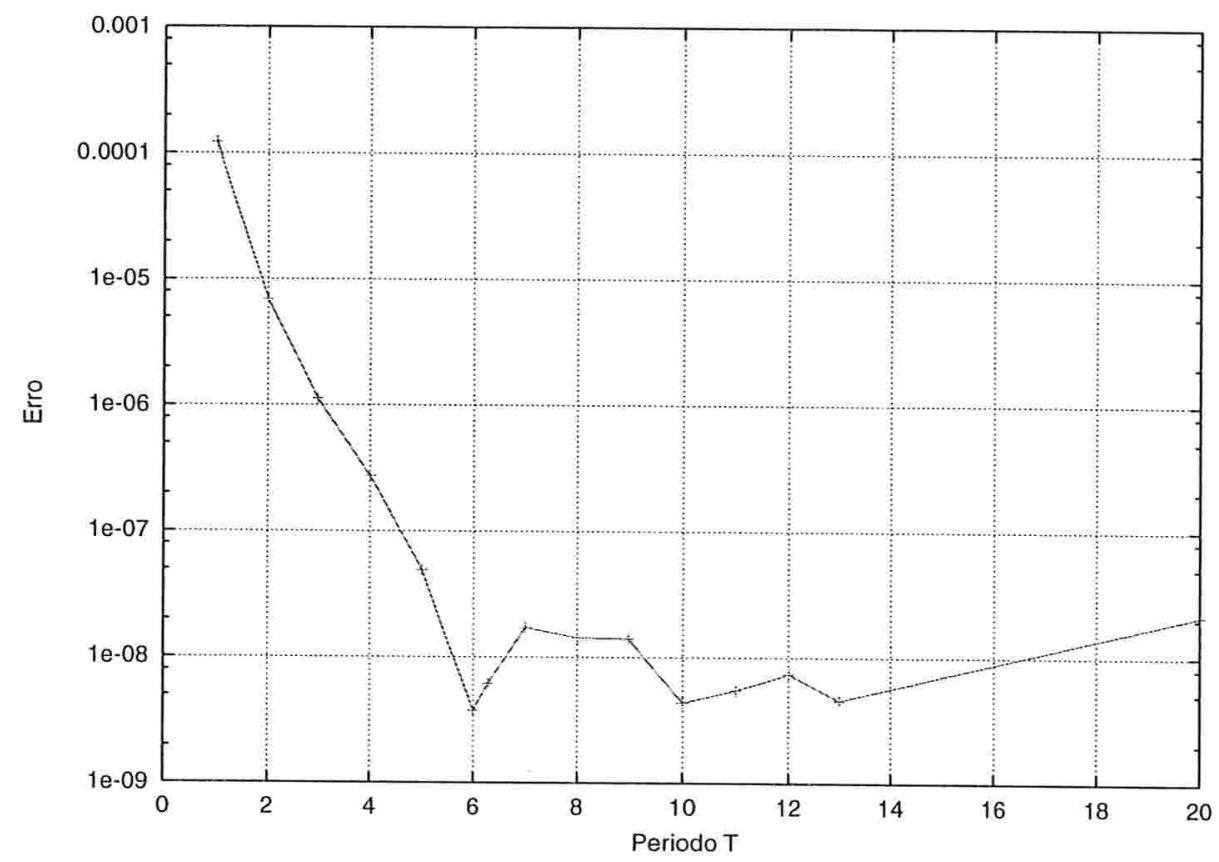

Figura 3.4: Erro no método Gautshi em função da escolha do período $T$ 
Este é um método multipasso, $k=4$, havendo, portanto, necessidade de se fornecer 3 pontos adicionais, além da condição inicial. Estes pontos adicionais foram calculados utilizando-se o método Runge-Kutta-Fehlberg com um tamanho de passo $h_{0}=h / 150$, onde $h$ é o tamanho do passo do método Gautshi. chi.

A Tabela (3.4) e a Figura (3.5) mostram o desempenho do Método Gauts-

Tabela 3.4: Método Gautshi.

\begin{tabular}{|r|c|c|c|c|}
\hline \multicolumn{5}{|c|}{ Método Gautshi } \\
\hline \hline \multicolumn{1}{|c|}{$\boldsymbol{h}$} & sen(3650) & cos(3650) & Erro & Tempo \\
& $-0,50610567511$ & 0,86247147525 & & \\
\hline 1 & Diverge & Diverge & - & - \\
0,5 & 0,00000000000 & 0,00000000000 & $1,000 \mathrm{E}+00$ & - \\
0,2 & $-0,75446756276$ & 0,25402659463 & $6,572 \mathrm{E}-01$ & - \\
0,1 & $-0,53863563309$ & 0,83469088592 & $4,278 \mathrm{E}-02$ & - \\
0,08 & $-0,51979286655$ & 0,85177463744 & $1,737 \mathrm{E}-02$ & - \\
0,05 & $-0,50825529461$ & 0,86097033474 & $2,622 \mathrm{E}-03$ & - \\
0,04 & $-0,50699366640$ & 0,86187263809 & $1,071 \mathrm{E}-03$ & - \\
0,02 & $-0,50616211432$ & 0,86243595321 & $6,668 \mathrm{E}-05$ & - \\
0,01 & $-0,50610923342$ & 0,86246931397 & $4,160 \mathrm{E}-06$ & - \\
0,008 & $-0,50610712898$ & 0,86247059955 & $1,694 \mathrm{E}-06$ & - \\
0,005 & $-0,50610591020$ & 0,86247133679 & $2,699 \mathrm{E}-07$ & - \\
0,004 & $-0,50610575507$ & 0,86247142991 & $8,896 \mathrm{E}-08$ & - \\
0,002 & $-0,50610568014$ & 0,86247147656 & $3,745 \mathrm{E}-09$ & - \\
0,001 & $-0,50610567970$ & 0,86247148127 & $7,787 \mathrm{E}-09$ & - \\
0,0008 & $-0,50610569056$ & 0,86247147703 & $1,331 \mathrm{E}-08$ & - \\
0,0005 & $-0,50610569412$ & 0,86247148173 & $1,829 \mathrm{E}-08$ & $30^{\prime \prime}$ \\
0,0004 & $-0,50610569781$ & 0,86247148573 & $2,344 \mathrm{E}-08$ & $55^{\prime \prime}$ \\
0,0002 & $-0,50610572145$ & 0,86247149165 & $4,731 \mathrm{E}-08$ & $2^{\prime} 10^{\prime \prime}$ \\
0,0001 & $-0,50610576157$ & 0,86247151462 & $9,333 \mathrm{E}-08$ & $4^{\prime} 30^{\prime \prime}$ \\
\hline
\end{tabular}

Esse método tem a vantagem de tempo de processamento ser muito pequeno, sendo o método mais eficiente neste quesito. Entretanto, a necessidade 


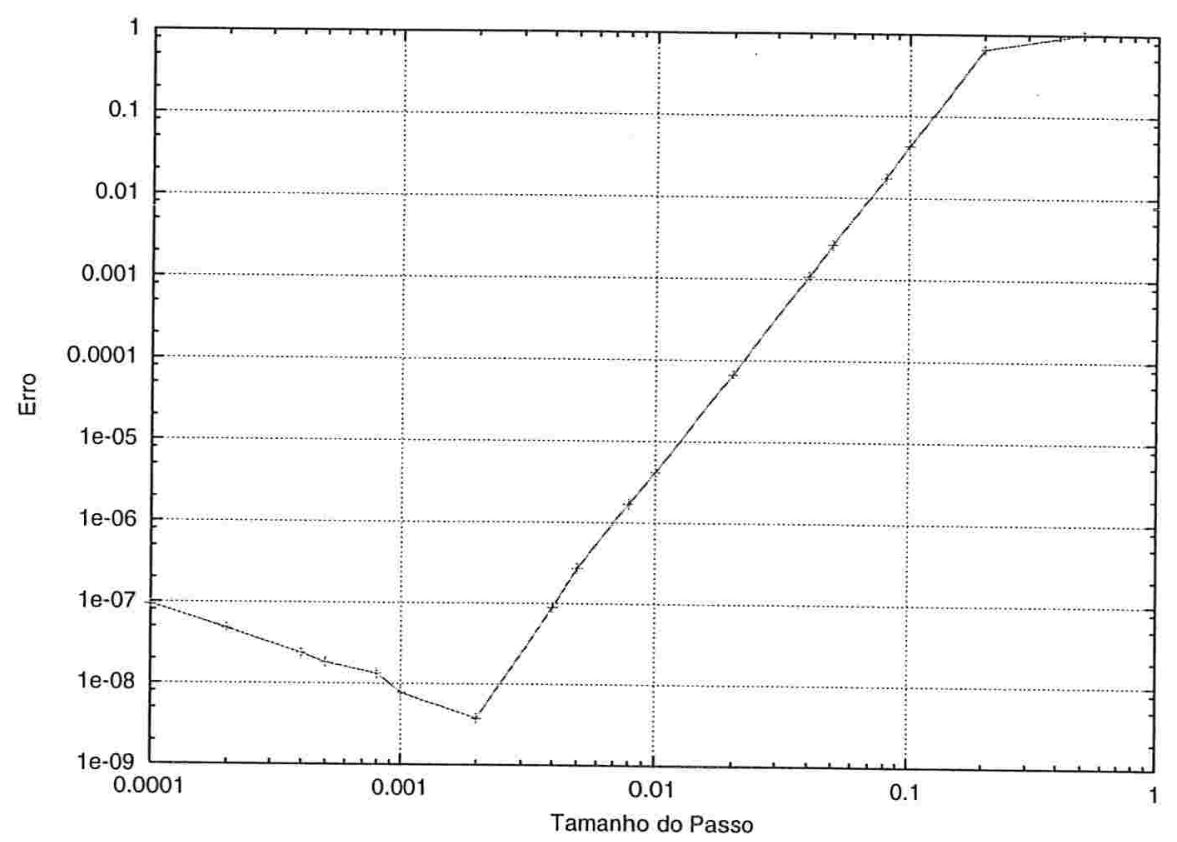

Figura 3.5: Gráfico de Desempenho do Método Gautshi

de se ter uma estimativa razoável do período $T$ apresenta uma desvantagem para esse método, pois o erro varia enormemente em função do período $T$ escolhido, conforme Figura (3.4) (neste teste usamos um período $T=6$ ).

O erro fica abaixo de $10^{-7}$ a partir de $h \leq 0,004$. 


\subsubsection{Método Simos}

O método Simos ( Simos [1995] ) é um método do tipo Runge-Kutta explícito e é utilizado para a integração numérica de problemas de valores iniciais de segunda ordem da forma:

$$
\left\{\begin{aligned}
x^{\prime \prime} & =f(t, x) \\
x\left(t_{0}\right) & =x_{0} \\
x^{\prime}\left(t_{0}\right) & =x_{0}^{\prime}
\end{aligned}\right.
$$

com soluções oscilatórias.

Essa família de métodos é chamada de método preditor-corretor e tem a forma:

$$
\begin{aligned}
\bar{x}_{n+1} & =2 x_{n}-x_{n-1}+h^{2} f_{n}, \\
\overline{\bar{x}}_{n+1} & =2 x_{n}-x_{n-1}+\frac{h^{2}}{12}\left(\bar{f}_{n+1}+10 f_{n}+f_{n-1}\right), \\
\bar{x}_{n+1 / 2} & =\frac{1}{2}\left(x_{n}+\overline{\bar{x}}_{n+1}\right)-h^{2}\left(a f_{n}+\left(\frac{1}{8}-a\right) \bar{f}_{n+1}\right), \\
\bar{x}_{n-1 / 2} & =\frac{1}{2}\left(x_{n}+x_{n-1}\right)-h^{2}\left(a f_{n}+\left(\frac{1}{8}-a\right) f_{n-1}\right), \\
\overline{\bar{x}}_{n+1 / 2} & =\frac{1}{2}\left(x_{n}+\overline{\bar{x}}_{n+1}\right)-\frac{h^{2}}{96}\left(\bar{f}_{n+1}+10 \bar{f}_{n+1 / 2}+f_{n}\right), \\
\overline{\bar{x}}_{n-1 / 2} & =\frac{1}{2}\left(x_{n}+x_{n-1}\right)-\frac{h^{2}}{96}\left(f_{n-1}+10 \bar{f}_{n-1 / 2}+f_{n}\right), \\
x_{n+1}-2 x_{n}+x_{n-1} & =\frac{h^{2}}{60}\left[\left(\overline{\bar{f}}_{n+1}+f_{n-1}\right)+16\left(\overline{\bar{f}}_{n+1 / 2}+\overline{\bar{f}}_{n-1 / 2}\right)+26 f_{n}\right],
\end{aligned}
$$

onde

$$
\begin{gathered}
\bar{f}_{n+1}=f\left(t_{n+1}, \bar{x}_{n+1}\right), \overline{\bar{f}}_{n+1}=f\left(t_{n+1}, \overline{\bar{x}}_{n+1}\right), \bar{f}_{n+1 / 2}=f\left(t_{n+1 / 2}, \bar{x}_{n+1 / 2}\right), \\
\bar{f}_{n-1 / 2}=f\left(t_{n-1 / 2}, \bar{x}_{n-1 / 2}\right), \overline{\bar{f}}_{n+1 / 2}=f\left(t_{n+1 / 2}, \overline{\bar{x}}_{n+1 / 2}\right), \overline{\bar{f}}_{n-1 / 2}=f\left(t_{n-1 / 2}, \overline{\bar{x}}_{n-1 / 2}\right) .
\end{gathered}
$$

Esse método apresenta ordem 6 e o erro de truncamento local é dado por:

$$
T(h)=h^{8}\left[\frac{-1}{120960} x_{n}^{(8)}-\frac{29}{57600} x_{n}^{(6)}-\left(\frac{121}{34560}-\frac{a}{36}\right) x_{n}^{(4)}\right] .
$$

A Tabela (3.5) e a Figura (3.6) mostram o desempenho do Método Simos.

Esse método é utilizado na integração numérica de problemas de valores iniciais de segunda ordem com soluções periódicas, sendo assim, é necessário 
Tabela 3.5: Método Simos.

\begin{tabular}{|r|c|c|c|c|}
\hline \multicolumn{5}{|c|}{ Método Simos } \\
\hline \hline \multicolumn{1}{|c|}{$\boldsymbol{h}$} & $\operatorname{sen}(\mathbf{3 6 5 0})$ & $\cos (\mathbf{3 6 5 0})$ & Erro & Tempo \\
& $-0,50610567511$ & 0,86247147525 & & \\
\hline 1 & $-0,50712860329$ & 0,86187062404 & $1,186 \mathrm{E}-03$ & - \\
0,5 & $-0,50610920644$ & 0,86246940485 & $4,091 \mathrm{E}-06$ & - \\
0,4 & $-0,50610626903$ & 0,86247112872 & $6,847 \mathrm{E}-07$ & - \\
0,2 & $-0,50610569345$ & 0,86247146873 & $1,657 \mathrm{E}-08$ & - \\
0,1 & $-0,50610570216$ & 0,86247146940 & $2,488 \mathrm{E}-08$ & - \\
0,05 & $-0,50610572455$ & 0,86247146645 & $4,746 \mathrm{E}-08$ & - \\
0,02 & $-0,50610580427$ & 0,86247146137 & $1,272 \mathrm{E}-07$ & - \\
0,01 & $-0,50610594069$ & 0,86247140645 & $2,715 \mathrm{E}-07$ & - \\
0,005 & $-0,50610632615$ & 0,86247132578 & $6,652 \mathrm{E}-07$ & $45^{\prime \prime}$ \\
0,002 & $-0,50610818082$ & 0,86247035154 & $2,743 \mathrm{E}-06$ & $1^{\prime} 50^{\prime \prime}$ \\
0,001 & $-0,50611451792$ & 0,86246771376 & $9,607 \mathrm{E}-06$ & $3^{\prime} 40^{\prime \prime}$ \\
0,0005 & $-0,50613603755$ & 0,86245601461 & $3,407 \mathrm{E}-05$ & $7^{\prime} 10^{\prime \prime}$ \\
0,0002 & $-0,50635027729$ & 0,86232389737 & $2,857 \mathrm{E}-04$ & $17^{\prime} 50^{\prime \prime}$ \\
0,0001 & $-0,50623128920$ & 0,86243231066 & $1,316 \mathrm{E}-04$ & $35^{\prime} 20^{\prime \prime}$ \\
\hline
\end{tabular}

transformar um problema de primeira ordem em um de segunda, o que em determinados casos pode acarretar algumas dificuldades. O tempo de processamento foi relativamente longo, sendo o segundo mais demorado. O erro fica abaixo de $10^{-7}$ para tamanhos de passos compreendidos entre $h=0,05$ e $h=0,2$. Em nenhum momento o erro fica abaixo de $10^{-8}$.

Em função das considerações acima, optamos por utilizar o Método Obrechkoff, pois o mesmo apresenta um erro relativamente pequeno em um intervalo longo, atingindo valores para o erro da ordem de $10^{-9}$.

O tempo de processamento é bastante razoável. Quanto a necessidade de se calcular as derivadas totais, o sistema de equações diferenciais do Capítulo 2, dado pelas Equações (2.1), (2.2), (2.3) e (2.4) não apresenta maiores dificuldades na obtenção de tais derivadas. 


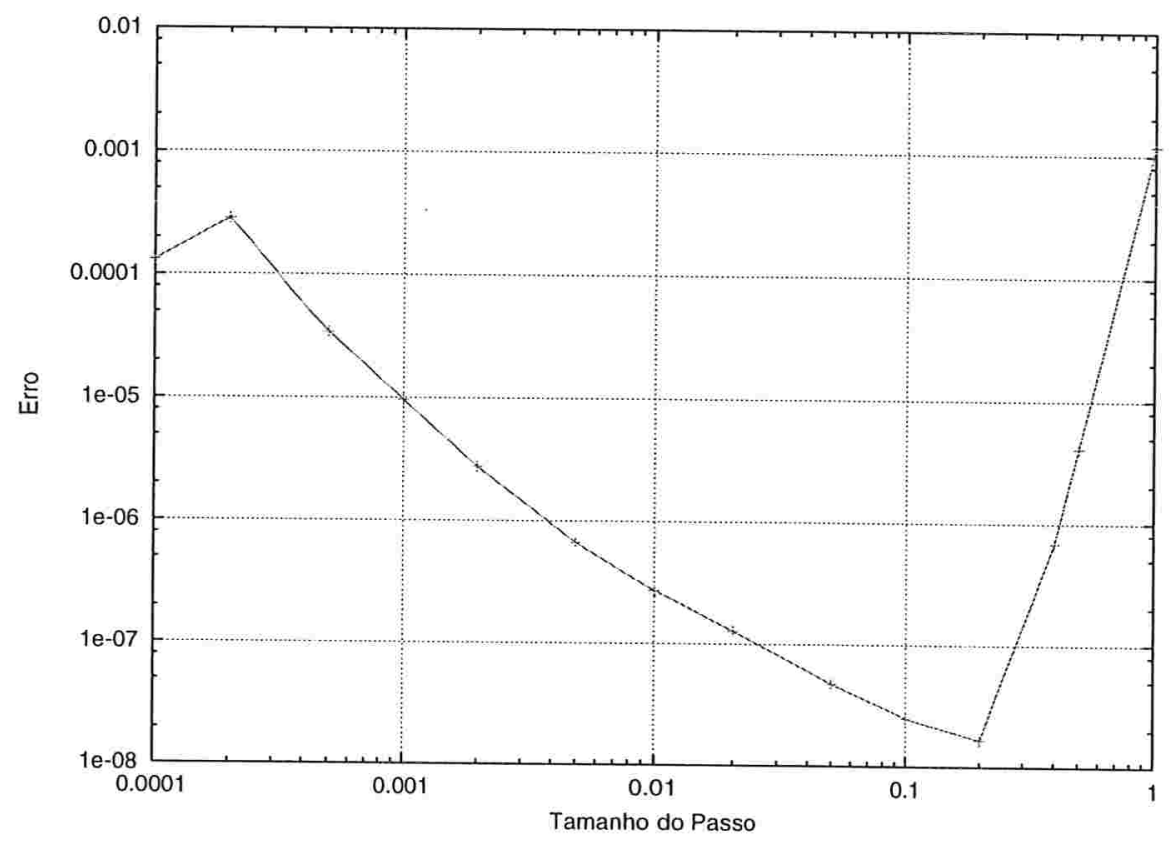

Figura 3.6: Gráfico de Desempenho do Método Simos

\subsection{Ilustrações Numéricas}

Nesta seção utilizaremos o método Obrechkoff, página 45, para apresentar os resultados de algumas simulações efetuadas com o Oscilador de Van der Pol que, sob determinadas condições, apresenta órbitas periódicas, as Equações de Lorenz que apresentam resultados intrigantes como, por exemplo, atratores estranhos ( Guckenheimer [1983] e Wiggins [1990] ) e, finalmente, mostramos as órbitas periódicas que surgem no modelo de Perelson [1999] e que foram objeto de estudo no capítulo anterior. 


\subsubsection{Oscilador de Van der Pol}

A equação de Van der Pol descreve a corrente $x$ em um triodo oscilador. Trata-se de uma equação diferencial de segunda ordem dependente de um parâmetro escalar $\kappa$, e é dada por

$$
x^{\prime \prime}-\left(2 \kappa-x^{2}\right) x^{\prime}+x=0,
$$

que é equivalente ao sistema:

$$
\left\{\begin{array}{l}
x^{\prime}=y \\
y^{\prime}=-x+2 \kappa y-x^{2} y .
\end{array}\right.
$$

Os autovalores da linearização das Equações (3.11) no ponto de equilíbrio na origem são $\kappa \pm i \sqrt{1-\kappa^{2}}$.

Para $\kappa<0$, a origem é assintoticamente estável. Em $\kappa=0$, a origem ainda é assintoticamente estável. Para $\kappa>0$, a parte real dos autovalores torna-se positiva e assim a origem é instável ( Hale [1991] ).

Pode-se mostrar que o sistema (3.11) satisfaz as hipóteses do Teorema de Bifurcação de Poincaré-Andronov-Hopf e assim, deve ter uma órbita periódica próxima a origem para pequenos valores de $\kappa>0$, como mostram as Figuras (3.7) e (3.8) ( Hale [1991] ). 

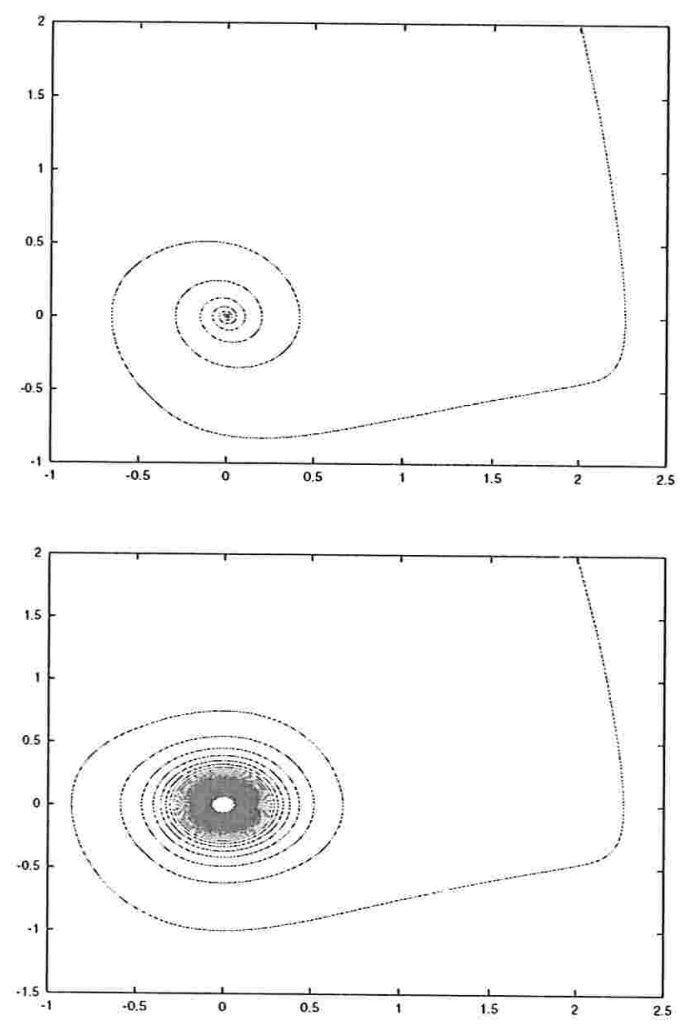

Figura 3.7: Bifurcação de Poincaré-Andronov-Hopf nas equações de Van der Pol: $\kappa=-0,1$ e $\kappa=0$. 

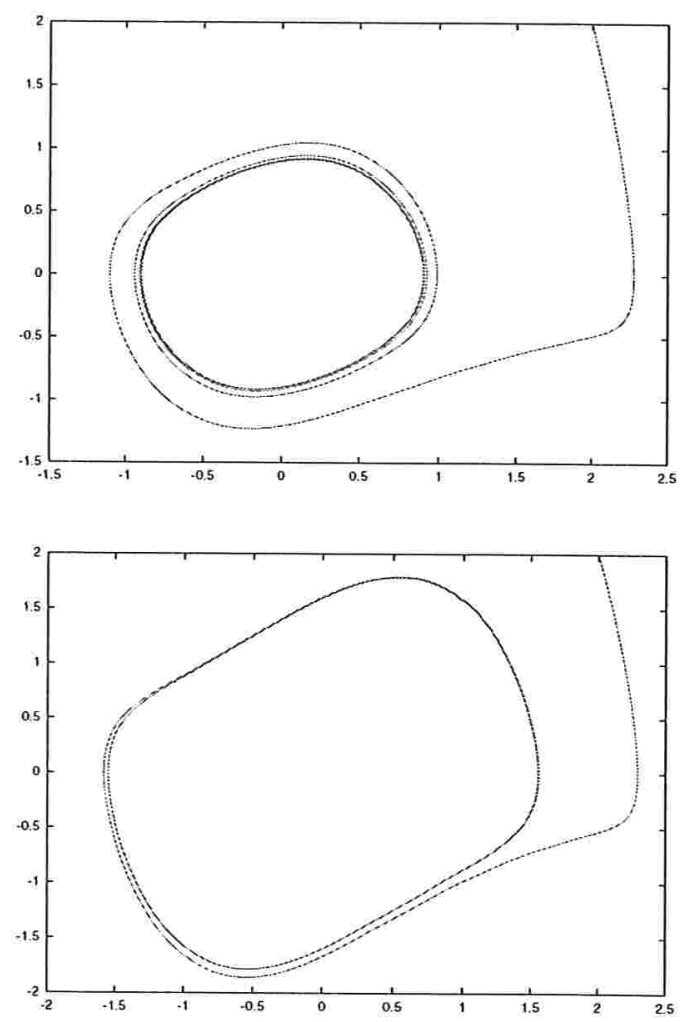

Figura 3.8: Bifurcação de Poincaré-Andronov-Hopf nas equações de Van der Pol: $\kappa=0,1$ e $\kappa=0,3$. 


\subsubsection{Equações de Lorenz}

As equações de Lorenz são um sistema de equações diferenciais autônomas de terceira ordem que envolvem não-linearidades quadráticas. Essas equações modelam o movimento de uma camada de fluido, como a atmosfera terrestre, que é mais quente na base do que no topo. Se a diferença de temperatura vertical for pequena, há uma variação linear de temperatura com a altura, e não há movimento significativo da camada fluida. No entanto, se a variação de temperatura for suficientemente grande, o ar mais quente se eleva, deslocando o ar mais frio que está por cima, e provoca um movimento convectivo permanente. Aumentando ainda mais a temperatura, este movimento convectivo permanente é perturbado é se instala um movimento turbulento mais complicado ( Guckenheimer [1983] e Boyce [1992] ).

As equações de Lorenz são dadas por:

$$
\left\{\begin{array}{l}
x^{\prime}=s(-x+y) \\
y^{\prime}=r x-y-x z \\
z^{\prime}=-b z+x y
\end{array}\right.
$$

onde, $s, r$ e $b$ são parâmetros reais positivos.

A Figura (3.9) mostra uma ilustração no caso em que $s=10,0, r=28.0$ e $b=8 / 3$ onde temos um atrator estranho (Guckenheimer [1983] e Hale [1991]). 


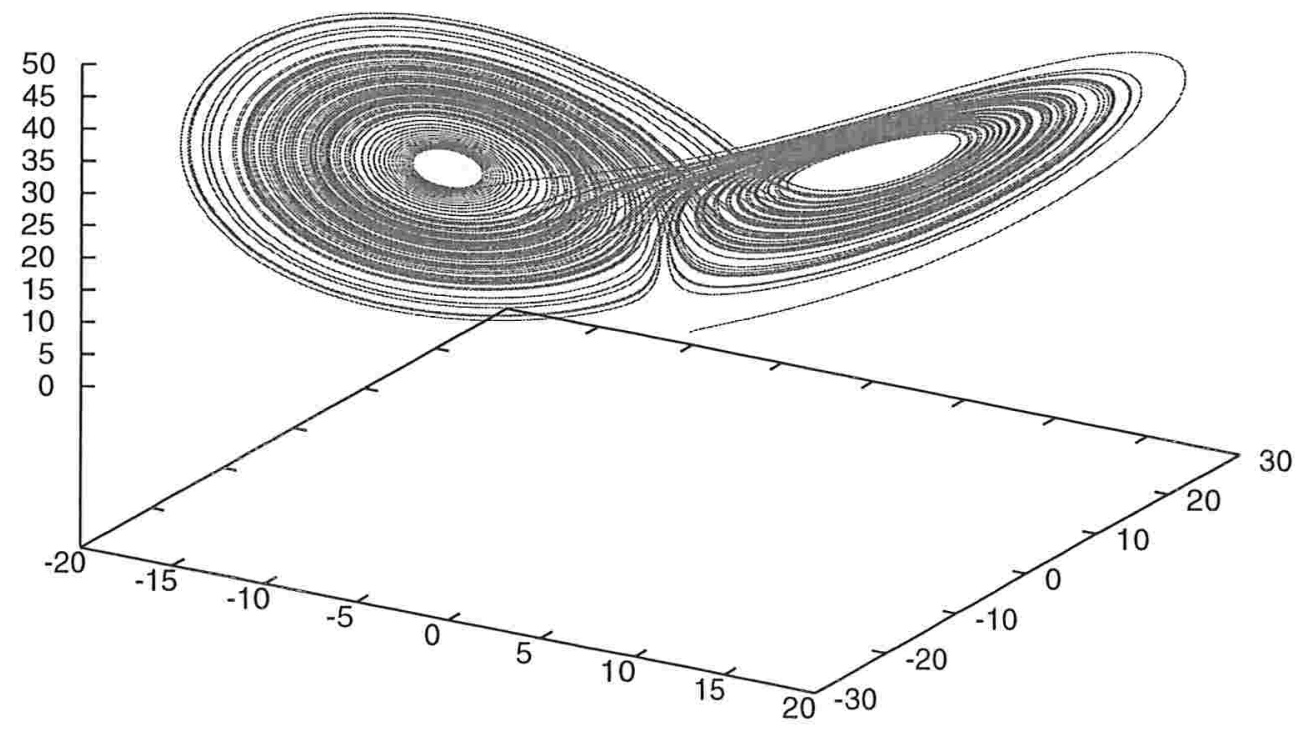

Figura 3.9: Uma órbita não-periódica nas Equações de Lorenz 


\subsubsection{O Modelo de Perelson}

Mostraremos, agora, algumas simulações feitas com o modelo de Perelson [1999], analisado no Capítulo 2, e descrito abaixo

$$
\begin{aligned}
\frac{d T}{d t} & =s+p T\left(1-\frac{T}{T_{\max }}\right)-d_{T} T-\mu k V_{I} T \\
\frac{d T^{*}}{d t} & =\mu k V_{I} T-\delta T^{*} \\
\frac{d V_{I}}{d t} & =\varepsilon N \delta T^{*}-c V_{I} \\
\frac{d V_{N I}}{d t} & =\eta_{P I} N \delta T^{*}-c V_{N I} .
\end{aligned}
$$

Para os dados da Tabela (3.6), temos que $s_{c}=0,04 \mathrm{~mm}^{-3} \mathrm{dia}^{-1}$, conforme Equação (2.20) e $\Re\left(c_{1}(0)\right)=-2,8 \cdot 10^{-6}$ que é negativo, conforme Equação (2.41), assim, se $s>s_{c}$, então o ponto de equilíbrio infectado é estável ( Figura (3.10) ), se $s=s_{c}$, então o ponto de equilíbrio é neutramente estável ( Figura (3.11) ) e se $0 \leq s<s_{c}$, então o ponto de equilíbrio infectado é instável e temos uma órbita periódica estável em torno deste ponto ( Figura (3.12)). 
Tabela 3.6: Modelo de Perelson [1999].

\begin{tabular}{|c|c|c|}
\hline & Variáveis e Parâmetros & Valores \\
\hline \multicolumn{2}{|r|}{ Variáveis Dependentes } & \multirow{5}{*}{$\begin{array}{l}100 \mathrm{~mm}^{-3} \\
1 \mathrm{~mm}^{-3} \\
1 \mathrm{~mm}^{-3} \\
1 \mathrm{~mm}^{-3} \\
\end{array}$} \\
\hline$T$ & Quantidade de cél. T CD4 ${ }^{+}$não-infectadas & \\
\hline$T^{*}$ & Quantidade de cél. T CD4 ${ }^{+}$infectadas produtivamente & \\
\hline$V_{I}$ & Quantidade de vírus infecciosos & \\
\hline$V_{N I}$ & Quantidade de vírus não infecciosos & \\
\hline \multicolumn{2}{|r|}{ Parâmetros e Constantes } & \multirow{11}{*}{$\begin{array}{l}\text { varia, } 0<s \leq 10 \\
0,06 \mathrm{dia}^{-1} \\
1500 \mathrm{~mm}^{-3} \\
0,04 \mathrm{dia}^{-1} \\
0,5 \\
0,4 \\
2,4 \cdot 10^{-5} \mathrm{~mm}^{3} \mathrm{dia}^{-1} \\
1,2 \mathrm{dia}^{-1} \\
1 \mathrm{dia}^{-1} \\
1500\end{array}$} \\
\hline$s$ & Taxa de fornecimento de cél. T CD $4^{+}$ & \\
\hline$p$ & Taxa de crescimento de cél. T CD4 ${ }^{+}$ & \\
\hline$T_{\max }$ & Nível máximo da população de cél. T CD4+ & \\
\hline$d_{T}$ & Taxa de morte de cél. T CD4 ${ }^{+}$não infectadas & \\
\hline$\eta_{R T}$ & Efetividade da droga ( transcriptase reversa ) & \\
\hline$\eta_{P I}$ & Efetividade da droga ( inibidor de protease ) & \\
\hline$k$ & Taxa para cél. T $\mathrm{CD} 4^{+}$que se infectam por vírus & \\
\hline$\delta$ & Taxa de morte de cél. T CD $4^{+}$infectadas & \\
\hline$c$ & Taxa de morte de vírus livres & \\
\hline$N$ & Número de vírus prod. por lise de cél. T $\mathrm{CD} 4^{+}$ & \\
\hline \multicolumn{2}{|r|}{ Quantidades Derivadas } & \multirow{7}{*}{$\begin{array}{l}0,5 \\
0,6 \\
0,04 \mathrm{~mm}^{-3} \mathrm{dia}^{-1} \\
-2,8 \cdot 10^{-6} \\
-6,9 \cdot 10^{-4} \\
65,8 \text { dias }\end{array}$} \\
\hline$\mu$ & $\mu=1-\eta_{R T}$ & \\
\hline$\varepsilon$ & $\varepsilon=1-\eta_{P I}$ & \\
\hline & Número crítico de cél. T CD4 ${ }^{+}$prod., ver Equação (2.20) & \\
\hline$\Re\left(c_{1}(0)\right)$ & Parte Real de $c_{1}(0)$, ver Equação (2.41) & \\
\hline$\mu_{2}$ & $\mu_{2}=-\frac{\Re\left(c_{1}(0)\right)}{\gamma^{\prime}(0)}$, ver Equação $(2.34)$ & \\
\hline Per & Período aproximado & \\
\hline
\end{tabular}



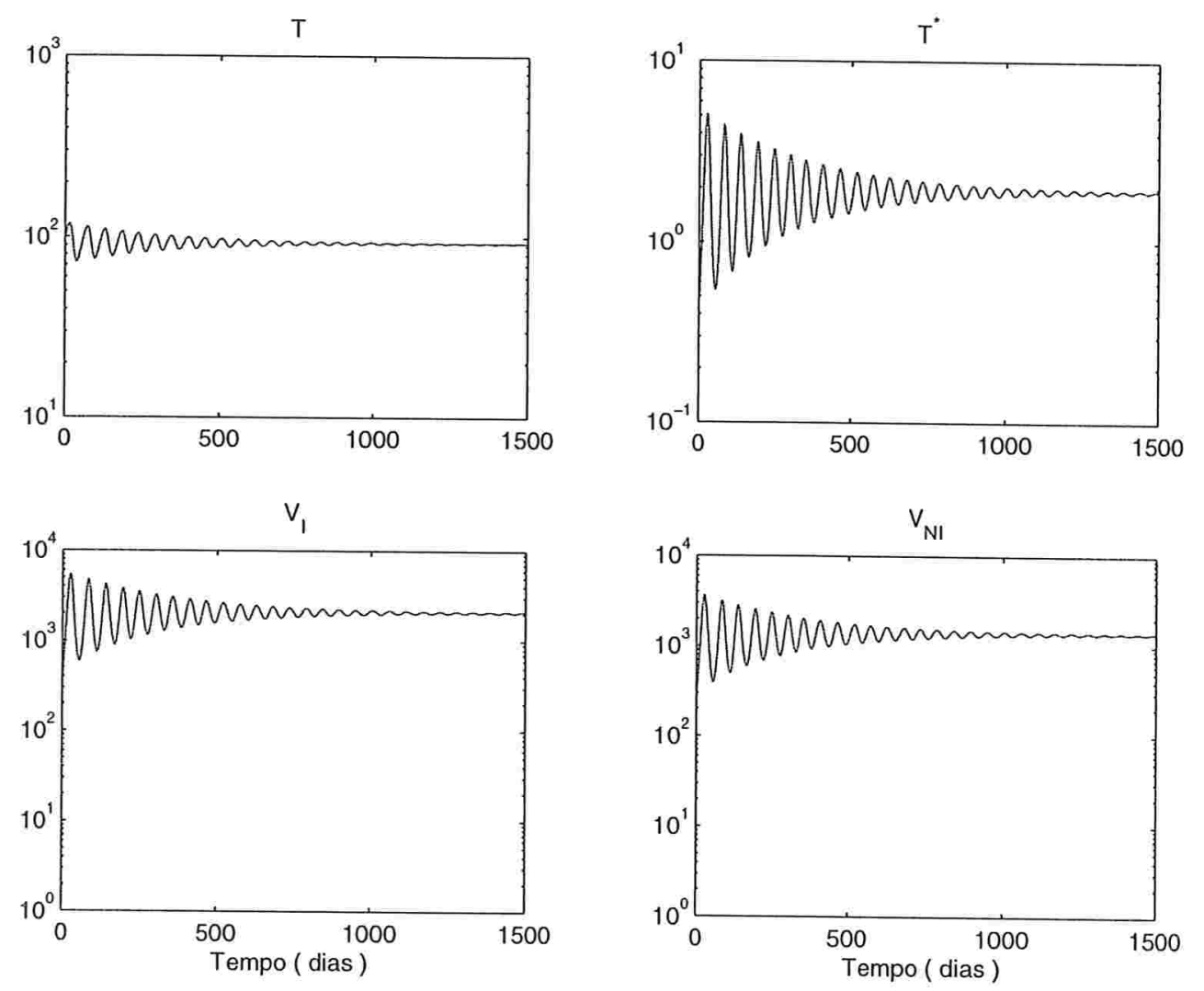

Figura 3.10: Bifurcação de Poincaré-Andronov-Hopf nas equações de Perelson: $s=0.8$. 

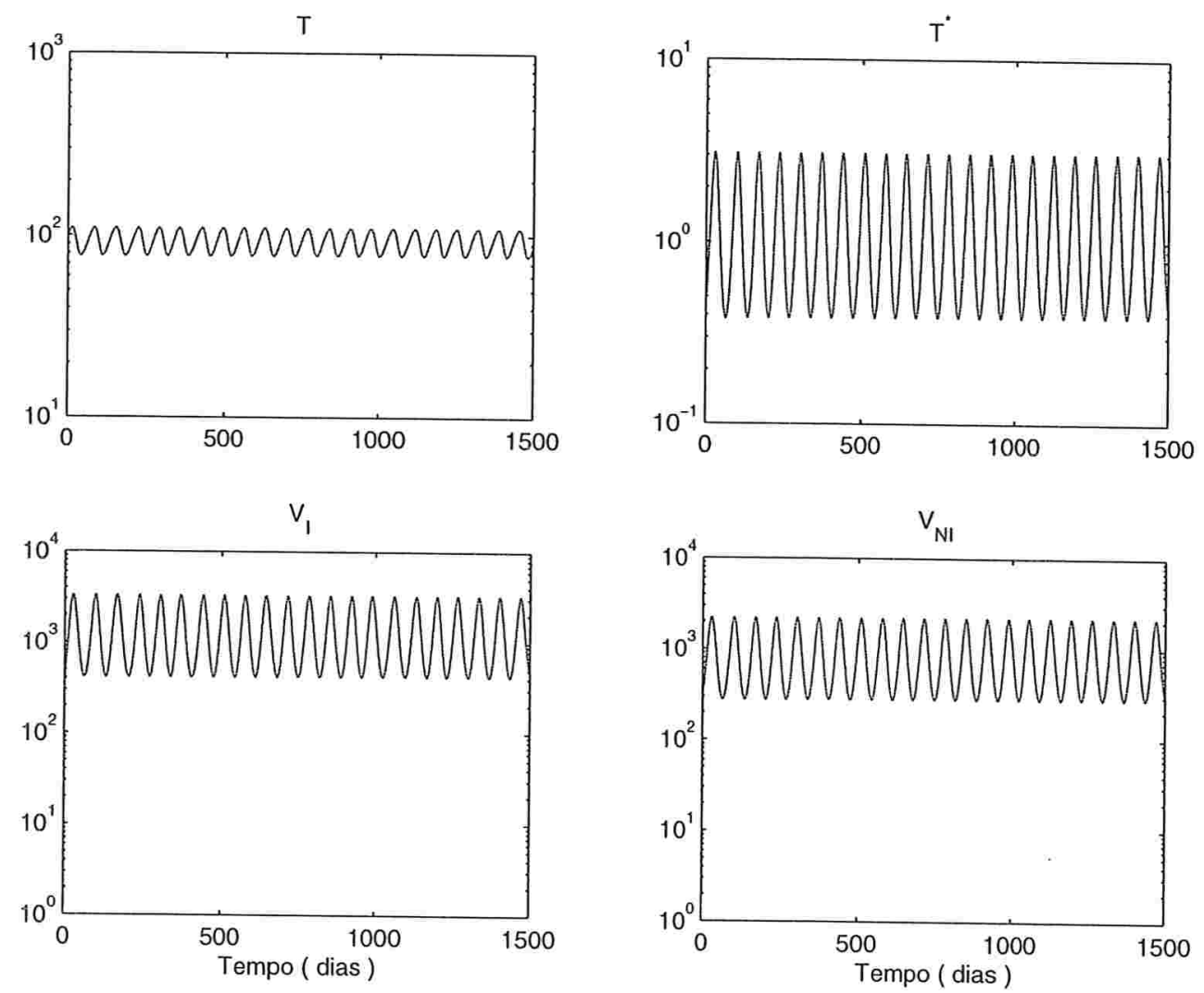

Figura 3.11: Bifurcação de Poincaré-Andronov-Hopf nas equações de Perelson: $s=0.04$. 

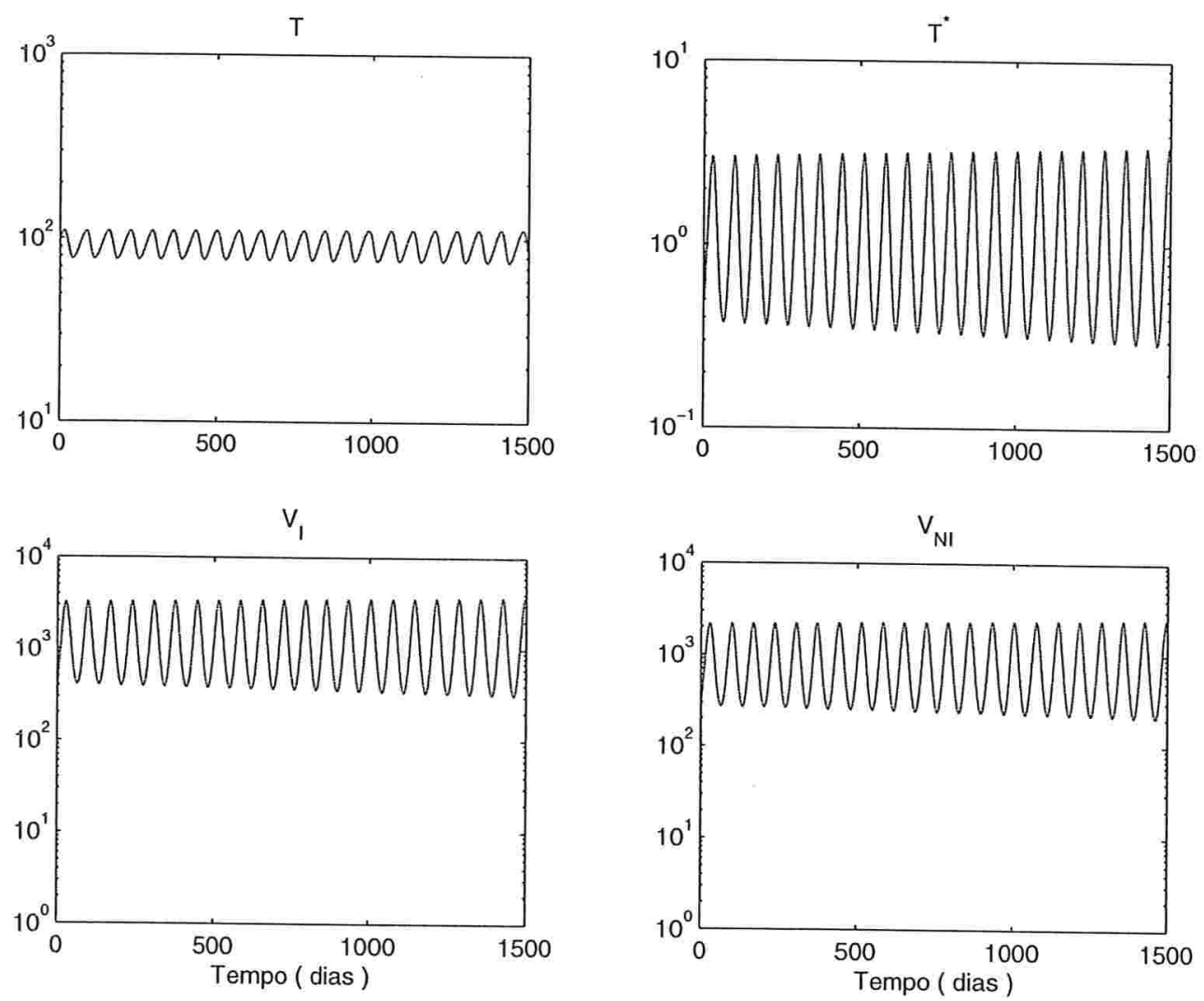

Figura 3.12: Bifurcação de Poincaré-Andronov-Hopf nas equações de Perelson: $s=0.01$. 


\section{Capítulo 4}

\section{Estudo da Variação dos Parâmetros}

No Capítulo 2 fizemos uma análise qualitativa de um sistema de equações diferenciais não lineares e mostramos a existência, sob determinadas condições, de órbitas periódicas. No Capítulo 3 foram estudados alguns integradores para resolvermos numericamente sistemas de equações diferenciais ordinárias. É importante ressaltar que foram selecionados integradores específicos, ou seja, integradores utilizados para a análise de sistemas de equações diferenciais com trajetórias periódicas. No Capítulo 2 trabalhamos sob a hipótese dos parâmetros serem constantes e o objetivo agora é estudar o comportamento das soluções do sistema de equações diferenciais com parâmetros que variam em função do tempo. Conforme observações da literatura médica, é bastante razoável que parâmetros envolvidos na dinâmica HIV-AIDS variem em um período longo de tempo, aproximadamente 10 anos, que é o tempo decorrido para que os sintomas da AIDS apareçam em um indivíduo sem nenhum tipo de terapia.

A análise desenvolvida no Capítulo 2 não se aplica a sistemas de equações diferenciais com parâmetros que variam em função do tempo, assim o estudo de tais sistemas justifica a implementação e aplicação dos integradores apresentados no Capítulo 3. 


\subsection{Introdução}

Modelos, como propostos por Ho [1995], Wei [1995], Perelson [1996] e Perelson [1999] foram utilizados para estimar a produção viral diária lançada no organismo e a taxa de eliminação viral diária. No trabalho de Perelson [1996], em particular, essas taxas foram tomadas como os valores de parâmetros do modelo que melhor se ajustavam aos dados coletados de um grupo de pacientes infectados com o vírus HIV-1.

Simulamos o sistema de equações diferenciais proposto por Perelson [1999] com os valores dos parâmetros e condições iniciais dados pela Tabela (4.1) e os resultados são mostrados na Figura (4.1)

Conforme Perelson [1999] esse modelo se aplicaria apenas para curtos períodos de tempo, da ordem de dias, semanas ou em alguns casos meses e mesmo que o modelo pareça acurado nessas escalas de tempo, ele pode não ser adequado para predizer eventos à longo prazo em pacientes individuais.

\subsection{Parâmetros Variando}

Nesse trabalho pretende-se avaliar algumas possibilidades de variação temporal de alguns parâmetros, tanto do ponto de vista teórico, quanto sob a ótica de sua adequação à realidade biológica, e se possível propor algum protocolo terapêutico. Tendo esse objetivo em vista, apresentamos alguns tipos de comportamento desses parâmetros que foram propostos ou sugeridos por outros trabalhos e os utilizamos nos modelos propostos por Perelson [1993], Perelson [1999] e Kirschner [1996] a fim de verificar se tais comportamentos são coerentes com alguns resultados que são esperados. 
Tabela 4.1: Modelo de Perelson [1999]: Parâmetros Constantes.

\begin{tabular}{|c|c|c|}
\hline & Variáveis e Parâmetros & Valores \\
\hline \multicolumn{2}{|r|}{$\begin{array}{c}\text { Variáveis Dependentes } \\
\end{array}$} & \multirow{5}{*}{$\begin{array}{l}1000 \mathrm{~mm}^{-3} \\
0 \\
10^{-3} \mathrm{~mm}^{-3} \\
0\end{array}$} \\
\hline$T$ & Quantidade de cél. T CD4 ${ }^{+}$não-infectadas & \\
\hline$T^{*}$ & Quantidade de cél. T CD4 ${ }^{+}$infectadas produtivamente & \\
\hline$V_{I}$ & Quantidade de vírus infecciosos & \\
\hline$V_{N I}$ & Quantidade de vírus não infecciosos & \\
\hline \multicolumn{2}{|r|}{ Parâmetros } & \multirow{11}{*}{$\begin{array}{l}10 \mathrm{~mm}^{-3} \mathrm{dia}^{-1} \\
0,06 \mathrm{dia}^{-1} \\
1500 \mathrm{~mm}^{-3} \\
0,04 \mathrm{dia}^{-1} \\
0 \\
0 \\
2,4 \cdot 10^{-5} \mathrm{~mm}^{3} \mathrm{dia}^{-1} \\
1,2 \mathrm{dia}^{-1} \\
2,4 \mathrm{dia}^{-1} \\
800\end{array}$} \\
\hline$s$ & Taxa de fornecimento de cél. T CD $4^{+}$ & \\
\hline$p$ & Taxa de crescimento de cél. T CD4 ${ }^{+}$ & \\
\hline$T_{\max }$ & Nível máximo da população de cél. T CD4 ${ }^{+}$ & \\
\hline$d_{T}$ & Taxa de morte de cél. T CD4 ${ }^{+}$não infectadas & \\
\hline$\eta_{R T}$ & Eficácia da droga ( transcriptase reversa ) & \\
\hline$\eta_{P I}$ & Eficácia da droga ( inibidor de protease ) & \\
\hline$k$ & Taxa para cél. T CD4 ${ }^{+}$que se infectam por vírus & \\
\hline$\delta$ & Taxa de morte de cél. T CD $4^{+}$infectadas & \\
\hline$c$ & Taxa de morte de vírus livres & \\
\hline$N$ & Número de vírus prod. por lise de cél. T $\mathrm{CD} 4^{+}$ & \\
\hline \multicolumn{2}{|r|}{ Quantidades Derivadas } & \multirow{3}{*}{$\begin{array}{l}1 \\
1 \\
\end{array}$} \\
\hline$\mu$ & $\mu=1-\eta_{R T}$ & \\
\hline$\varepsilon$ & $\varepsilon=1-\eta_{P I}$ & \\
\hline
\end{tabular}

\subsubsection{Modelo de Perelson [1999]}

No modelo de Perelson [1999], descrito abaixo

$$
\begin{aligned}
\frac{d T}{d t} & =s+p T\left(1-\frac{T}{T_{\max }}\right)-d_{T} T-\mu k V_{I} T, \\
\frac{d T^{*}}{d t} & =\mu k V_{I} T-\delta T^{*}, \\
\frac{d V_{I}}{d t} & =\varepsilon N \delta T^{*}-c V_{I}, \\
\frac{d V_{N I}}{d t} & =\eta_{P I} N \delta T^{*}-c V_{N I},
\end{aligned}
$$



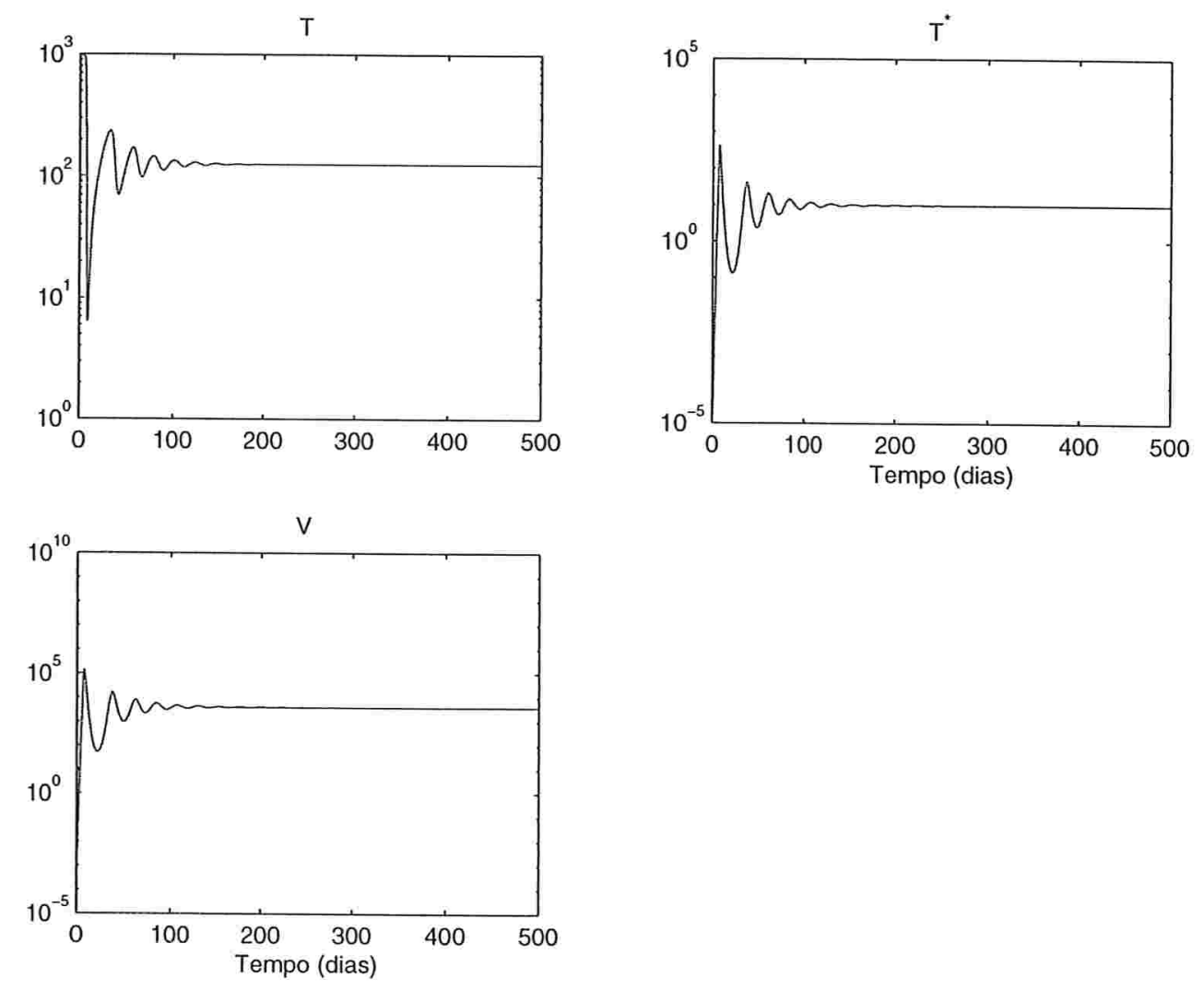

Figura 4.1: Modelo de Perelson [1999]: Soluções com parâmetros constantes

encontramos, conforme Capítulo 2, o ponto de equilíbrio não infectado $\left(T_{s s 1}, 0,0,0\right)$, onde:

$$
T_{s s 1}=\frac{T_{\max }}{2 p}\left[\left(p-d_{T}\right)+\sqrt{\left(p-d_{T}\right)^{2}+\frac{4 s p}{T_{\max }}}\right],
$$


e o equilíbrio infectado $\left(T_{s s 2}, \bar{T}^{*}, \bar{V}_{I}, \bar{V}_{N I}\right)$, onde:

$$
\begin{aligned}
T_{s s 2} & =\frac{c}{N k \varepsilon \mu}, \\
\bar{T}^{*} & =\frac{c \bar{V}_{I}}{N \delta \varepsilon} \\
\bar{V}_{I} & =\frac{s}{k T_{s s 2} \mu}+\frac{p}{k \mu}\left(1-\frac{T_{s s 2}}{T_{\max }}\right)-\frac{d_{T}}{k \mu} \\
& =\frac{s N \varepsilon}{c}+\frac{p-d_{T}}{k \mu}-\frac{p c}{N k^{2} T_{\max } \varepsilon \mu^{2}} \\
\bar{V}_{N I} & =\frac{\eta_{P I} \bar{V}_{I}}{\varepsilon},
\end{aligned}
$$

no conjunto

$$
\begin{aligned}
\Delta= & \left\{\left(T, T^{*}, V_{I}, V_{N I}\right) \in \mathbb{R}^{4} / T \geq 0, T^{*} \geq 0, V_{I} \geq 0, V_{N I} \geq 0,\right. \\
& \left.T+T^{*} \leq T_{\max }, V_{I} \leq \frac{N \delta T_{\max } \varepsilon}{c}, V_{N I} \leq \frac{N \delta T_{\max } \eta_{P I}}{c}\right\} .
\end{aligned}
$$

Mostramos, no Capítulo 2, que $\Delta$ é um conjunto positivamente invariante e como $\Delta$ é um conjunto compacto, então todas as soluções que comecem em $\Delta$ serão definidas e limitadas em $[0, \infty[$. Os parâmetros e constantes envolvidos no modelo estão apresentados na Tabela (4.1). Discutiremos agora quais parâmetros ficarão constantes e quais faremos variar e como serão essas variações.

É importante ressaltar, conforme Perelson [1993], que a escolha dos valores característicos dos parâmetros em situação in vivo apresenta sérias dificuldades, entre elas está a de que muitos parâmetros no modelo não foram medidos, ou, se tentativas de medições tenham sido feitas, elas não foram tão acuradas quanto o necessário para que possam ser feitas predições quantitativas. Dessa maneira, um dos objetivos da modelagem matemática seria o de apontar onde medições quantitativas podem melhorar o entendimento sobre a dinâmica HIV-AIDS.

\section{Parâmetros Constantes}

Começaremos essa análise supondo que os parâmetros $p, T_{m a x}, d_{T}, k$ e $\delta$ não variam em função do tempo. O parâmetro $p$ representa a taxa de crescimento da população de células T-CD $4^{+}$e será tomado igual a 0,06 por dia. 
O número de células T-CD4 ${ }^{+}$no sangue é de aproximadamente 1000 por $\mathrm{mm}^{3}$ embora possa variar e aumentar em até $50 \%$. Tomaremos, então, $T_{\max }=1500$.

Dados da literatura indicam que as células T-CD $4^{+}$podem viver de 2 a 6 semanas, assim, a taxa de morte de células T-CD4 não infectadas será tomada igual a 0,04 por dia e corresponde a uma meia-vida de 17 dias.

O parâmetro $k$ representa a taxa com que as células T $\mathrm{CD} 4^{+}$tornam-se infectadas por vírus livres e será tomada igual a 2,4 $\cdot 10^{-5} \mathrm{~mm}^{3} \mathrm{dia}^{-1}$. Esse parâmetro está associado com uma relação conhecida como lei de ação de massas, conforme Capítulo 1.

A taxa de morte para células T-CD4 ${ }^{+}$infectadas, $\delta$, que usaremos nas simulações será $1,2 \mathrm{dia}^{-1}$, o que corresponde a uma meia-vida de 20 horas.

\section{Parâmetros que Variam com o Tempo}

O parâmetro $s$ representa a taxa de fornecimento de células T-CD $4^{+}$de precursores como o timo. É razoável supor que na presença do vírus HIV-1, o valor de $s$ decresça, simulando o efeito da infecção de células $\mathrm{T}$ precursoras. Assim, vamos admitir um decaimento exponencial do parâmetro $s$ dado por

$$
s(t)=10 \mathrm{e}^{-\frac{t \ln 2}{120}},
$$

onde estamos supondo que no início da infecção, $t=0$, a taxa de fornecimento é de 10 células T-CD4 ${ }^{+}$por $\mathrm{mm}^{3}$ por dia e que a cada 120 dias essa taxa cai a metade ("meia-vida" de 120 dias ).

Assumiremos a seguinte forma para o parâmetro $s$

$$
s(t)=10[1+\operatorname{sen}(2 a \pi t) / b] \mathrm{e}^{-\frac{t \ln 2}{120}},
$$

onde $a=1$ e $b=5$. Simulações utilizando diferentes valores para $a$ e $b$ não apresentaram diferenças significativas nos resultados dessas simulações em relação aos resultados obtidos com a Equação (4.4), ou seja $a=0$, ou quando utilizamos os valores $a=1$ e $b=5$.

Vírus livres perdem sua infectividade ao longo do tempo. Em um ensaio realizado por Layne [1989] verificou-se que cepas de HIV-1 perderam metade de sua infectividade em um intervalo de 4 a 6 horas à $37^{\circ} \mathrm{C}$, assim tomaremos $c=2,4 \mathrm{dia}^{-1}$. Perelson [1993] sugere que mudanças na citopaticidade devido a. mutação do HIV-1 contribuem para uma diminuição no valor de $c$. A partir dessas considerações, tomaremos

$$
c(t)=1+1,4 \mathrm{e}^{-\frac{t \ln 2}{720}},
$$


onde estamos admitindo que inicialmente a taxa de morte de vírus livres é $c=$ 2, $4 \mathrm{dia}^{-1}$ com um decaimento exponencial tendendo para o valor constante $c=1 \mathrm{dia}^{-1}$.

O parâmetro $N$ representa a quantidade de vírus infecciosos produzidos por um célula infectada durante seu tempo de vida e seu valor não é conhecido precisamente. Trabalhos sugerem valores compreendidos entre 50 a 1000 , Merril [1987]. Layne [1989] estima $N>300$. Valores acima de $10^{3}$ também são possíveis. Perelson [1993] sugere que $N$ aumente em função de mutações do HIV-1. Admitiremos, nesse trabalho, que inicialmente $N=801 \mathrm{e} \mathrm{em} \mathrm{um}$ prazo de 10 anos praticamente duplique seu valor, sendo essa variação dada pela equação logística

$$
N(t)=800\left(1+\frac{1}{1+500 \mathrm{e}^{-\frac{t}{300}}}\right)
$$

O parâmetro $\eta_{R T}$ representa a eficácia de uma alguma droga que iniba a ação da enzima transcriptase reversa. Um inibidor de transcriptase reversa bloqueia a infecção e assim reduzem o valor do parâmetro $k$. O parâmetro $\eta_{R T}$ pode variar de 0 a 1 . Se $\eta_{R T}=1$, a inibição é $100 \%$ efetiva, entretanto se $\eta_{R T}=0$, não há inibição alguma.

Nelson [1998] sugere a seguinte expressão para a eficácia da droga

$$
\eta_{R T}(t, \tau)=\beta \tanh \left(\frac{t-\tau}{\varepsilon}\right) \mathrm{e}^{-\alpha(t-\tau)},
$$

onde $\beta$ é a eficácia máxima da droga, $\tau$ é um retardo na ativação da medicação e

$$
\alpha(t)= \begin{cases}0, & t=0,4,8, \ldots \\ K, & \text { caso contrário. }\end{cases}
$$

Usaremos a seguinte expressão para a eficácia da droga inibidora da transcriptase reversa

$$
\eta_{R T}(t)=\beta \tanh (10 t) \mathrm{e}^{-\frac{\operatorname{frac}(t / 8)}{4}} \mathrm{e}^{-\frac{t \ln 2}{360}},
$$

onde frac $(t)$ é a parte fracionária do número real $t$ e assumiremos que $\tau=0$. O gráfico da função (4.9) está esboçado na Figura (4.2).

Estamos assumindo que uma dose é dada a cada intervalo de 8 horas e também que existe uma tolerância com relação à droga, de modo que a eficácia decai exponencialmente ao longo do tempo. 


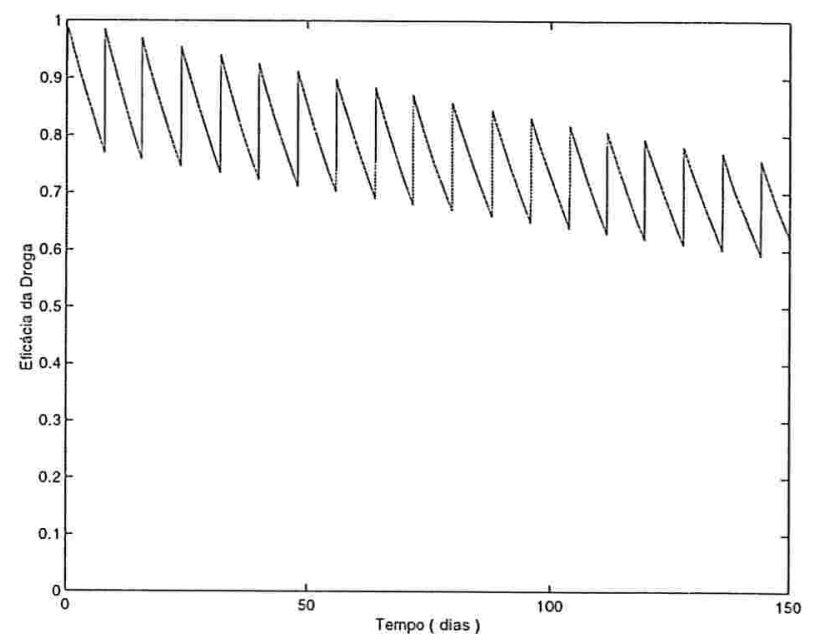

Figura 4.2: Eficácia da droga: Doses tomadas em intervalos de 8 horas. $\beta$ assumido igual a 1

O parâmetro $\eta_{P I}$ modela a eficácia de drogas que atuem na inibição da enzima protease. As partículas virais que saem de uma célula infectada necessitam da protease para seu processo de maturação, que não ocorre na presença de inibidores de protease segundo Veronesi [1996]. Assim, na presença de inibidores de protease são considerados dois tipos de partículas virais: partículas virais infectantes e partículas virais não infectantes. Inibidores de protease não são drogas perfeitas, de modo que sua eficácia pode variar entre 0 e 1 . Assumiremos que a eficácia da droga inibidora de protease seja também dada pela expressão

$$
\eta_{P I}(t)=\beta \tanh (10 t) \mathrm{e}^{-\frac{\operatorname{frac}(t / 8)}{4}} \mathrm{e}^{-\frac{t \ln 2}{360}},
$$

ver Figura (4.2).

A Tabela (4.2) apresenta os parâmetros e suas respectivas variações.

\section{Simulações Numéricas}

Apresentaremos agora simulações numéricas utilizando os parâmetros que foram discutidos anteriormente.

Na Figura (4.3) temos uma simulação feita na ausência de qualquer tipo de terapia. 
Tabela 4.2: Modelo de Perelson [1999]: Parâmetros Variando.

\begin{tabular}{|c|c|c|}
\hline & Parâmetros & Fontes \\
\hline \multicolumn{2}{|r|}{ Parâmetros Constantes } & \multirow{7}{*}{$\begin{array}{l}\text { Perelson [1993] } \\
\text { Perelson [1993] } \\
\text { Perelson [1993] } \\
\text { Perelson [1993] } \\
- \\
\text { Nelson [1998] }\end{array}$} \\
\hline$p$ & $0,06 \mathrm{dia}^{-1}$ & \\
\hline$T_{\max }$ & $1500 \mathrm{~mm}^{-3}$ & \\
\hline$d_{T}$ & $0,04 \mathrm{dia}^{-1}$ & \\
\hline$k$ & $2,4 \cdot 10^{-5} \mathrm{~mm}^{3} \mathrm{dia}^{-1}$ & \\
\hline$\delta$ & $1,2 \mathrm{dia}^{-1}$ & \\
\hline$\beta$ & {$[0,1[$} & \\
\hline \multicolumn{2}{|r|}{ Parâmetros que variam } & \multirow{6}{*}{$\begin{array}{l}\text { Perelson [1993] } \\
\text { Perelson [1993] } \\
\text { Perelson [1993] } \\
\text { Nelson [1998] } \\
\text { Nelson [1998] }\end{array}$} \\
\hline$s$ & $s(t)=10[1+\operatorname{sen}(2 \pi t) / 5] \mathrm{e}^{-\frac{t \ln 2}{120}}$ & \\
\hline$c$ & $c(t)=1+1,4 \mathrm{e}^{-\frac{t \ln 2}{720}}$ & \\
\hline$N$ & $N(t)=800\left(1+\frac{1}{1+500 \mathrm{e}^{-\frac{t}{300}}}\right)$ & \\
\hline$\eta_{R T}$ & $\eta_{R T}(t)=\beta \tanh (10 t) \mathrm{e}^{-\frac{\operatorname{frac}(t / 8)}{4}} \mathrm{e}^{-\frac{\ln 2}{360}}$ & \\
\hline$\eta_{P I}$ & $\eta_{P I}(t)=\beta \tanh (10 t) \mathrm{e}^{-\frac{\operatorname{frac}(t / 8)}{4}} \mathrm{e}^{-\frac{t \ln 2}{360}}$ & \\
\hline
\end{tabular}

Notemos que esse modelo capta o declínio no número de células T-CD4 ${ }^{+}$ao longo do tempo, embora seu valor fique sempre abaixo de $200 \mathrm{~mm}^{-3}$. Observemos que os resultados obtidos nos 100 primeiros dias, aproximadamente, estão associados com o estágio inicial da infecção, quando os números de células infectadas e vírus são pequenos, e assim modelos estocásticos seriam mais adequados ao estudo dessa fase, portanto nesses primeiros 100 dias estamos diante de um resultado transiente e que talvez não corresponda ao curso típico de um paciente com infecção pelo HIV-1. A oscilação verificada a partir de 3000 dias e que tende a aumentar em intensidade pode ser interpretada como o colapso do sistema imune e como consequiência o modelo sugere que a partir desse momento teríamos o surgimento da AIDS.

$\mathrm{Na}$ Figura (4.3) os valores médios dos números de células T-CD4 ${ }^{+} \mathrm{e}$ vírus infecciosos na ausência de terapia, no período de 4000 dias a partir da infeccão com o HIV-1, são de 55 células T-CD4 ${ }^{+} \mathrm{mm}^{-3}$ e 985 vírus $\mathrm{mm}^{-3}$.

As Figuras (4.4), (4.5) e (4.6) apresentam resultados que foram obtidos simulando-se o efeito da utilização da monoterapia, ou seja, tratamento com apenas um tipo de droga, que nesse caso, trata-se de uma terapia à base de drogas que inibam a ação da protease. 

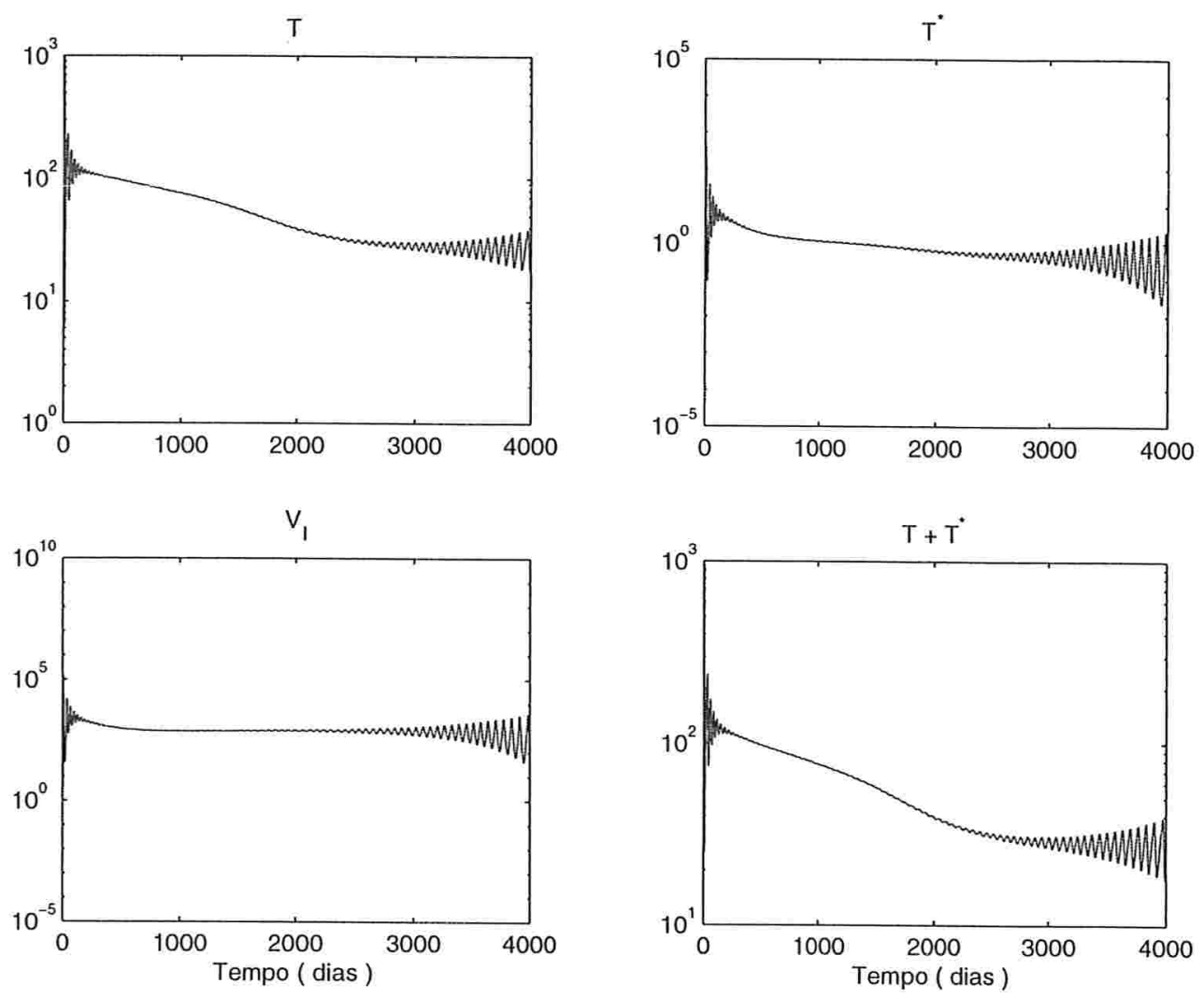

Figura 4.3: Modelo de Perelson [1999]: Simulação feita na ausência de terapia

Na Figura (4.4), onde é simulado a ação de inibidores de protease com uma eficácia máxima $\beta=0,5$, verifica-se que os valores médios para o número de células T-CD4 ${ }^{+}$e vírus infecciosos são $63 \mathrm{~mm}^{-3}$ e $886 \mathrm{~mm}^{-3}$, respectivamente.

$\mathrm{Na}$ Figura (4.5) a eficácia máxima é $\beta=0,7$ e os valores médios para o números de células T-CD4 $4^{+}$e vírus infecciosos são $69 \mathrm{~mm}^{-3}$ e $861 \mathrm{~mm}^{-3}$, respectivamente.

Por fim, na Figura (4.6) a eficácia máxima é $\beta=0,9$ e os valores médios para o números de células T-CD $4^{+} \mathrm{e}$ vírus infecciosos são $78 \mathrm{~mm}^{-3} \mathrm{e}$ $805 \mathrm{~mm}^{-3}$, respectivamente.

Esses resultados sugerem a estratégia do "hit early, hit hard" conforme trabalhos de Ho [1995], Markowitz[1996], Perelson [1997], ou seja, uma te- 
rapia deveria iniciar tão logo quanto possível e de maneira intensa a fim de inibir a replicação viral com o intuito de erradicar o vírus.
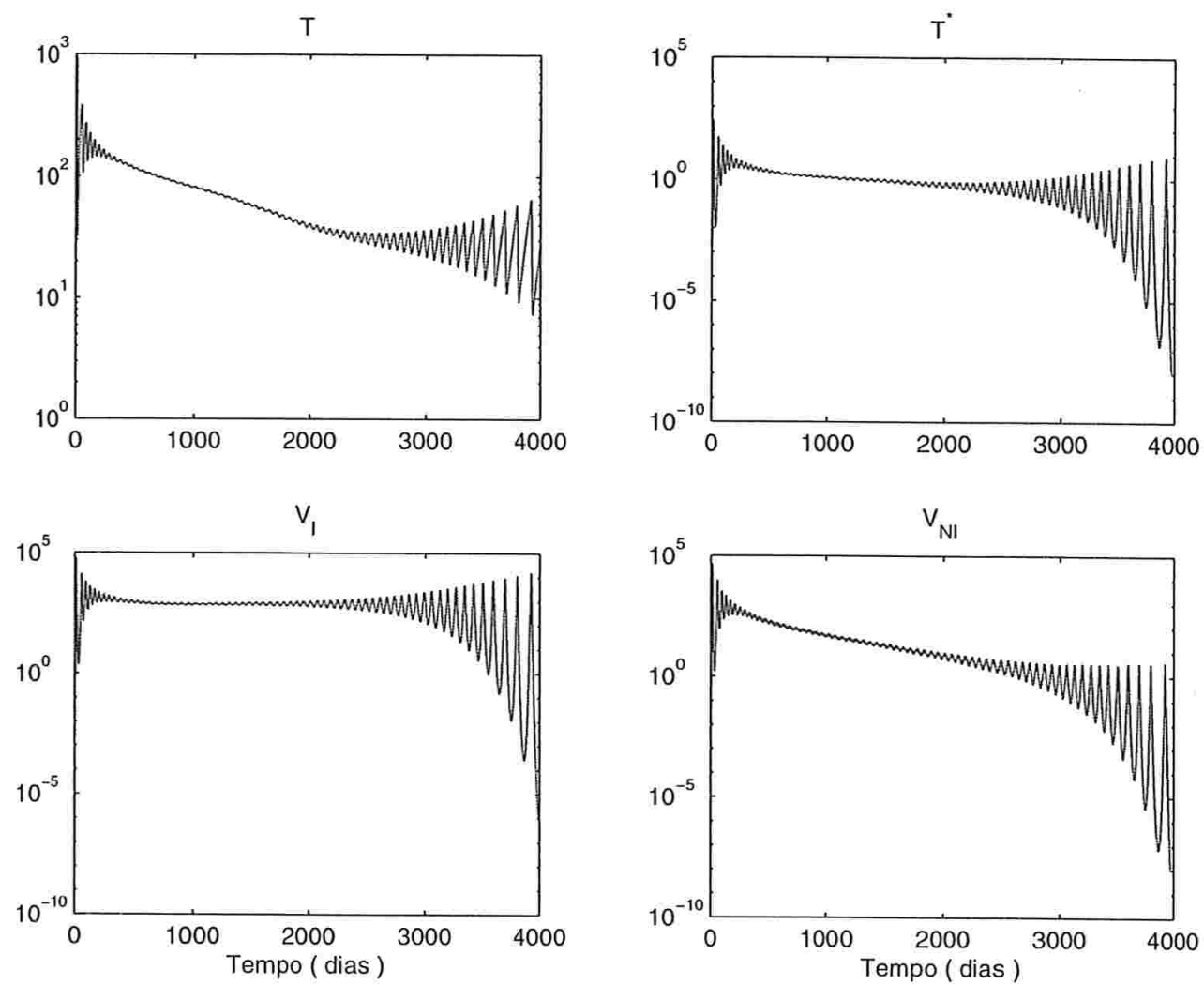

Figura 4.4: Modelo de Perelson [1999]: Simulação feita utilizando-se de um inibidores de protease com eficácia máxima $\beta=0,5$.

Das Equações (4.2), (4.3) e (4.4) podemos notar que a relação entre os parâmetros $\varepsilon=1-\eta_{P I}$ e $\mu=1-\eta_{R T}$ e o número de células T-CD4 ${ }^{+}$, $T_{s s 2}$, e células T-CD $4^{+}$infectadas, $\bar{T}^{*}$, é a mesma, ou seja, os resultados da eficácia de um tipo de droga é o mesmo se o sistema usa somente inibidores de protease $(\mu=1)$ ou somente inibidores de transcriptase reversa $(\varepsilon=1)$.

De fato, podemos observar que

$$
T_{s s 2}=\frac{c}{N k \varepsilon \mu} \quad \text { e } \quad \bar{T}^{*}=\frac{s N}{c}+\frac{p-d_{T}}{k \varepsilon \mu}-\frac{p c}{N k^{2} T_{\max }(\varepsilon \mu)^{2}}
$$



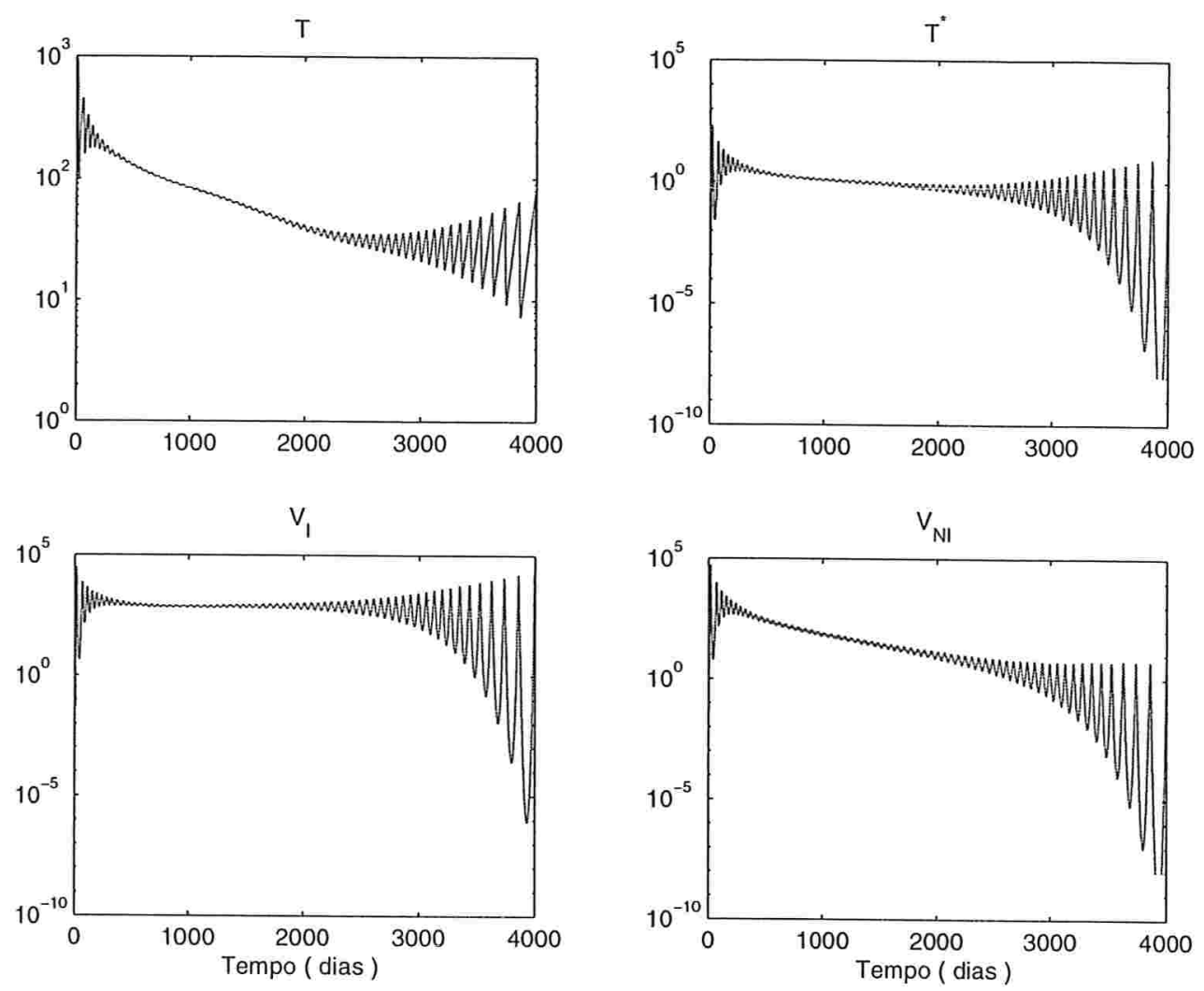

Figura 4.5: Modelo de Perelson [1999]: Simulação feita utilizando-se de um inibidor de protease com eficácia máxima $\beta=0,7$.

Entretanto, da Equação (4.4) temos que

$$
\bar{V}\left(\eta_{R T}\right)=\frac{s N \varepsilon}{c}+\frac{p-d_{T}}{k\left(1-\eta_{R T}\right)}-\frac{p c}{N k^{2} T_{\max } \varepsilon\left(1-\eta_{R T}\right)^{2}} .
$$

A derivada de $\bar{V}$ em relação a $\eta_{R T}$ é dada por

$$
\frac{d \bar{V}}{d \eta_{R T}}=\frac{1}{k\left(1-\eta_{R T}\right)^{2}}\left[p-d_{T}-\frac{2 p c}{N k T_{\max } \varepsilon\left(1-\eta_{R T}\right)}\right],
$$

e é positiva se

$$
\eta_{R T}<1-\frac{2 p c}{N k T_{\max } \varepsilon\left(p-d_{T}\right)}
$$



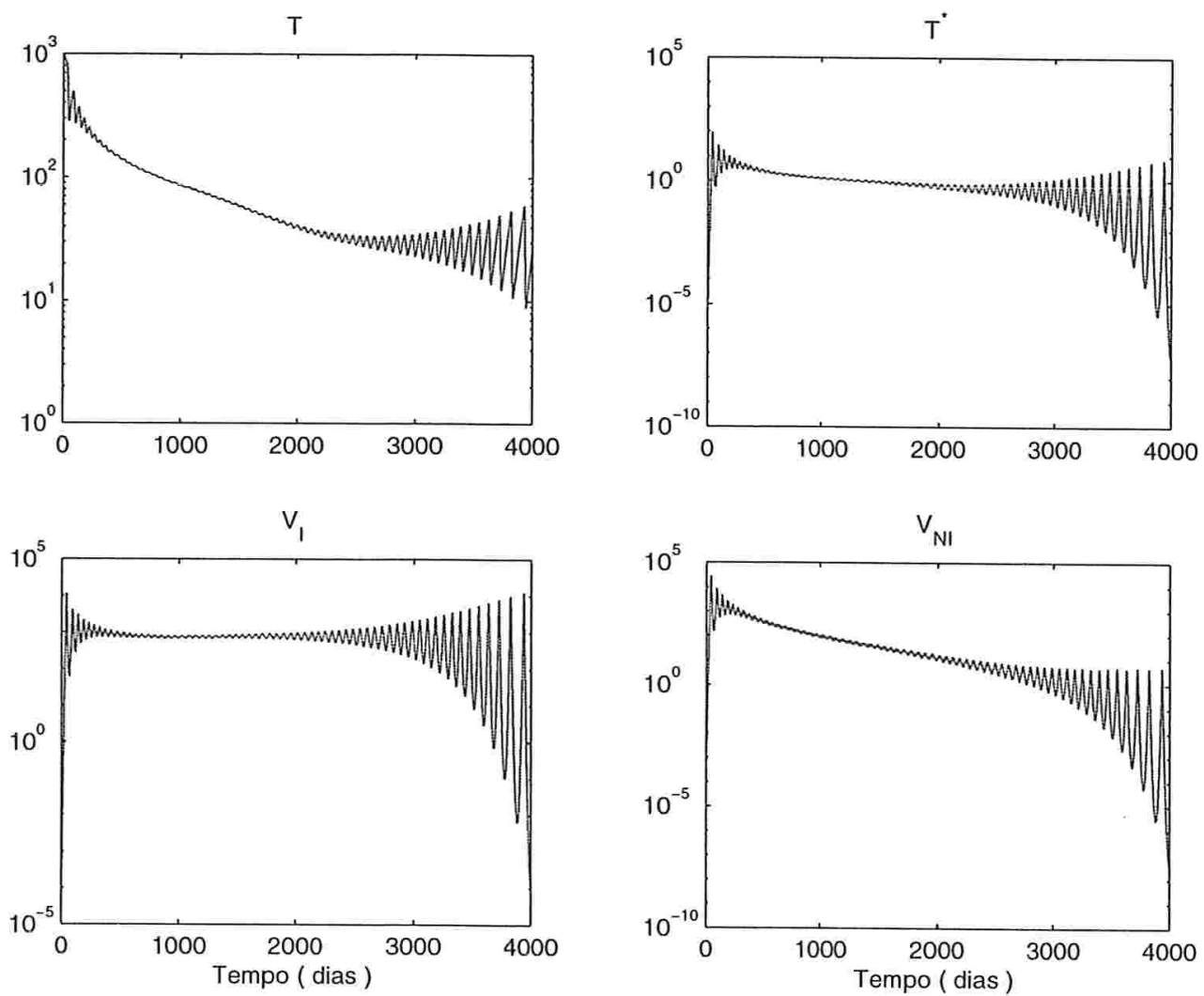

Figura 4.6: Modelo de Perelson [1999]: Simulação feita utilizando-se de um inibidor de protease com eficácia máxima $\beta=0,9$.

e negativa se

$$
\eta_{R T}>1-\frac{2 p c}{N k T_{\max } \varepsilon\left(p-d_{T}\right)} .
$$

Quando $\eta_{R T}=1-\frac{2 p c}{N k T_{\max } \varepsilon\left(p-d_{T}\right)}$, temos o ponto de máximo com

$$
\bar{V}=\frac{N \varepsilon}{4 c}\left[4 s+c T_{\max }\left(p-d_{T}\right)^{2}\right] .
$$

Quando $\eta_{R T}=1-\frac{3 p c}{N k T_{\max } \varepsilon\left(p-d_{T}\right)}$, temos um ponto de inflexão, ou seja, a derivada segunda de $\bar{V}$ em relação a $\eta_{R T}$

$$
\frac{d^{2} \bar{V}}{d \eta_{R T}^{2}}=\frac{2}{k\left(1-\eta_{R T}\right)^{3}}\left[p-d_{T}-\frac{3 p c}{N k T_{\max } \varepsilon\left(1-\eta_{R T}\right)}\right]
$$


se anula.

Se $\eta_{R T}=1-\frac{p c}{N k T_{\max } \varepsilon\left(p-d_{T}\right)}$, então $\bar{V}=\frac{s N \varepsilon}{c}$.

É interessante ressaltar também que $\eta_{R T}=1$ é uma assíntota vertical para $\bar{V}$ e que

$$
\lim _{\eta_{R T} \rightarrow-\infty} \bar{V}\left(\eta_{R T}\right)=\frac{s N \varepsilon}{c} .
$$

Assim, concluímos que se

$$
0 \leq \eta_{R T}<1-\frac{2 p c}{N k T_{\max } \varepsilon\left(p-d_{T}\right)}
$$

um aumento na eficácia da droga, acarretará um aumento na carga viral. E essa conclusão, em princípio contraditória, nos leva a dois caminhos: a necessidade de um modelo matemático mais refinado, ou seja, este resultado seria uma conseqüência de várias simplificações feitas no modelo, ou então que de fato esse fenômeno pode acontecer e que deveria ser levado em conta nas terapias antiretrovirais a base de inibidores da ação da enzima transcriptase reversa.

Por outro lado, se

$$
\frac{p c}{N k T_{\max } \varepsilon\left(p-d_{T}\right)}>\frac{1}{2},
$$

então a derivada de $\bar{V}$ tem sinal negativo e portanto, um aumento na eficácia da droga, acarretará um diminuição na carga viral.

O gráfico da carga viral, $\bar{V}$, em função da eficácia de drogas que inibam a ação da transcriptase reversa, $\eta_{R T}$, está representado na Figura (4.7), com dados da Tabela (4.1). Nesse caso, o ponto de maior carga viral ocorre quando $\eta_{R T}=0,5$ e assim, se $\eta_{R T}<0,5$, então um aumento na eficácia da droga acarreta um aumento na carga viral e se $0,5<\eta_{R T}$ um aumento na eficácia da droga diminui a carga viral. 


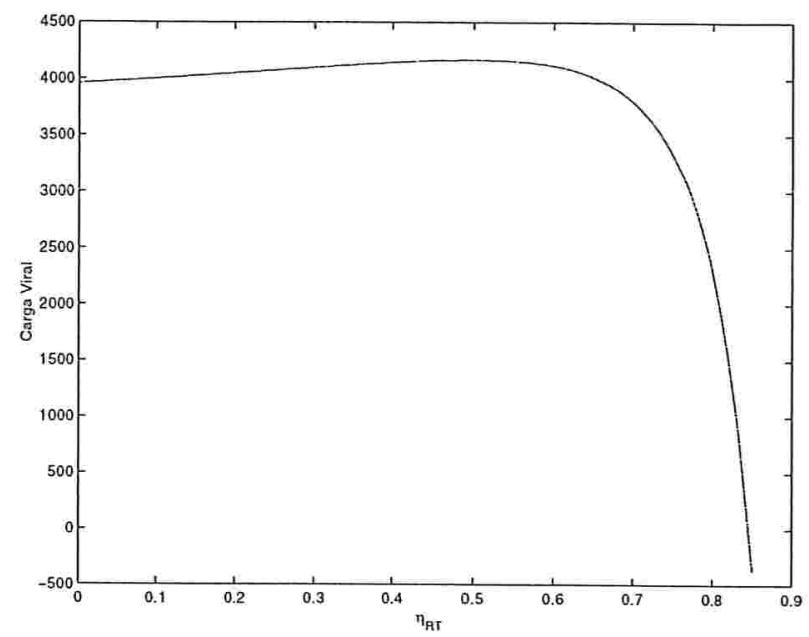

Figura 4.7: Carga Viral $V$ em função da eficácia de drogas inibidoras da transcriptase reversa

Finalmente, as Figuras (4.8) e (4.9) mostram os resultados do modelo quando da simulação do efeito dos dois tipos de drogas, ou seja, a ação conjunta de inibidores de protease e inibidores da transcriptase reversa. Para $\beta=0,5$ os valores médios para o números de células $\mathrm{T}-\mathrm{CD} 4^{+} \mathrm{e}$ vírus infecciosos são $75 \mathrm{~mm}^{-3}$ e $899 \mathrm{~mm}^{-3}$, respectivamente. Para $\beta=0,7$ os valores médios são $92 \mathrm{~mm}^{-3}$ e $854 \mathrm{~mm}^{-3}$. 

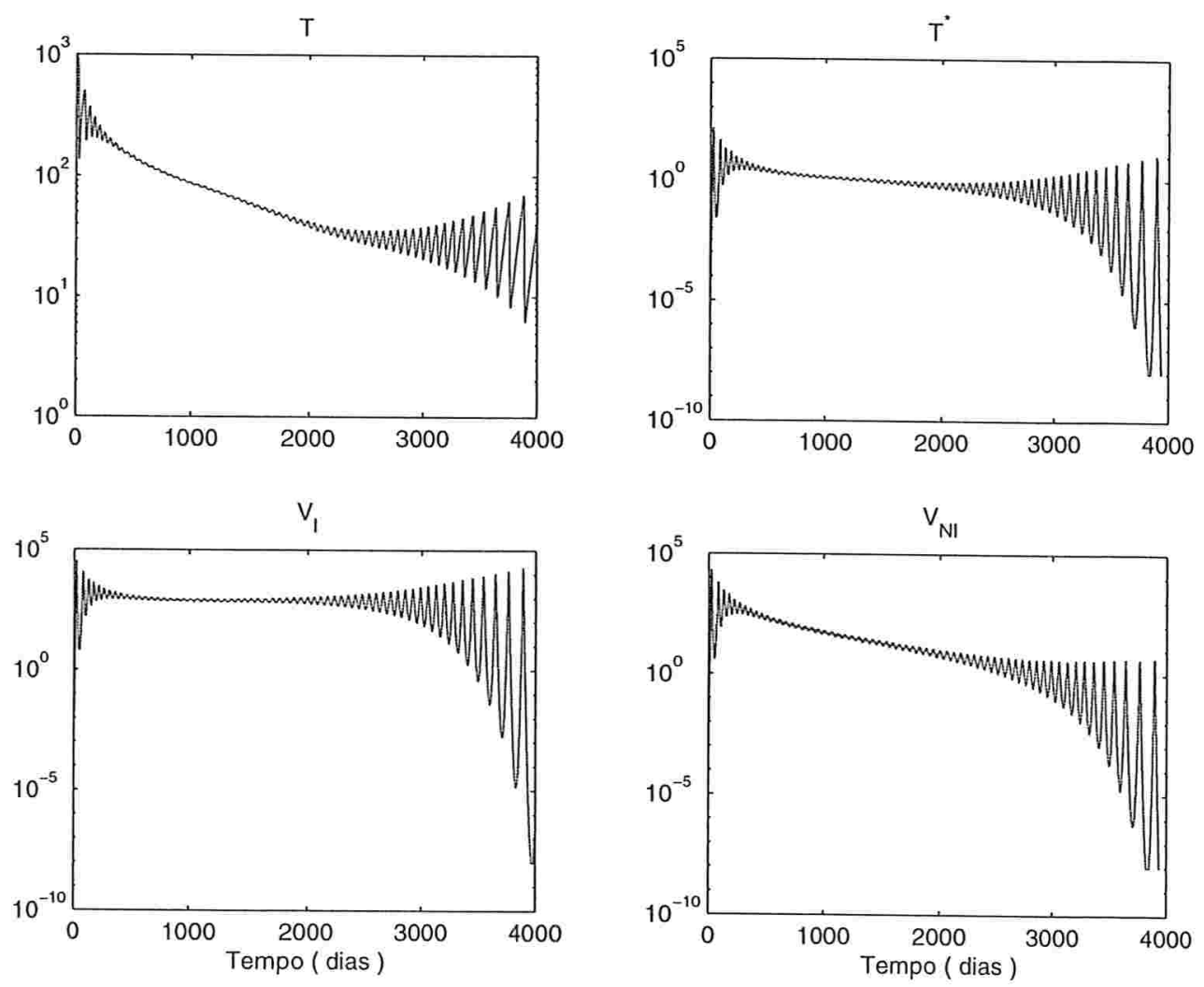

Figura 4.8: Modelo de Perelson [1999]: Simulação feita utilizando-se inibidores de protease e de transcriptase reversa com eficácia máxima $\beta=0,5$ em ambas as drogas. 

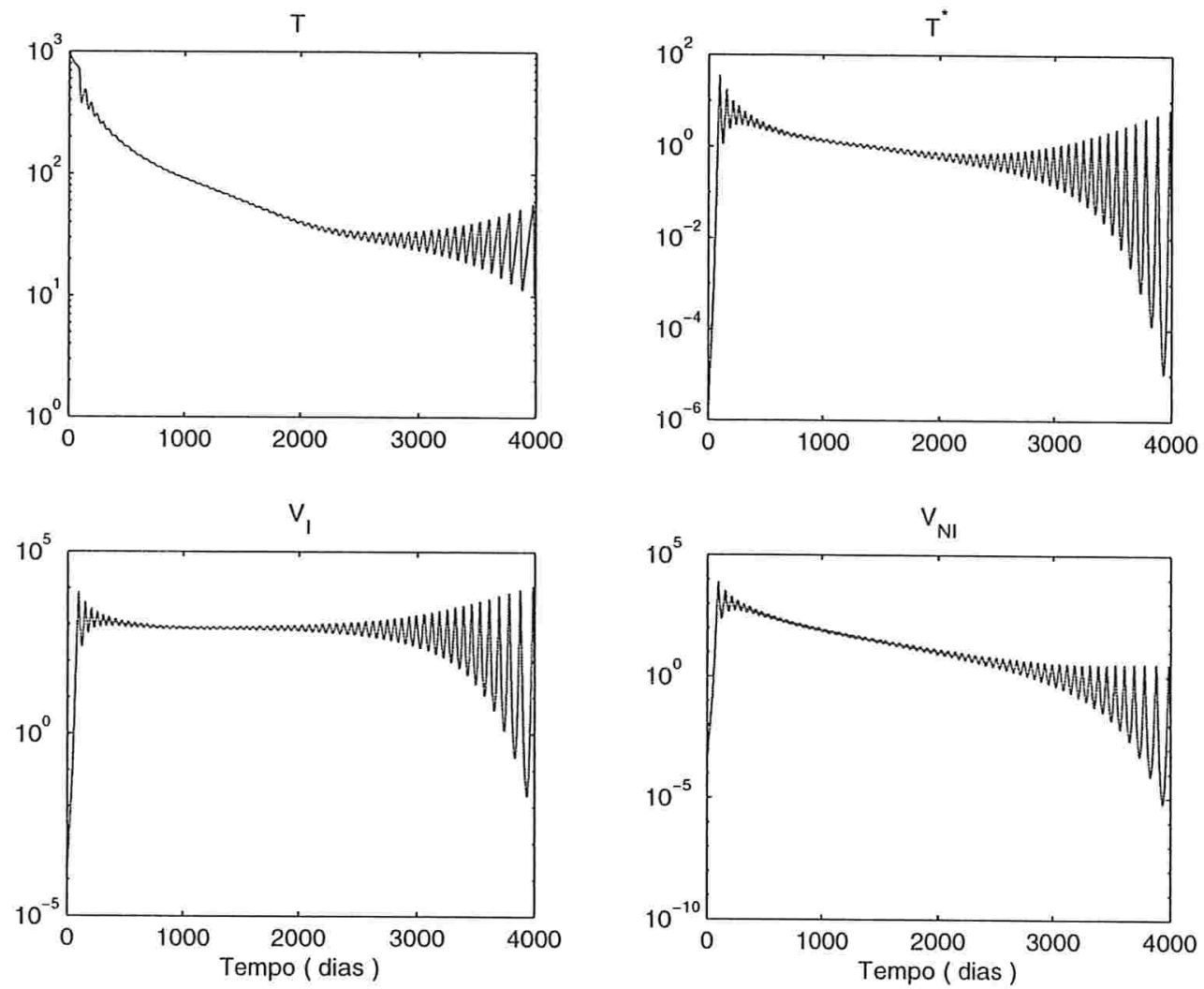

Figura 4.9: Modelo de Perelson [1999]: Simulação feita utilizando-se inibidores de protease e de transcriptase reversa com eficácia máxima $\beta=0,7$ em ambas as drogas. 


\subsubsection{Modelo de Perelson [1993]}

Dados da literatura informam que existe uma população de células T-CD4+ não-infectadas que após a infecção pelo HIV-1 tornam-se infectadas e latentes.

Depois de um período de tempo que pode variar, essas células T CD4 ${ }^{+}$ tornam-se infectadas ativas. Assim, no modelo de Perelson [1993], descrito abaixo,

$$
\begin{aligned}
\frac{d T}{d t} & =s-\mu_{T} T+r T\left(1-\frac{T+T^{*}+T^{* *}}{T_{\max }}\right)-k_{1} V T, \\
\frac{d T^{*}}{d t} & =k_{1} V T-\mu_{T} T^{*}-k_{2} T^{*} \\
\frac{d T^{* *}}{d t} & =k_{2} T^{*}-\mu_{b} T^{* *} \\
\frac{d V}{d t} & =N \mu_{b} T^{* *}-k_{1} V T-\mu_{V} V .
\end{aligned}
$$

temos, além da primeira equação em que $T$ representa as células T-CD $4^{+}$ não-infectadas, a equação em $T^{*}$ que representa as células T-CD $4^{+}$infectadas e latentes e a equação em $T^{* *}$ que representa as células T-CD $4^{+}$infectadas ativas, dessa maneira, o modelo incorpora mais informações sobre o processo biológico em estudo em relação ao modelo anterior.

Nesse trabalho de Perelson [1993] é mostrado a existência de dois pontos de equilíbrio, um na ausência de vírus $\left(T_{0}, 0,0,0\right)$, onde

$$
T_{0}=\frac{T_{\max }}{2 r}\left[\left(r-\mu_{T}\right)+\sqrt{\left(r-\mu_{T}\right)^{2}+\frac{4 s r}{T_{\max }}}\right],
$$

e outro com a presença do vírus $\left(\bar{T}, \bar{T}^{*}, \bar{T}^{* *}, \bar{V}\right)$, onde

$$
\begin{aligned}
\bar{T} & =\frac{\mu_{V} k_{3}}{k_{1}\left(N k_{2}-k_{3}\right)}, \\
\bar{T}^{*} & =\frac{\mu_{V} \bar{V}}{N k_{2}-k_{3}}, \\
\bar{T}^{* *} & =\frac{k_{2} \mu_{V} \bar{V}}{\mu_{b}\left(N k_{2}-k_{3}\right)}, \\
\bar{V} & =\frac{s \alpha^{2}+p \alpha \mu_{V}-\gamma \mu_{V}^{2}}{k_{1} \mu_{V}\left(\alpha+\beta \mu_{V}\right)},
\end{aligned}
$$


e $k_{3}=k_{2}+\mu_{T}, \alpha=k_{1}\left(\frac{N k_{2}}{k_{3}}-1\right), \gamma=\frac{r}{T_{\max }}$ e $\beta=\frac{\gamma}{k_{3}}\left(1+\frac{k_{2}}{\mu_{b}}\right)$ no conjunto

$$
\begin{aligned}
\Delta_{2}= & \left\{\left(T, T^{*}, T^{* *}, V\right) \in \mathbb{R}^{4} / T \geq 0, T^{*} \geq 0, T^{* *} \geq 0, V \geq 0,\right. \\
& \left.T+T^{*}+T^{* *} \leq T_{\max }, V \leq \frac{N \mu_{b} T_{\max }}{\mu_{V}}\right\} .
\end{aligned}
$$

Pode-se mostrar que $\Delta_{2}$ é um conjunto positivamente invariante e compacto, logo todas as soluções que comecem em $\Delta_{2}$ são limitadas.

Também são apresentados resultados, obtidos por métodos númericos, relativos a existência de órbitas periódicas. Essas órbitas periódicas, no entanto, não foram encontrados em uma região biologicamente realista. Possivelmente uma análise qualitativa, como feita no Capítulo 2, conduzirá a resultados mais robustos. Esse é um tema que pretendemos discutir em um outro trabalho.

A Figura (4.10) apresenta uma simulação feita utilizando-se parâmetros constantes.

\begin{tabular}{|c|c|c|}
\hline & Variáveis e Parâmetros & Valores \\
\hline \multicolumn{2}{|r|}{ Variáveis Dependentes } & \multirow{5}{*}{$\begin{array}{l}1000 \mathrm{~mm}^{-3} \\
0 \\
0 \\
10^{-3} \mathrm{~mm}^{-3}\end{array}$} \\
\hline$T$ & 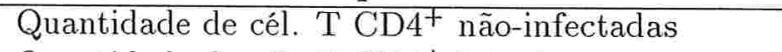 & \\
\hline$T^{*}$ & Quantidade de cél. T CD4+ latentes & \\
\hline$T^{* *}$ & Quantidade de cél. T CD4 ${ }^{+}$ativas & \\
\hline$V$ & Quantidade de vírus & \\
\hline \multicolumn{2}{|r|}{ Parâmetros } & \multirow{10}{*}{$\begin{array}{l}10 \mathrm{~mm}^{-3} \mathrm{dia}^{-1} \\
0,03 \mathrm{dia}^{-1} \\
1500 \mathrm{~mm}^{-3} \\
0,02 \mathrm{dia}^{-1} \\
0,24 \mathrm{dia}^{-1} \\
2,4 \mathrm{dia}^{-1} \\
2,4 \cdot 10^{-5} \mathrm{~mm}^{3} \mathrm{dia}^{-1} \\
3 \cdot 10^{-3} \mathrm{dia}^{-1} \\
1400\end{array}$} \\
\hline$s$ & Taxa de fornecimento de cél. T CD $4^{+}$ & \\
\hline$r$ & Taxa de crescimento de cél. T CD4 ${ }^{+}$ & \\
\hline$T_{\max }$ & Nível máximo da população de cél. T CD4 ${ }^{+}$ & \\
\hline$\mu_{T}$ & Taxa de morte de cél. T $\mathrm{CD}^{+}{ }^{+}$infec. e não infec. & \\
\hline$\mu_{b}$ & Taxa de morte de cél. T CD4 ${ }^{+}$infec. ativas & \\
\hline$\mu_{V}$ & Taxa de morte de vírus livres & \\
\hline$k_{1}$ & Taxa para cél. T $\mathrm{CD} 4^{+}$que se infec. por vírus & \\
\hline$k_{2}$ & Taxa para cél. T CD4 ${ }^{+}$que se tornam ativas & \\
\hline$N$ & Número de vírus prod. por lise de cél. T CD $4^{+}$ & \\
\hline
\end{tabular}

Tabela 4.3: Modelo de Perelson [1993]: Parâmetros Constantes. 

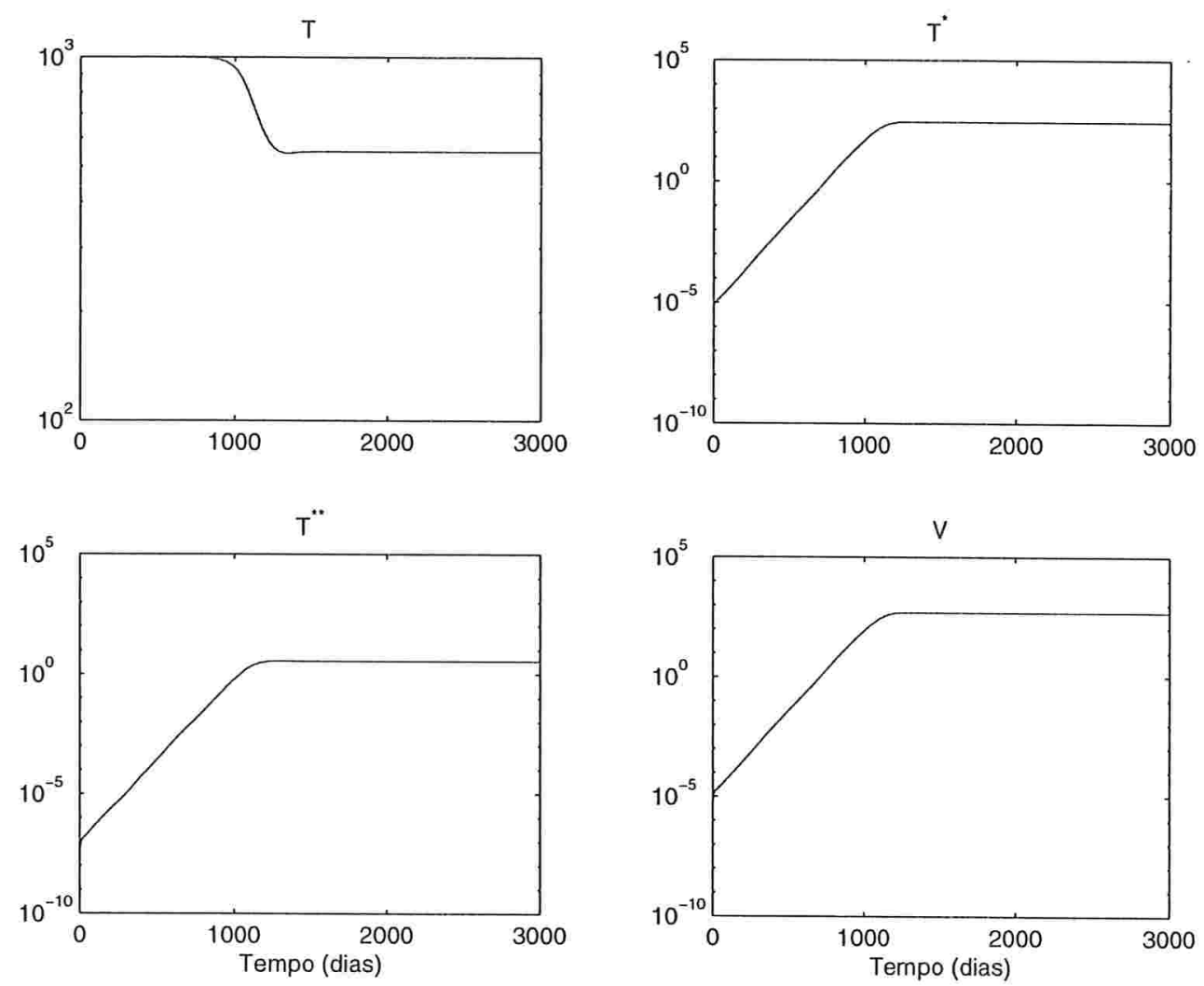

Figura 4.10: Modelo de Perelson [1993]: Soluções com parâmetros constantes

\section{Simulações Numéricas}

A Figura (4.11) mostra uma simulação feita com dados da Tabela (4.4) onde podemos notar que logo após a infecção pelo vírus HIV-1 temos uma queda acentuada no número de células T-CD4 ${ }^{+}$. Essa queda tende a diminuir de intensidade para, finalmente, após cerca de 2000 dias ( 5 anos aproximadamente ) ocorrer um declínio brusco no número de células T-CD4 ${ }^{+}$e um aumento significativo na carga viral. Esse instante na qual o número de células T-CD4 ${ }^{+}$fica abaixo de $200 \mathrm{~mm}^{3}$ e a carga viral aumenta consideravelmente sugere o instante na qual teríamos o surgimento da AIDS.

$\mathrm{Na}$ Figura (4.11) os valores médios dos números de células T-CD4 ${ }^{+}$e vírus infecciosos na ausência de terapia, no período de 5000 dias a partir da infecção com o vírus HIV-1, são de 316 células T-CD4 $4^{+} \mathrm{mm}^{-3}$ e 166 vírus $\mathrm{mm}^{-3}$. 
Tabela 4.4: Modelo de Perelson [1993]: Parâmetros Variando.

\begin{tabular}{|c|c|c|}
\hline & Parâmetros & Fontes \\
\hline \multicolumn{2}{|r|}{ Parâmetros Constantes } & \multirow{8}{*}{$\begin{array}{l}\text { Perelson [1993] } \\
\text { Perelson [1993] } \\
\text { Perelson [1993] } \\
\text { Perelson [1993] } \\
\text { Perelson [1993] } \\
\text { Perelson [1993] } \\
\text { Nelson [1998] }\end{array}$} \\
\hline$r$ & $0,03 \mathrm{dia}^{-1}$ & \\
\hline$T_{\max }$ & $1500 \mathrm{~mm}^{-3}$ & \\
\hline$\mu_{T}$ & $0,02 \mathrm{dia}^{-1}$ & \\
\hline$\mu_{b}$ & $0,24 \mathrm{dia}^{-1}$ & \\
\hline$k_{1}$ & $2,4 \cdot 10^{-5} \mathrm{~mm}^{3} \mathrm{dia}^{-1}$ & \\
\hline$k_{2}$ & $3 \cdot 10^{-3} \mathrm{dia}^{-1}$ & \\
\hline$\beta$ & {$[0,1[$} & \\
\hline \multicolumn{2}{|r|}{ Parâmetros que variam } & \multirow{6}{*}{$\begin{array}{l}\text { Perelson [1993] } \\
\text { Perelson [1993] } \\
\text { Perelson [1993] } \\
\text { Nelson [1998] } \\
\text { Nelson [1998] }\end{array}$} \\
\hline$s$ & $s(t)=10[1+\operatorname{sen}(2 \pi t) / 5] \mathrm{e}^{-\frac{t \ln 2}{120}}$ & \\
\hline$\mu_{V}$ & $\mu_{V}(t)=0,8+1,6 \mathrm{e}^{-\frac{t \ln 2}{720}}$ & \\
\hline$N$ & $N(t)=1000\left(1+\frac{1}{1+500 \mathrm{e}^{-\frac{t}{300}}}\right)$ & \\
\hline$\eta_{R T}$ & $\eta_{R T}(t)=\beta \tanh (10 t) \mathrm{e}^{-\frac{\operatorname{frac}(t / 8)}{4}} \mathrm{e}^{-\frac{\operatorname{tn} 2}{360}}$ & \\
\hline$\eta_{P I}$ & $\eta_{P I}(t)=\beta \tanh (10 t) \mathrm{e}^{-\frac{\operatorname{frac}(t / 8)}{4}} \mathrm{e}^{-\frac{t \ln 2}{360}}$ & \\
\hline
\end{tabular}

A Figura (4.11) sugere também, que o surgimento da AIDS ocorre, em aproximadamente, 1960 dias após infeç̧ão com o vírus.

Para obtermos resultados com terapias antiretrovirais, multiplicamos o termo $k_{1}$ nas Equações (4.14), (4.15) e (4.17) por $\left(1-\eta_{R T}(t)\right)$ e multiplicamos $N$ na Equação (4.17) por $\left(1-\eta_{P I}(t)\right)$, onde $\eta_{R T}$ e $\eta_{P I}$ são dados pelas Equações (4.9) e (4.10), respectivamente.

Dessa maneira, temos o seguinte sistema de equações diferenciais

$$
\begin{aligned}
\frac{d T}{d t} & =s(t)-\mu_{T} T+r T\left(1-\frac{T+T^{*}+T^{* *}}{T_{\max }}\right)-\left(1-\eta_{R T}(t)\right) k_{1} V_{I} T, \\
\frac{d T^{*}}{d t} & =\left(1-\eta_{R T}(t)\right) k_{1} V_{I} T-\mu_{T} T^{*}-k_{2} T^{*}, \\
\frac{d T^{* *}}{d t} & =k_{2} T^{*}-\mu_{b} T^{* *}, \\
\frac{d V_{I}}{d t} & =\left(1-\eta_{P I}(t)\right) N(t) \mu_{b} T^{* *}-k_{1} V_{I} T-\mu_{V}(t) V_{I} .
\end{aligned}
$$



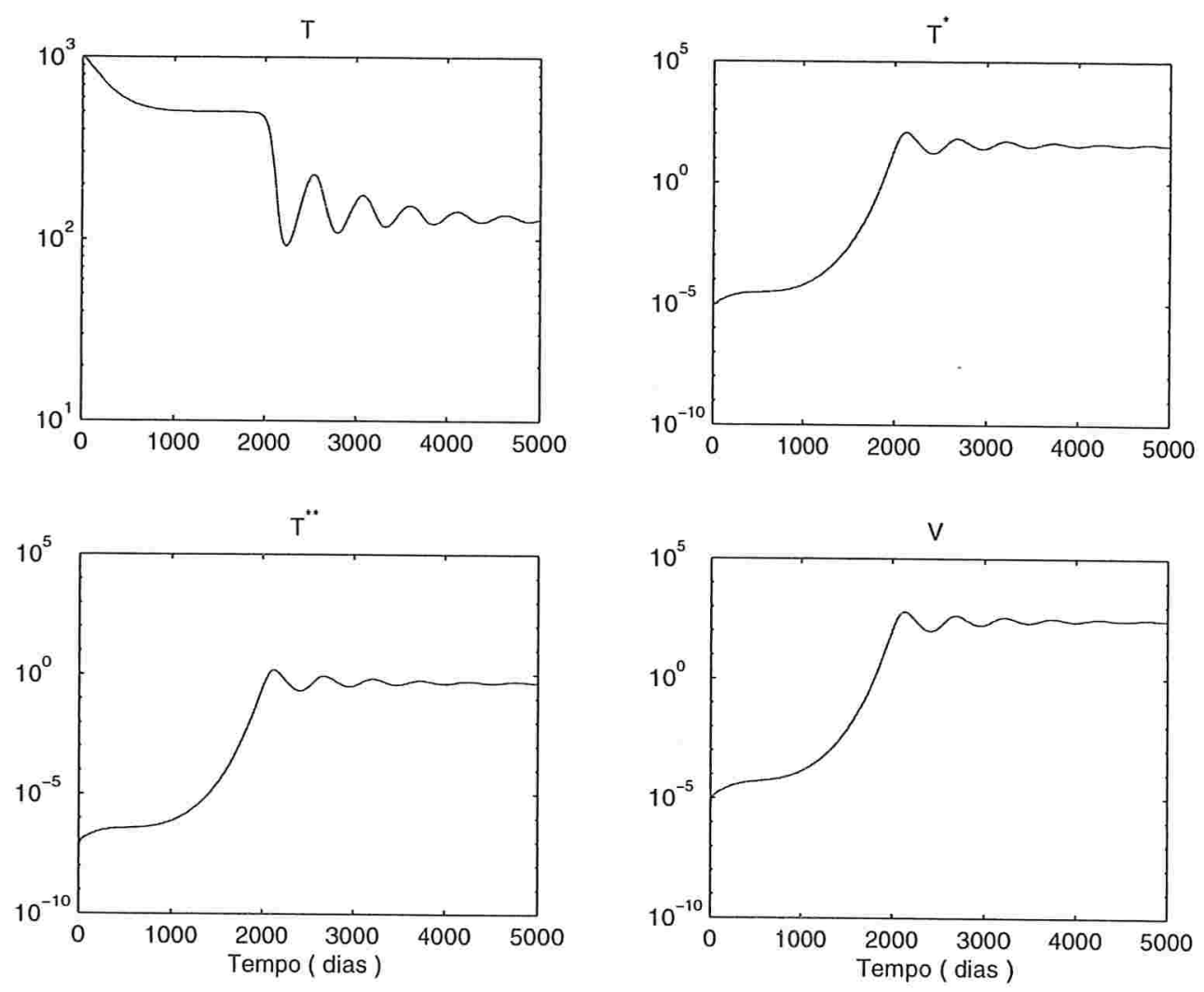

Figura 4.11: Modelo de Perelson [1993]: Simulação feita na ausência de terapia.

Introduzimos também a equação

$$
\frac{d V_{N I}}{d t}=\eta_{P I}(t) N(t) \mu_{b} T^{* *}-\mu_{V}(t) V_{N I}
$$

que descreve mudanças na população de vírus não infecciosos com a condição inicial $V_{N I}(0)=0$.

As Figuras (4.12) e (4.13) apresentam resultados obtidos com uma monoterapia à base de drogas que inibam a ação da protease.

Na Figura (4.12), onde é simulado a ação de inibidores da protease com uma eficácia máxima $\beta=0,7$, podemos verificar que os valores médios para o número de células T-CD4+ é de $333 \mathrm{~mm}^{-3}$ e para a quantidade de vírus infecciosos é de $154 \mathrm{~mm}^{-3}$. O surgimento da AIDS ocorre, em aproximadamente, 


\section{2 dias após a infeç̧ão.}

Na Figura (4.13), com uma eficácia máxima $\beta=0,9$, os valores médios para o número de células T-CD4 ${ }^{+}$e vírus infecciosos são de $338 \mathrm{~mm}^{-3}$ e $150 \mathrm{~mm}^{-3}$, respectivamente. O surgimento da AIDS ocorre em 2314 dias após a infecção.

Apresentamos, em seguida, as Figuras (4.14) e (4.15) que mostram os resultados obtidos quando simulamos a ação de drogas que inibam a ação da enzima transcriptase reversa. Os resultados são bastante próximos dos resultados obtidos com drogas inibidoras da protease.

Na Figura (4.14), onde é simulado a ação de inibidores da transcriptase reversa com eficácia máxima $\beta=0,7$, podemos verificar que os valores médios para o número de células T-CD4 $4^{+}$é de $335 \mathrm{~mm}^{-3}$ e para a quantidade de vírus infecciosos é de $153 \mathrm{~mm}^{-3}$. O surgimento da AIDS ocorre, em aproximadamente, 2250 dias após a infecção.

Na Figura (4.15), com uma eficácia máxima $\beta=0,9$, os valores médios para o número de células T-CD4 ${ }^{+} \mathrm{e}$ vírus infecciosos são de $340 \mathrm{~mm}^{-3}$ e $149 \mathrm{~mm}^{-3}$, respectivamente. O surgimento da AIDS ocorre em 2350 dias após a infecção.

Finalmente, na Figura (4.16), simulamos a ação conjunta de drogas inibidoras da protease e drogas inibidoras da transcriptase reversa, com eficácia máxima $\beta=0,9$ em ambas as drogas. Os resultados obtidos foram 352 células T-CD4 ${ }^{+} \mathrm{mm}^{-3}$ e 141 vírus infecciosos $\mathrm{mm}^{-3}$. O surgimento da AIDS ocorre 2552 dias após a infecção.

É interessante notar que essas simulações sugerem que um aumento na eficácia de uma dada droga aumente o número de células $\mathrm{T}_{-\mathrm{CD}} 4^{+} \mathrm{e}$ uma diminuição na carga viral, além de postergar o início da AIDS. 

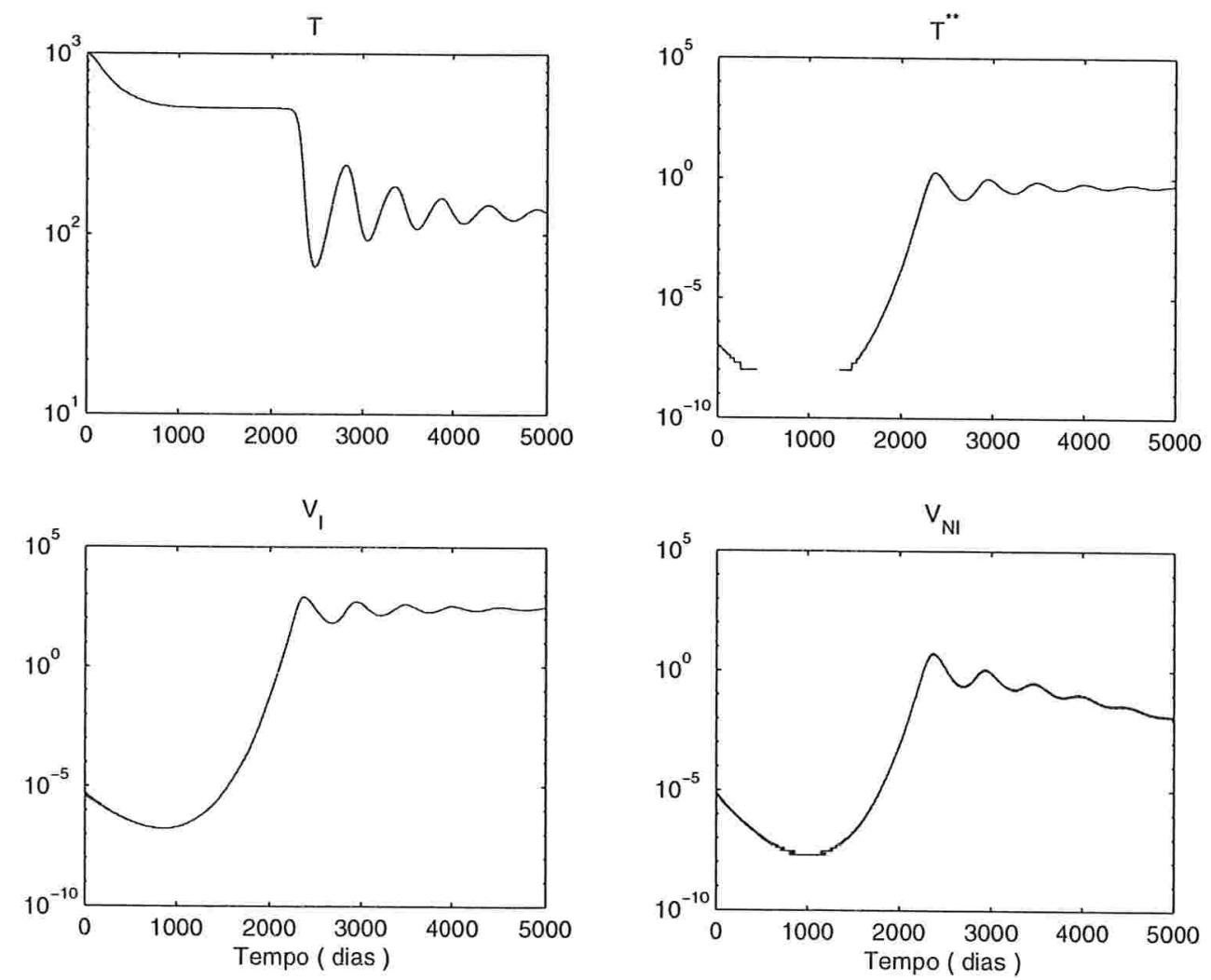

Figura 4.12: Modelo de Perelson [1993]: Simulação feita utilizando-se um inibidor de protease com eficácia máxima $\beta=0,7$. 

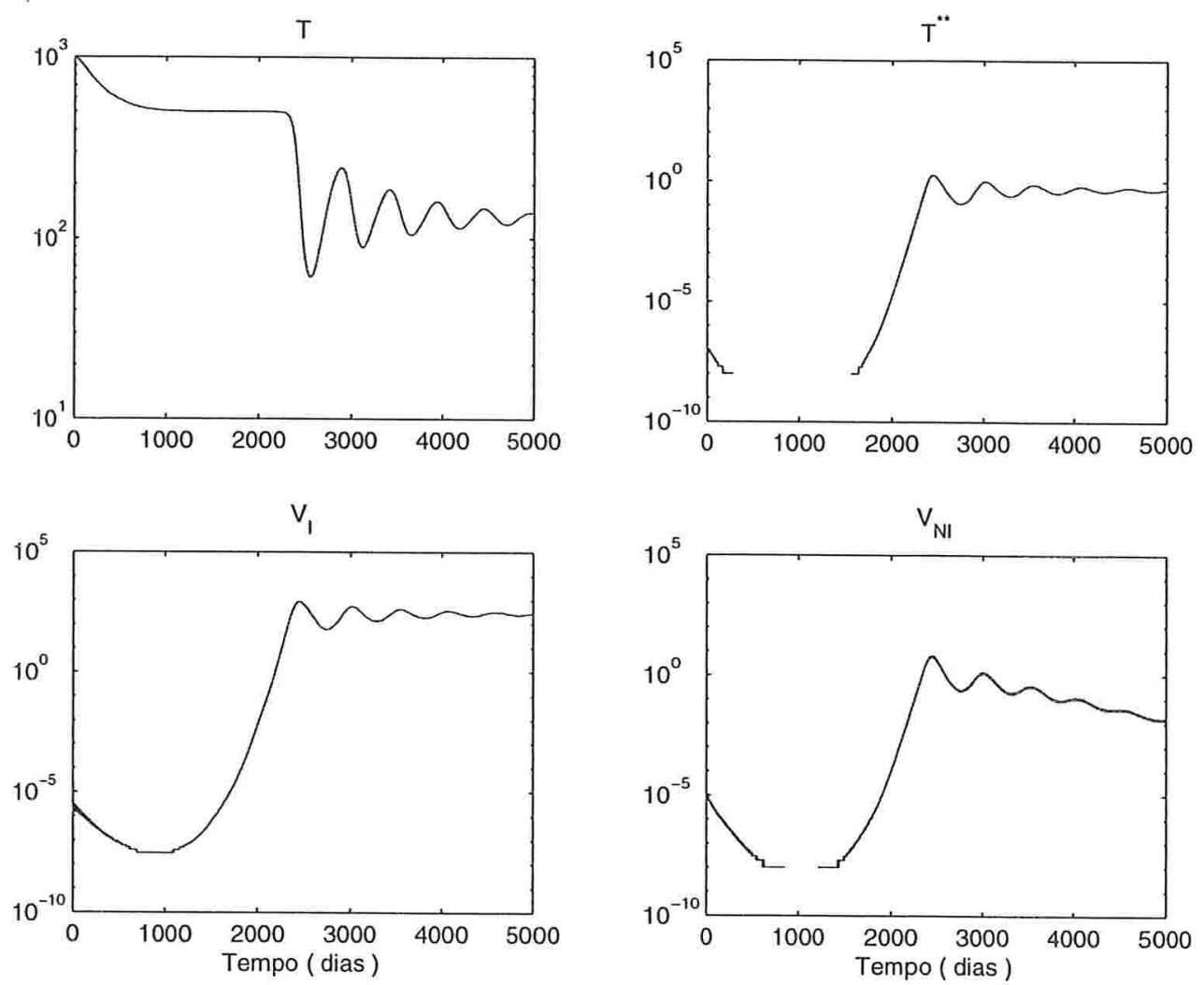

Figura 4.13: Modelo de Perelson [1993]: Simulação feita utilizando-se um inibidor de protease com eficácia máxima $\beta=0,9$. 

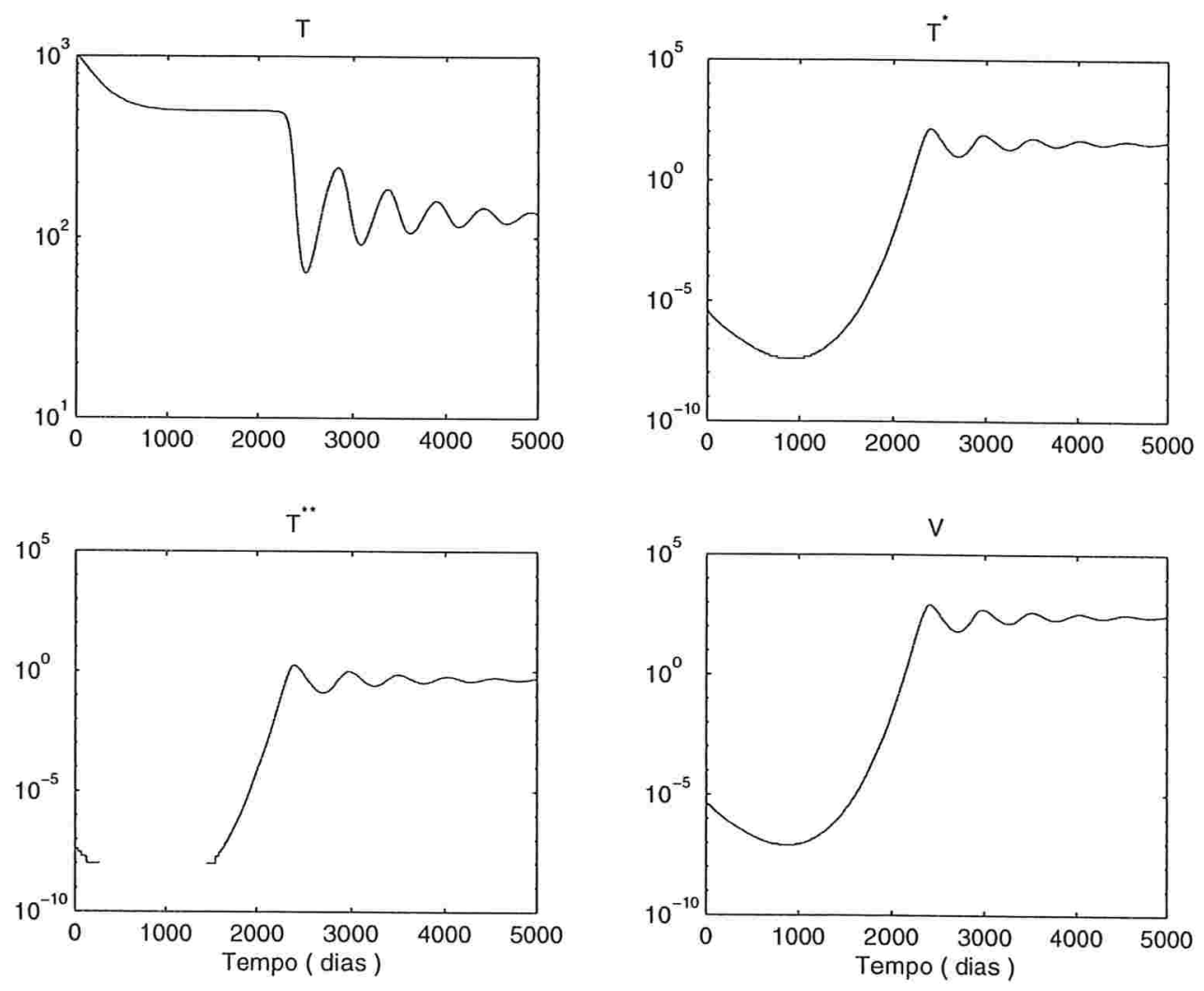

Figura 4.14: Modelo de Perelson [1993]: Simulação feita utilizando-se um inibidor de transcriptase reversa com eficácia máxima $\beta=0,7$. 

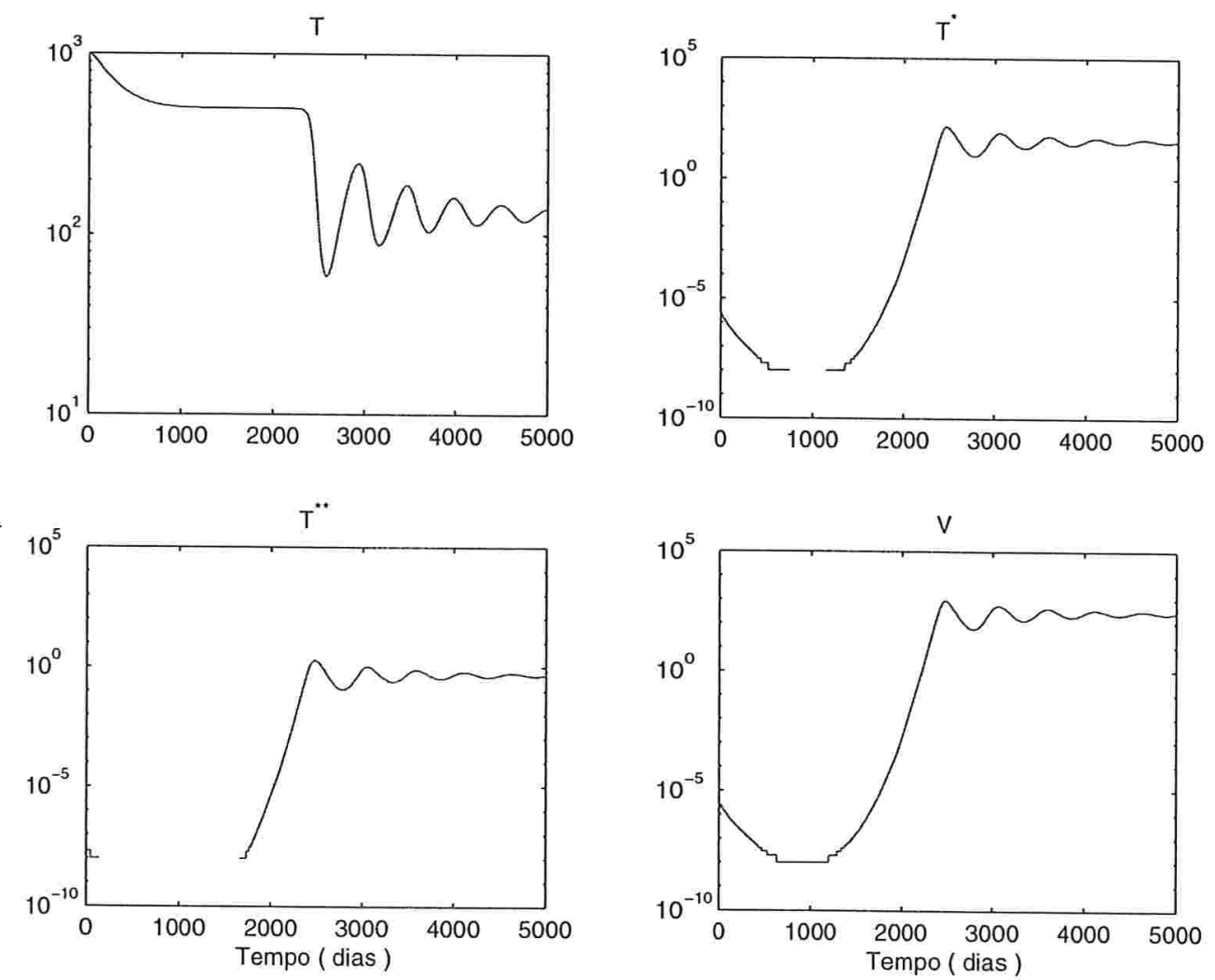

Figura 4.15: Modelo de Perelson [1993]: Simulação feita utilizando-se um inibidor de transcriptase reversa com eficácia máxima $\beta=0,9$. 

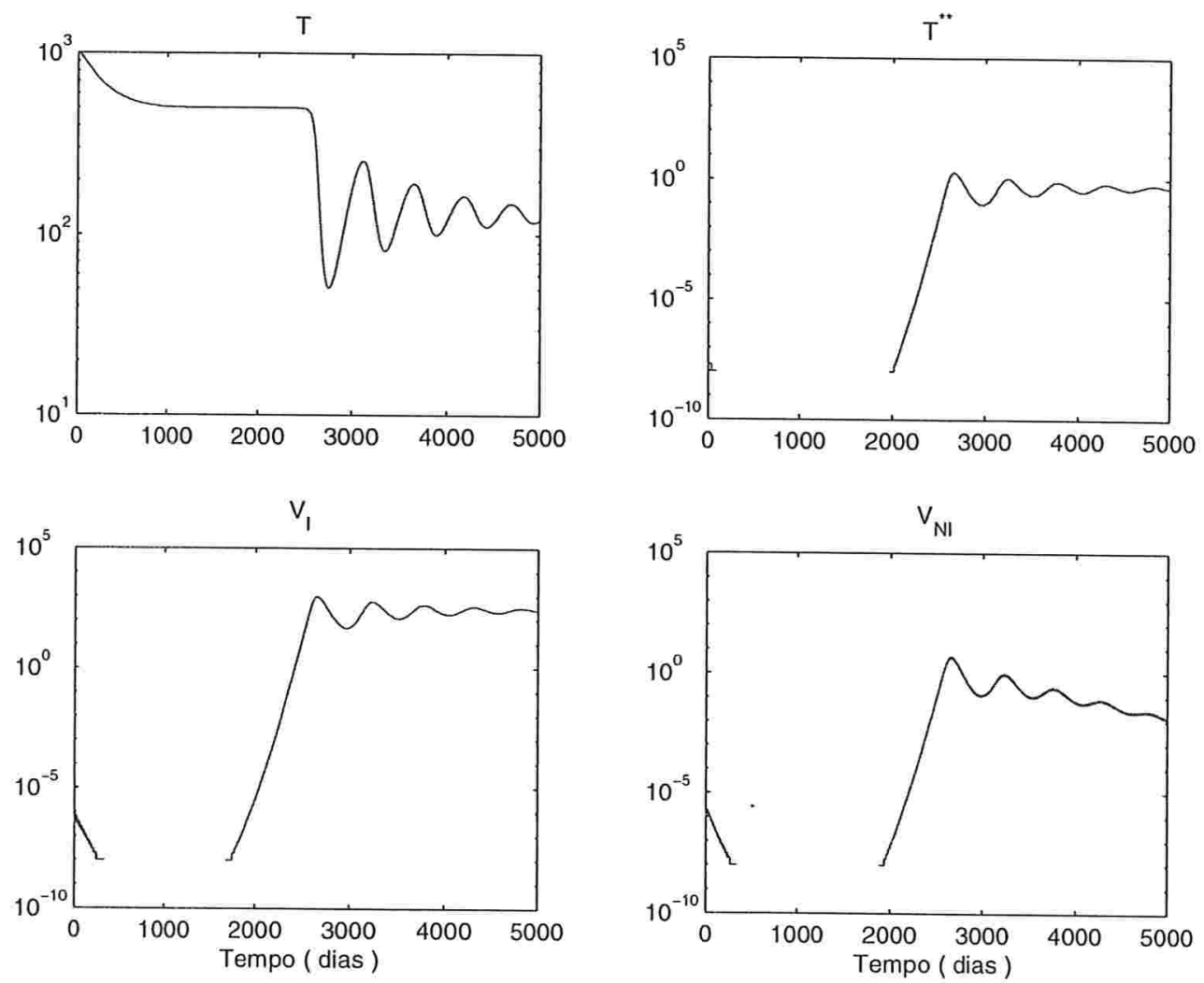

Figura 4.16: Modelo de Perelson [1993]: Simulação feita utilizando-se de inibidores de protease e inibidores de transcriptase reversa com eficácia máxima $\beta=0,9$ em ambas as drogas. 


\subsubsection{Modelo de Kirschner [1996]}

No modelo de Kirschner [1996], descrito abaixo,

$$
\begin{aligned}
\frac{d T}{d t} & =s-\mu_{T} T+r \frac{T V}{C+V}-k_{V} T V, \\
\frac{d T^{i}}{d t} & =k_{V} T V-\mu_{T i} T^{i}-r \frac{T^{i} V}{C+V}, \\
\frac{d V}{d t} & =N r \frac{T^{i} V}{C+V}-k_{T} T V+\frac{g_{V} V}{b+V},
\end{aligned}
$$

$s$ corresponde a fonte de células $\mathrm{T}-\mathrm{CD} 4^{+}, \mu_{T} T$ representa a morte natural das células T-CD4 ${ }^{+}$, o terceiro termo representa a estimulação das células T$\mathrm{CD}^{+}$a se proliferarem na presença do vírus HIV-1, sendo que $r$ é a máxima taxa de proliferação. O último termo da Equação (4.22) simula a infecção de células T-CD4+ por vírus.

Na Equação (4.23) temos a população de células T-CD4+infectadas e o primeiro termo descreve o ganho advindo da infecção de células T-CD4 ${ }^{+}$ suscetíveis, $\mu_{T^{i}}$ é taxa de morte de células T-CD4 ${ }^{+}$infectadas. O terceiro termo representa o processo de lise das células T-CD $4^{+}$infectadas.

A Equação (4.24) descreve a população de vírus HIV-1. O primeiro e o terceiro termos são as fontes de vírus. Por brotamento de vírus pela lise das células T-CD4 ${ }^{+}$, primeiro termo. Por outras células, como macrófagos e timócitos infectados, terceiro termo. Perda de vírus por ação do sistema imune é representado pelo termo $k_{T} T V$.

Foram feitas simulações utilizando-se $s=5+\frac{5}{1+V}$ conforme descrição do trabalho, no entanto, não foram obtidos os resultados que aparecem no artigo. Após uma consulta feita na página da autora na Internet, encontramos uma errata onde é sugerido que seja tomado $s=10 \mathrm{~mm}^{-3} \mathrm{dia}^{-1}$ ( o endereço da autora na Internet é http://www.malthus.micro.med.umich.edu/ ). Com essa informação obtivemos os resultados apresentados no artigo.

Segue abaixo uma simulação feita utilizando-se parâmetros constantes, em um caso $g_{V}=5$, Figura (4.17), e em outro caso $g_{V}=20$, Figura (4.18), conforme dados da Tabela (4.5).

Na Figura (4.19) apresentamos uma simulação feita na ausência de terapia, com dados da Tabela (4.6). Podemos notar que o número de células T-CD4 ${ }^{+}$apresenta inicialmente uma queda acentuada nos primeiros 100 dias após a infecção com o vírus HIV-1, essa queda diminui de intensidade para finalmente, em torno de 1500 dias, o número de células T-CD4+ ficar abaixo 
Tabela 4.5: Modelo de Kirschner [1996]: Parâmetros Cónstantes.

\begin{tabular}{|c|c|c|}
\hline \multicolumn{2}{|r|}{ Variáveis e Parâmetros } & Valores \\
\hline \multicolumn{2}{|r|}{ Variáveis Dependentes } & \multirow{4}{*}{$\begin{array}{l}1000 \mathrm{~mm}^{-3} \\
0 \\
10^{-3} \mathrm{~mm}^{-3}\end{array}$} \\
\hline$T$ & Quantidade de cél. T CD4 ${ }^{+}$não-infectadas & \\
\hline$T^{i}$ & Quantidade de cél. T CD4 ${ }^{+}$infectadas e ativas & \\
\hline$V$ & Quantidade de vírus infecciosos & \\
\hline \multicolumn{2}{|r|}{ Parâmetros } & \multirow{11}{*}{$\begin{array}{l}10 \mathrm{~mm}^{-3} \mathrm{dia}^{-1} \\
0,01 \mathrm{dia}^{-1} \\
0,02 \mathrm{dia}^{-1} \\
0,24 \mathrm{dia}^{-1} \\
2,4 \cdot 10^{-5} \mathrm{~mm}^{3} \mathrm{dia}^{-1} \\
7,4 \cdot 10^{-4} \mathrm{~mm}^{3} \mathrm{dia}^{-1} \\
10 \mathrm{~mm}^{-3} \\
5 \mathrm{dia}^{-1} \\
2,4 \mathrm{dia}^{-1} \\
1000\end{array}$} \\
\hline$s$ & Taxa de fornecimento de cél. T CD4 ${ }^{+}$ & \\
\hline$r$ & Taxa de crescimento de cél. T CD4 ${ }^{+}$ & \\
\hline$\mu_{T}$ & Taxa de morte de cél. T CD4 ${ }^{+}$não infectadas & \\
\hline$\mu_{T^{i}}$ & Taxa de morte de cél. T CD4 ${ }^{+}$infectadas & \\
\hline$k_{V}$ & Taxa para cél. T CD $4^{+}$que se infectam por vírus & \\
\hline$k_{T}$ & Taxa com qual cél. T CD8+ eliminam vírus & \\
\hline$b$ & Const. de meia saturação de fontes virais externas & \\
\hline$g_{V}$ & Taxa de crescim. de outras fontes virais externas & \\
\hline$C$ & Const. de meia saturação do processo de proliferação & \\
\hline$N$ & Número de vírus prod. por lise de cél. $\mathrm{T} \mathrm{CD}^{+}$ & \\
\hline
\end{tabular}

de 200 células T-CD4 ${ }^{+}$, sugerindo, dessa forma, o início da fase com a AIDS. É importante ressaltar também que a carga viral tem um aumento expressivo a partir dos 1500 dias após a infecção.

Na Figura (4.19) os valores médios dos números de células T-CD4 ${ }^{+}$e vírus infecciosos na ausência de terapia, no período de 3000 dias a partir da infecção com o vírus HIV-1, são de 166 células T-CD4 ${ }^{+} \mathrm{mm}^{-3}$ e 24961 vírus $\mathrm{mm}^{-3}$.

A Figura (4.19) sugere também, que o surgimento da AIDS ocorre, em aproximadamente, 1368 dias após infecção com o vírus.

Para simularmos, no modelo de Kirschner [1996], as terapias antiretrovirais, foram feitas as seguintes implementações: multiplicamos o termo $k_{V}$ nas Equações (4.22) e (4.23) por $\left(1-\eta_{R T}(t)\right)$ e multiplicamos $N$ na Equação (4.24) por $\left(1-\eta_{P I}(t)\right)$, onde $\eta_{R T}$ e $\eta_{P I}$ são dados pelas Equações (4.9) e (4.10), respectivamente. 

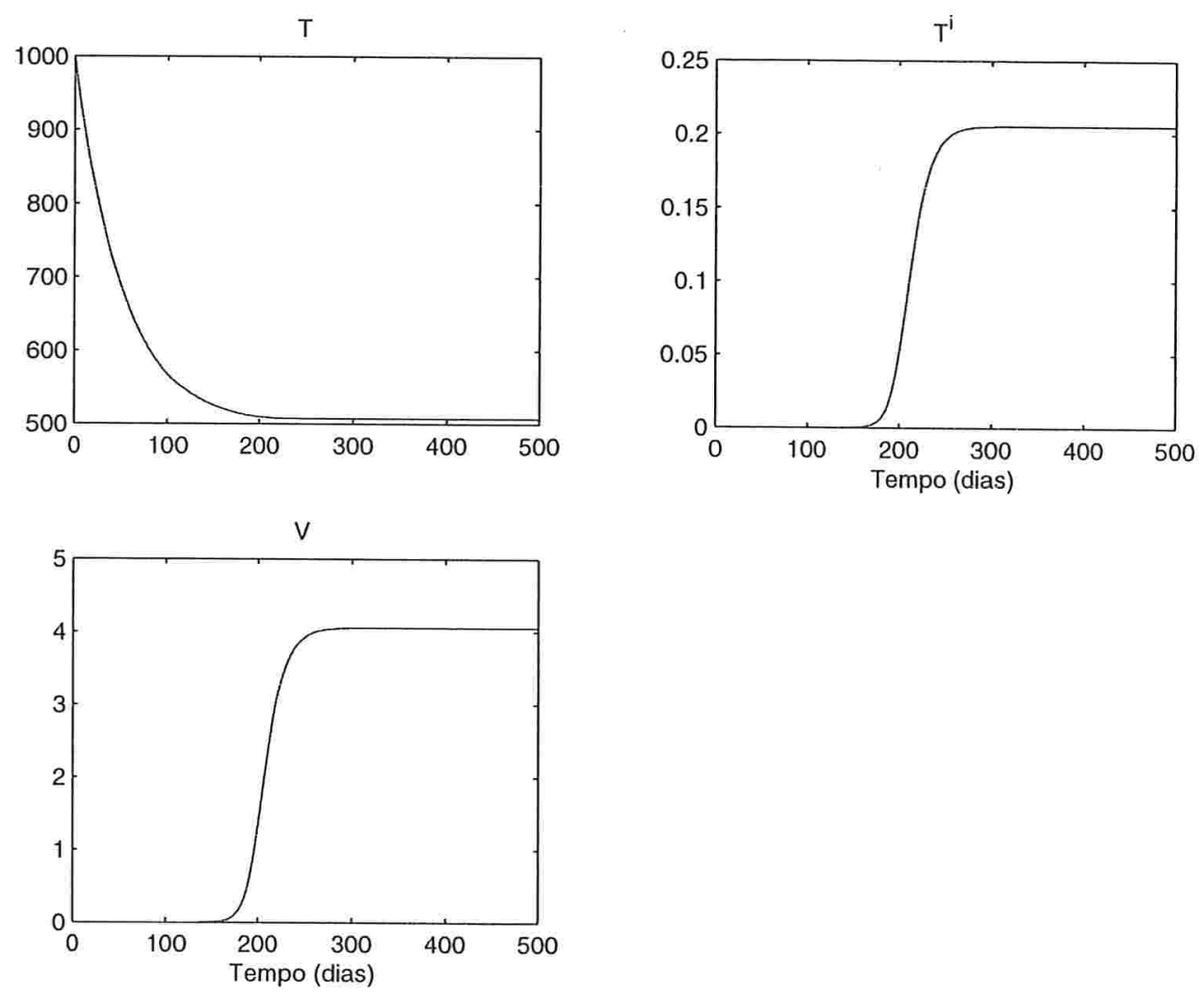

Figura 4.17: Modelo de Kirschner [1996]: Soluções com parâmetros constantes, $g_{V}=5$

Assim, obtemos o seguinte sistema de equações diferenciais

$$
\begin{aligned}
\frac{d T}{d t} & =s(t)-\mu_{T} T+r \frac{T V_{I}}{C+V_{I}}-\left(1-\eta_{R T}(t)\right) k_{V} T V_{I}, \\
\frac{d T^{i}}{d t} & =\left(1-\eta_{R T}(t)\right) k_{V} T V_{I}-\mu_{T i} T^{i}-r \frac{T^{i} V_{I}}{C+V_{I}}, \\
\frac{d V_{I}}{d t} & =\left(1-\eta_{P I}(t)\right) N(t) r \frac{T^{i} V_{I}}{C+V_{I}}-k_{T} T V_{I}+\frac{g_{V}(t) V_{I}}{b+V_{I}}
\end{aligned}
$$

Da mesma maneira que fizemos no modelo de Perelson [1993], introduziremos uma equação diferencial que descreve mudanças na população de vírus 

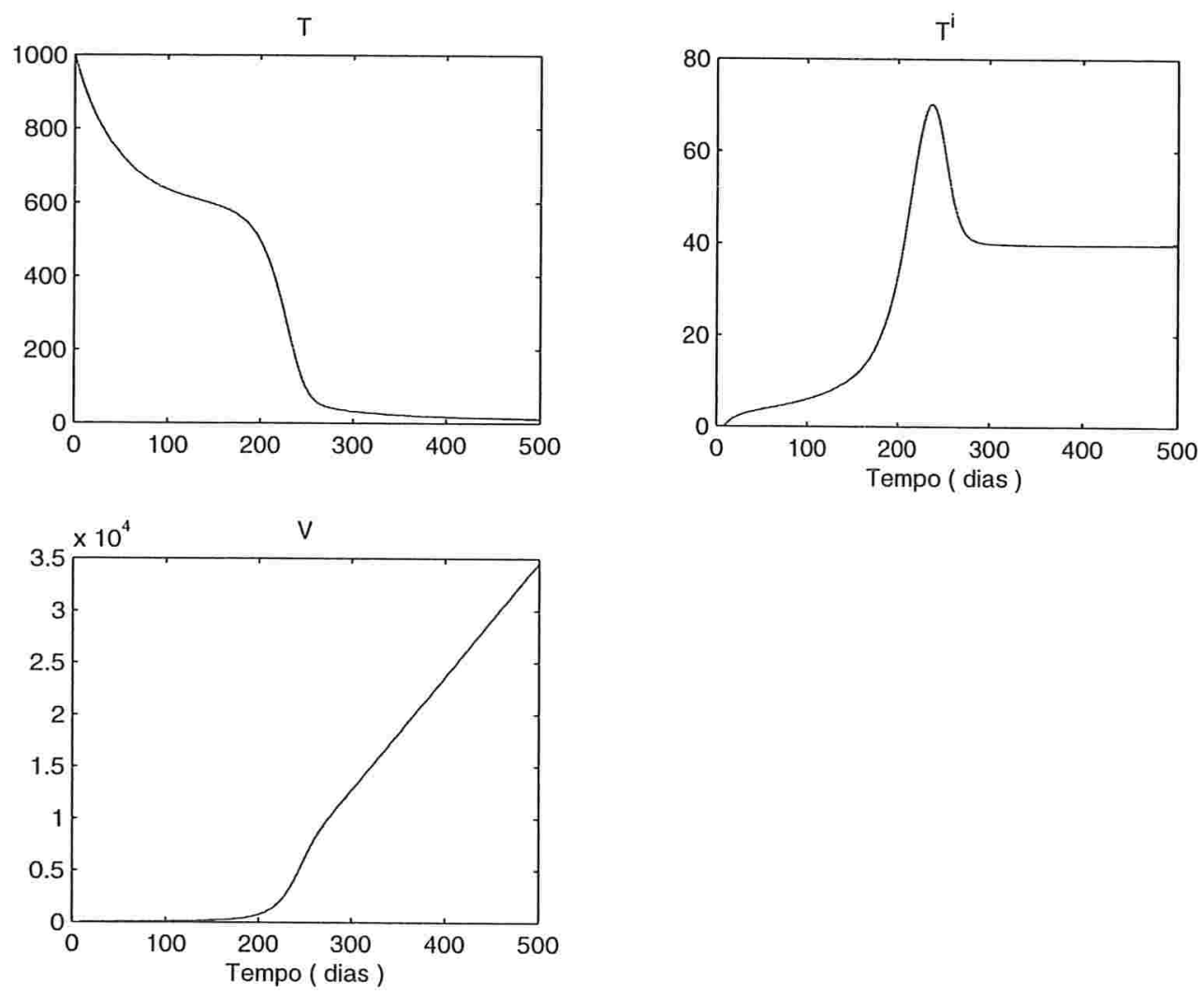

Figura 4.18: Modelo de Kirschner [1996]: Soluções com parâmetros constantes, $g_{V}=20$

não infecciosos dada por

$$
\frac{d V_{N I}}{d t}=\eta_{P I}(t) N(t) r \frac{T^{i} V_{N I}}{C+V_{N I}}-k_{T} T V_{I},
$$

com a condição inicial $V_{N I}(0)=0$.

As Figuras (4.20) e (4.21) apresentam resultados obtidos com uma monoterapia à base de drogas que inibam a ação da protease.

Na Figura (4.20), onde é simulado a ação de inibidores da protease com uma eficácia máxima $\beta=0,5$, podemos verificar que os valores médios para o número de células T-CD4+é de $168 \mathrm{~mm}^{-3}$ e para a quantidade de vírus infecciosos é de $23035 \mathrm{~mm}^{-3}$. O surgimento da AIDS ocorre, em aproximadamente, 1408 dias após a infecção. 
Tabela 4.6: Modelo de Kirschner [1996]: Parâmetros Variando.

\begin{tabular}{|c|c|c|}
\hline & Parâmetros & Fontes \\
\hline \multicolumn{2}{|r|}{ Parâmetros Constantes } & \multirow{9}{*}{$\begin{array}{l}\text { Kirschner [1996] } \\
\text { Perelson [1993] } \\
\text { Kirschner [1996] } \\
\text { Perelson [1993] } \\
\text { Kirschner [1996] } \\
\text { Kirschner [1996] } \\
\text { Kirschner [1996] } \\
\text { Nelson [1998] }\end{array}$} \\
\hline$r$ & $0,01 \mathrm{dia}^{-1}$ & \\
\hline$\mu_{T}$ & $0,02 \mathrm{dia}^{-1}$ & \\
\hline$\mu_{T^{i}}$ & $0,24 \mathrm{dia}^{-1}$ & \\
\hline$k_{V}$ & $2,4 \cdot 10^{-5} \mathrm{~mm}^{3} \mathrm{dia}^{-1}$ & \\
\hline$k_{T}$ & $7,4 \cdot 10^{-4} \mathrm{~mm}^{3} \mathrm{dia}^{-1}$ & \\
\hline$b$ & $10 \mathrm{~mm}^{-3}$ & \\
\hline$C$ & $2,4 \mathrm{dia}^{-1}$ & \\
\hline$\beta$ & {$[0,1[$} & \\
\hline \multicolumn{2}{|r|}{ Parâmetros que variam } & \multirow{3}{*}{ Perelson [1993] } \\
\hline$s$ & $s(t)=10[1+\operatorname{sen}(2 \pi t) / 5] \mathrm{e}^{-\frac{1 \ln 2}{900}}$ & \\
\hline$g_{V}$ & $g_{V}(t)=5\left(1+\frac{3}{1+500 \mathrm{e}^{-\frac{t}{300}}}\right)$ & \\
\hline$N$ & $N(t)=1000\left(1+\frac{1}{1+500 \mathrm{e}^{-\frac{t}{300}}}\right)$ & Perelson [1993] \\
\hline$\eta_{R T}$ & $\eta_{R T}(t)=\beta \tanh (10 t) \mathrm{e}^{-\frac{\operatorname{frac}(t / 8)}{4}} \mathrm{e}^{-\frac{\operatorname{tin} 2}{360}}$ & Nelson [1998] \\
\hline$\eta_{P I}$ & $\eta_{P I}(t)=\beta \tanh (10 t) \mathrm{e}^{-\frac{\operatorname{frac}(t / 8)}{4}} \mathrm{e}^{-\frac{t \ln 2}{360}}$ & Nelson [1998] \\
\hline
\end{tabular}

Na Figura (4.21), com uma eficácia máxima $\beta=0,9$, os valores médios para o número de células T-CD4 ${ }^{+}$e vírus infecciosos são de $171 \mathrm{~mm}^{-3} \mathrm{e}$ $21749 \mathrm{~mm}^{-3}$, respectivamente. O surgimento da AIDS ocorre em 1437 dias após a infecção.

Apresentamos, em seguida, as Figuras (4.22) e (4.23) que mostram os resultados obtidos quando simulamos a ação de drogas que inibam a ação da enzima transcriptase reversa. Novamente, os resultados são bastante próximos dos resultados obtidos com drogas inibidoras da protease.

$\mathrm{Na}$ Figura (4.22), onde é simulado a ação de inibidores da transcriptase reversa com eficácia máxima $\beta=0,5$, podemos verificar que os valores médios para o número de células T-CD4+é de $169 \mathrm{~mm}^{-3}$ e para a quantidade de vírus infecciosos é de $23216 \mathrm{~mm}^{-3}$. O surgimento da AIDS ocorre, em aproximadamente, 1414 dias após a infecção.

Na Figura (4.23), com uma eficácia máxima $\beta=0,9$, os valores médios para o número de células T-CD4 ${ }^{+}$e vírus infecciosos são de $171 \mathrm{~mm}^{-3} \mathrm{e}$ 

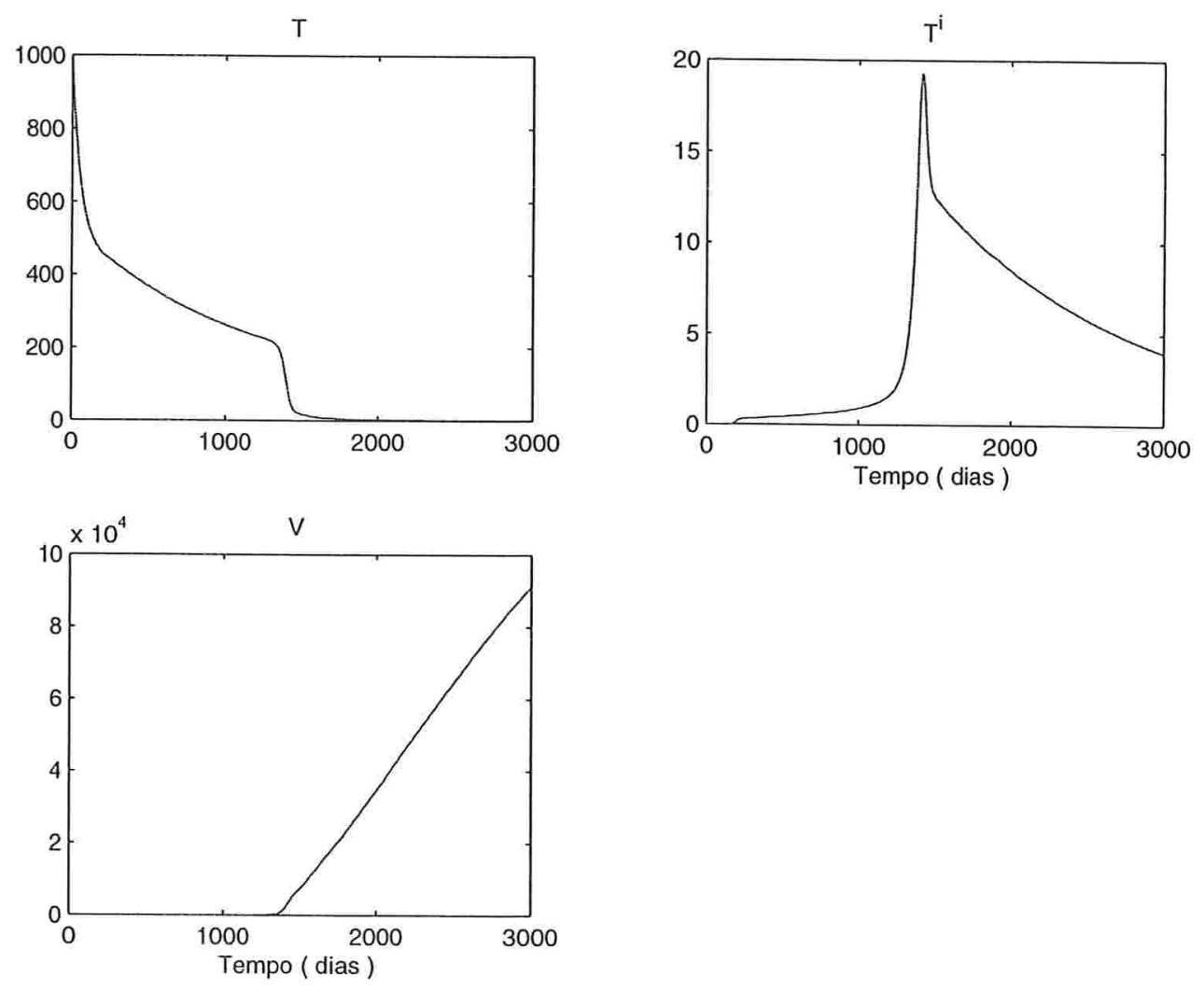

Figura 4.19: Modelo de Kirschner [1996]: Simulação feita na ausência de terapia.

$22044 \mathrm{~mm}^{-3}$, respectivamente. O surgimento da AIDS ocorre em 1433 dias após a infeç̧ão.

Finalmente, nas Figuras (4.24) e (4.25), simulamos a ação conjunta de drogas inibidoras da protease e drogas inibidoras da transcriptase reversa. $\mathrm{Na}$ Figura (4.24), com eficácia máxima $\beta=0,5 \mathrm{em}$ ambas as drogas, obtivemos os valores $171 \mathrm{~mm}^{-3}$ para o número de células T-CD4 ${ }^{+}$e $21652 \mathrm{~mm}^{-3}$ para o número de vírus infecciosos. O início da AIDS ocorre 1439 dias após a infecção. Na Figura (4.25) os resultados obtidos foram 175 células T-CD4 ${ }^{+} \mathrm{mm}^{-3}$ e 19740 vírus infecciosos $\mathrm{mm}^{-3}$. O surgimento da AIDS ocorre 1468 dias após a infecção.

Dos resultados obtidos com o modelo de Kirschner [1996] pode-se notar, 
como no modelo de Perelson [1993], que um aumento na eficácia de uma droga implica em um aumento no número de células T-CD4 ${ }^{+}$, uma diminuição na carga viral e o início da AIDS tende a ser postergado.
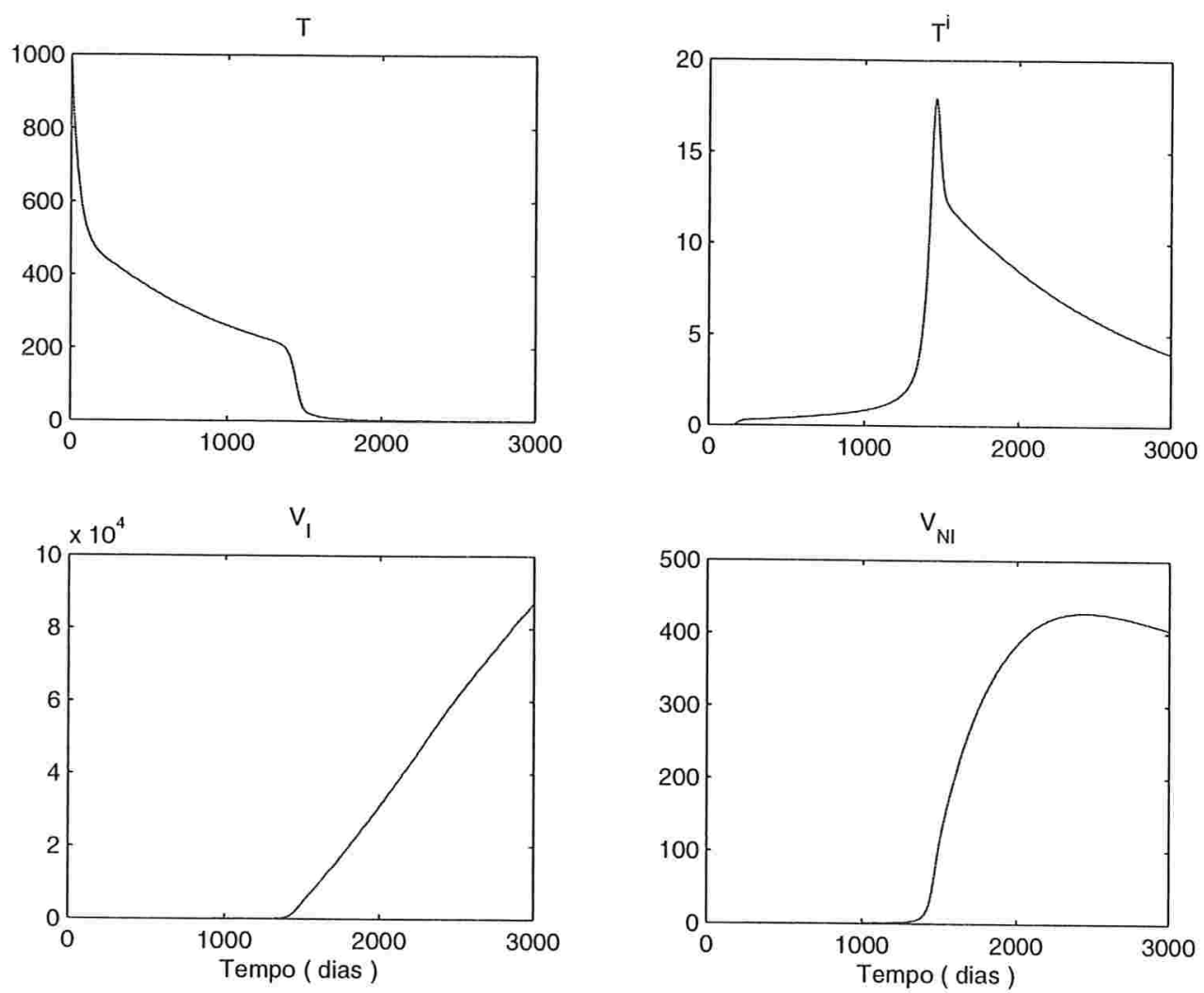

Figura 4.20: Modelo de Kirschner [1996]: Simulação feita utilizando-se um inibidor de protease com eficácia máxima $\beta=0,5$. 

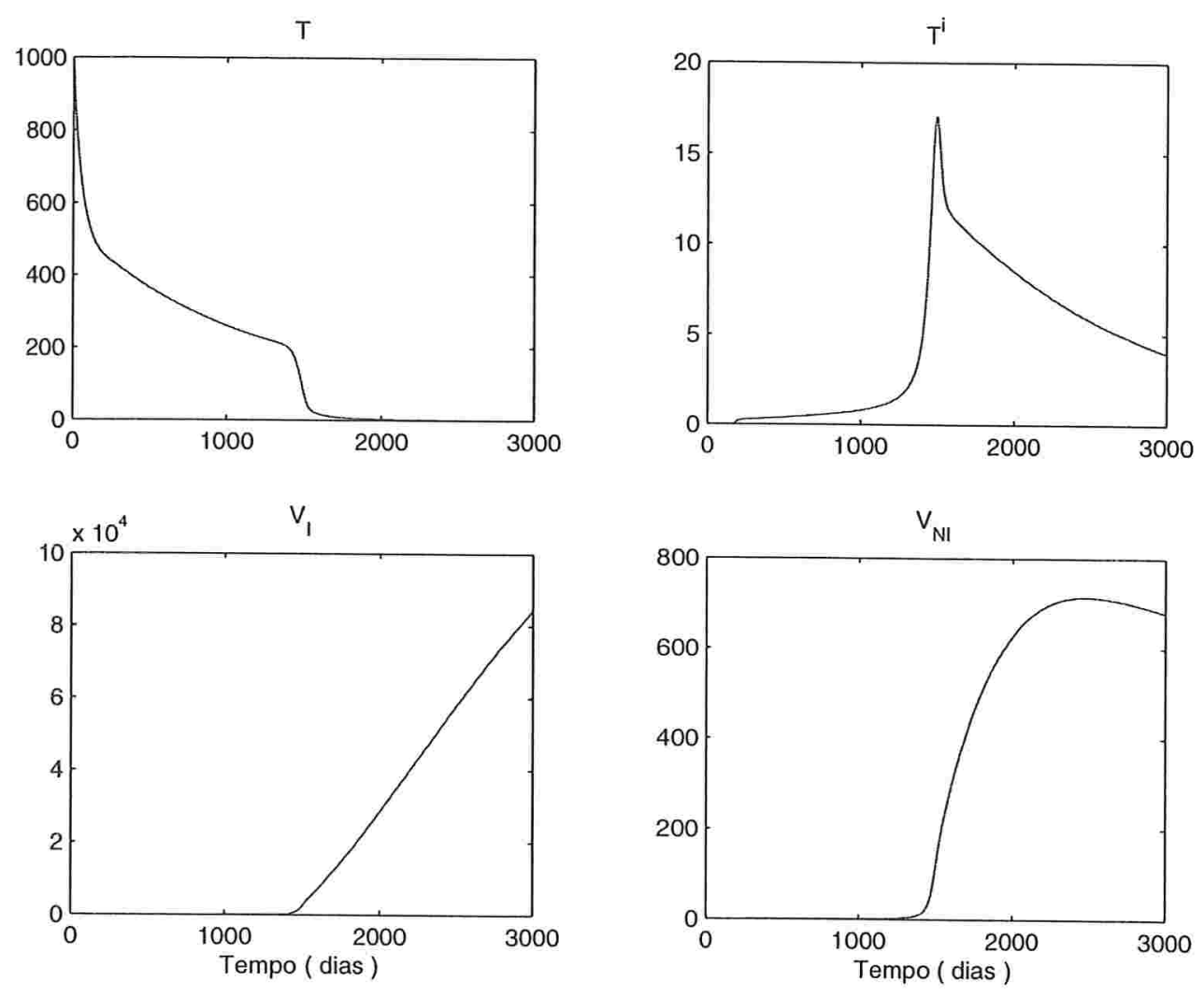

Figura 4.21: Modelo de Kirschner [1996]: Simulação feita utilizando-se um inibidor de protease com eficácia máxima $\beta=0,9$. 

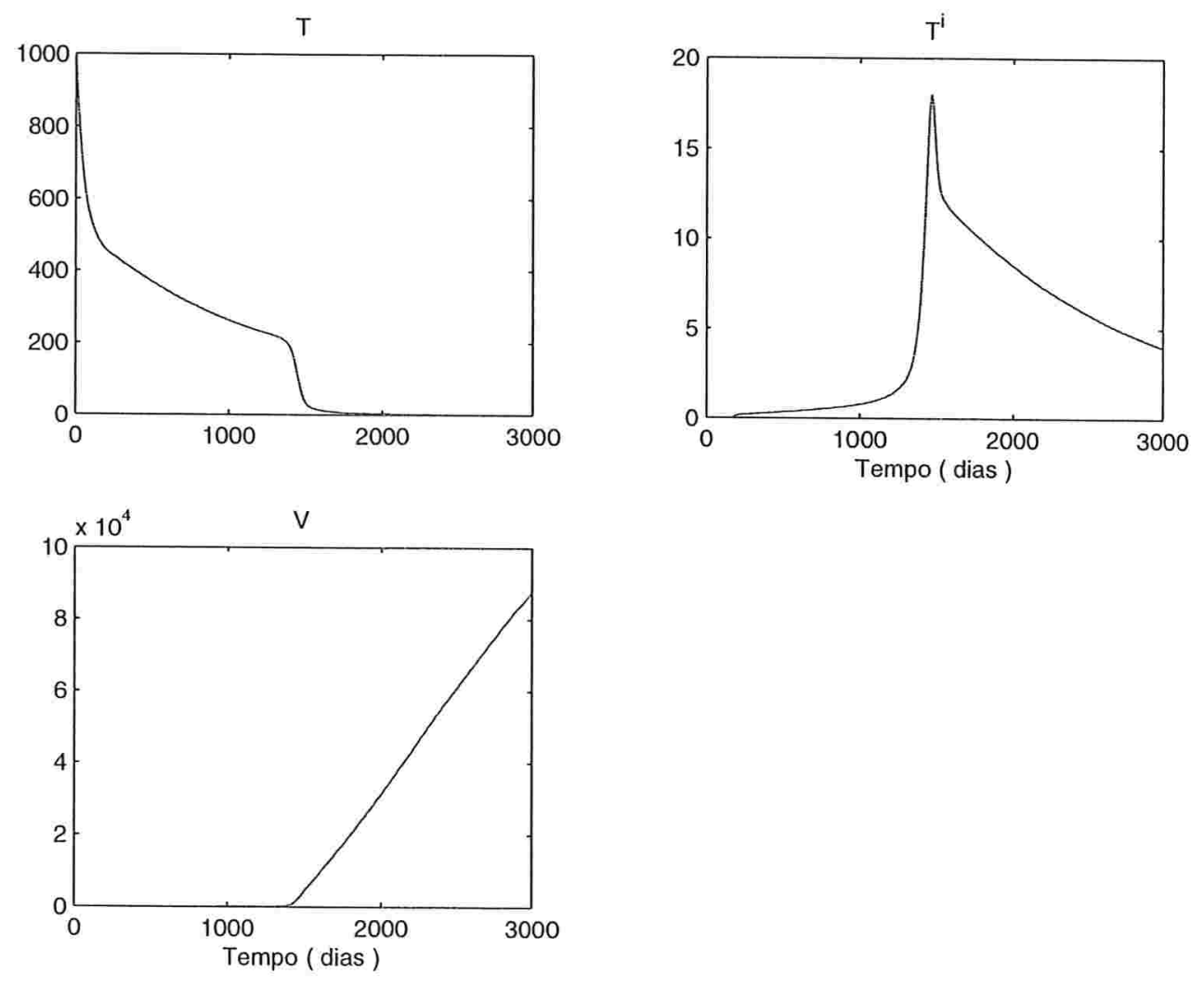

Figura 4.22: Modelo de Kirschner [1996]: Simulação feita utilizando-se um inibidor de transcriptase reversa com eficácia máxima $\beta=0,5$. 

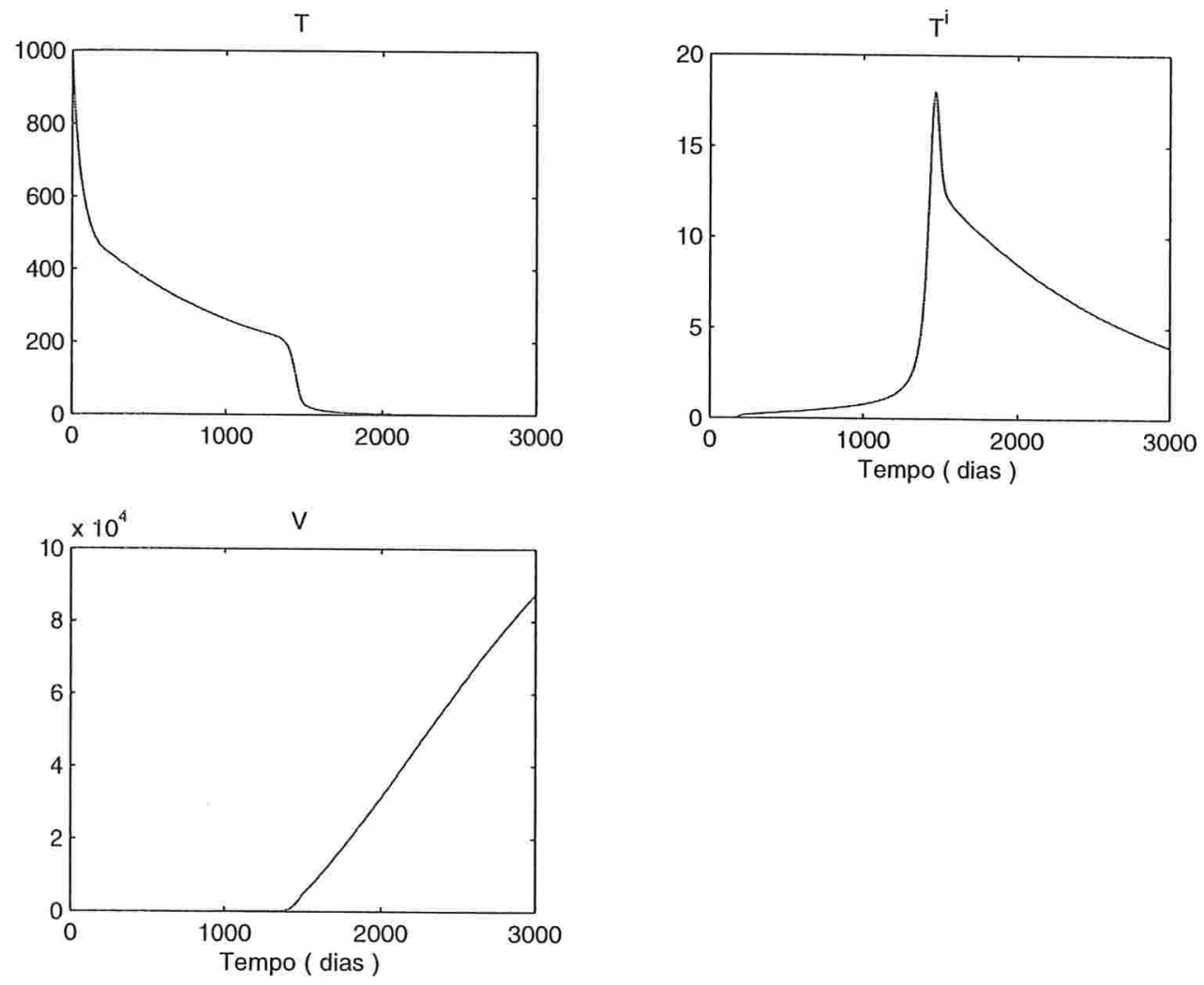

Figura 4.23: Modelo de Kirschner [1996]: Simulação feita utilizando-se um inibidor de transcriptase reversa com eficácia máxima $\beta=0,9$. 

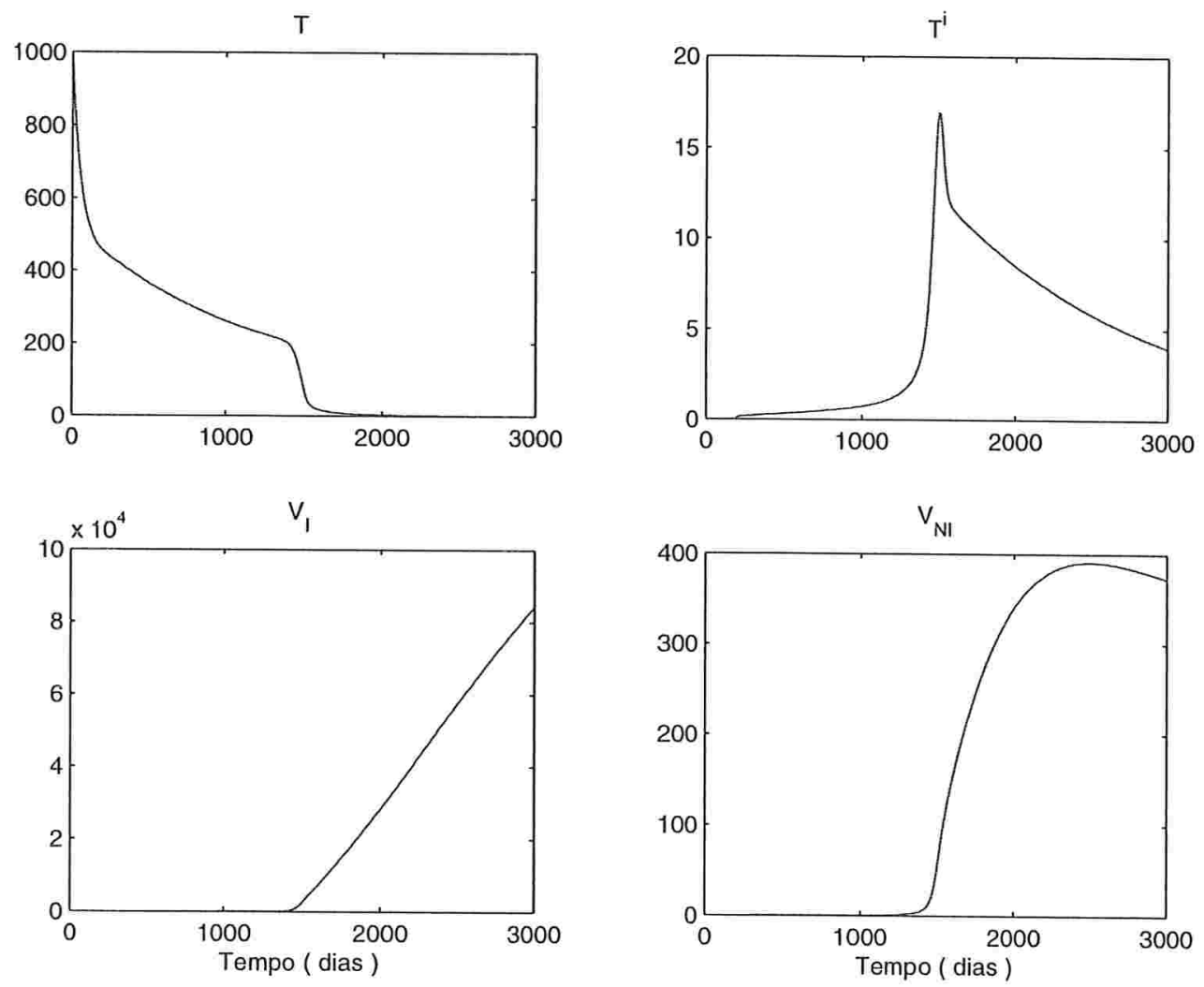

Figura 4.24: Modelo de Kirschner [1996]: Simulação feita utilizando-se um inibidores de protease e de transcriptase reversa com eficácia máxima $\beta=0,5$ em ambas as drogas. 

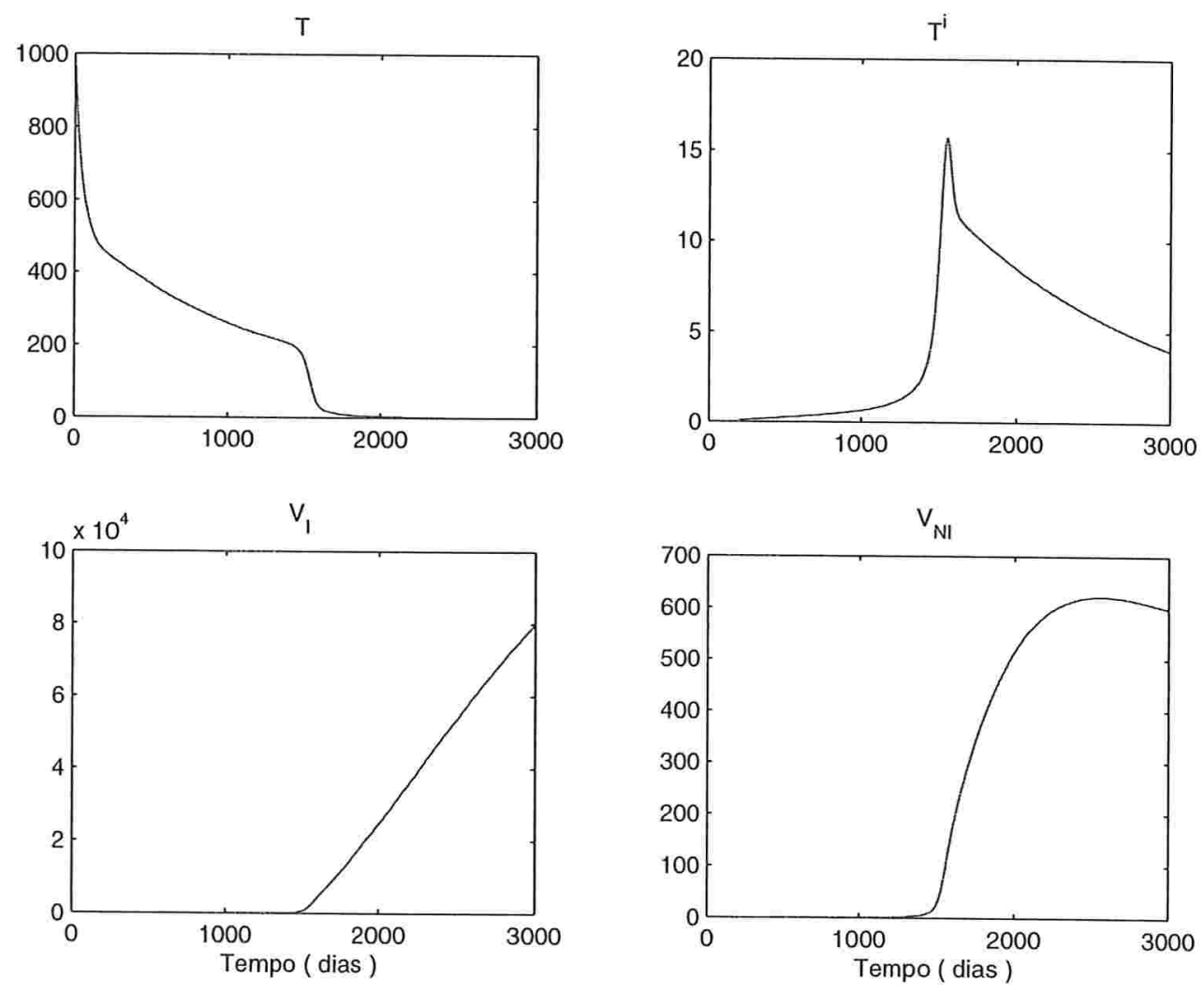

Figura 4.25: Modelo de Kirschner [1996]: Simulação feita utilizando-se um inibidores de protease e de transcriptase reversa com eficácia máxima $\beta=0,9$ em ambas as drogas. 


\section{Capítulo 5}

\section{Considerações Finais}

No Capítulo 1 apresentamos alguns modelos matemáticos determinísticos que ajudaram a revelar importantes aspectos da dinâmica HIV/AIDS, entre eles a estimativa quantitativa do quão rápido o vírus HIV-1 é produzido no organismo e do tempo necessário para que um tratamento antiretroviral 100\% efetivo eliminasse totalmente o vírus HIV-1 do organismo. Muitas outras abordagens têm sido propostas e são baseadas, por exemplo, em Celular Autômatos e em Lógica Fuzzy. A importância desses modelos reside no fato de, juntamente com os avanços na tecnologia, melhorarem os tratamentos e o entendimento sobre a patogênese do HIV-1.

No Capítulo 2 enunciamos e provamos um teorema que estabelece condições suficientes para a existência de órbitas periódicas via Teorema de Bifurcação de Poincaré-Andronov-Hopf em um modelo matemático da dinâmica HIV/AIDS. Essa bifurcação, a nosso ver, poderia ser interpretada como o início dos sintomas da Síndrome da Imunodeficiência Adquirida.

Ainda nesse modelo, foram encontradas apenas soluções periódicas estáveis para um conjunto de valores de parâmetros de interesse biológico. Não pudemos concluir sobre a existência ou não de soluções periódicas instáveis para um regime de parâmetros realista do ponto de vista biológico.

No Capítulo 3 foram implementados integradores com a característica de serem desenvolvidos para o estudo de sistemas de equações diferenciais cuja soluções sejam periódicas. Ao implementarmos esses algoritmos assumimos que além de variarem em função do tempo de maneira determinística seguindo sugestões de outros trabalhos, também haveria a possibilidade de incluir variações aleatórias segundo uma dada distribuição de probabilidades. Esses resultados não apresentados aqui poderão ser objeto de algum outro 
trabalho no futuro.

Finalmente, no Capítulo 4 sugerimos, seguindo comentários de outros trabalhos, que alguns parâmetros variassem em função do tempo de modo a representar de maneira mais realista os eventos que estão ocorrendo no intereção vírus HIV-1 e o sistema imune. É importante ressaltar que essas variações podem e devem ser muito mais complexas que as sugeridas nesse trabalho. Assunto que requer o trabalho conjunto de diferentes especialistas envolvidos no assunto. 


\section{Apêndice A}

\section{Resultados Técnicos}

Apresentamos neste Apêndice o enunciado de Teoremas que foram usados no texto.

\section{A.1 Critério de Liapunov}

O Critério de Liapunov como enunciado nesta seção pode ser encontrado em Wiggins [1990] e a demonstração em Rouche [1977].

Teorema 2 ( Critério de Liapunov) Considere o campo de vetores

$$
\dot{x}=f(x), \quad x \in \mathbb{R}^{n} .
$$

Seja $\bar{x}$ um ponto de equilíbrio de (A.1) e seja $V: U \rightarrow \mathbb{R}$ uma função $\mathcal{C}^{1}$ definida em uma vizinhança $U$ de $\bar{x}$ tal que

i) $V(\bar{x})=0$ e $V(x)>0$ se $x \neq \bar{x}$.

ii) $\dot{V}(x) \leq 0$ em $U-\{\bar{x}\}$.

Então $\bar{x}$ é estável. Além disso, se

iii) $\dot{V}(x)<0$ em $U-\{\bar{x}\}$

então $\bar{x}$ é assintoticamente estável.

Nos referimos a $V$ como uma função de Liapunov. Se $U$ for tomado como sendo $\mathbb{R}^{n}$, então $\bar{x}$ é globalmente assintoticamente estável se i) e iii) forem satisfeitas. 


\section{A.2 Teorema de Routh-Hurwitz}

O Teorema 3 pode ser visto em Pontriaguine [1969], página 62.

Teorema 3 ( Teorema de Routh-Hurwitz) Seja

$$
a_{0} p^{n}+a_{1} p^{n-1}+\cdots+a_{n}, a_{0}>0,
$$

um polinômio arbitrário de grau $n$ a coeficientes reais e tomemos a matriz $Q$ de ordem $n$ como segue abaixo:

$$
Q=\left(\begin{array}{ccccccc}
a_{1} & a_{3} & a_{5} & a_{7} & \ldots & 0 & 0 \\
a_{0} & a_{2} & a_{4} & a_{6} & \ldots & 0 & 0 \\
0 & a_{1} & a_{3} & a_{5} & \ldots & 0 & 0 \\
0 & a_{0} & a_{2} & a_{4} & \ldots & 0 & 0 \\
\vdots & \vdots & & \ddots & \ddots & \vdots & \vdots \\
0 & 0 & \ldots & & \ldots & a_{n-1} & 0 \\
0 & 0 & \ldots & & \ldots & a_{n-2} & a_{n}
\end{array}\right),
$$

então o polinômio (A.2) é estável se, e somente se, todos os menores principais da matriz $Q$ são positivos.

Um polinômio é estável se, e somente se, todas suas raízes possuem parte real negativa.

\section{A.3 Teorema de Poincaré-Andronov-Hopf}

Nesta seção enunciaremos uma forma simplificada do Teorema de Bifurcação de Poincaré-Andronov-Hopf suficiente para os nossos propósitos. Para um enunciado mais completo ver Hassard [1981], páginas 14, 15 e 16, a demonstração encontra-se em Marsden [1976], páginas 163 a 205.

Teorema 4 ( Teorema de Bifurcação de Poincaré-Andronov-Hopf ) Seja

$$
\frac{d X}{d t}=F(X, \mu)
$$

uma equação diferencial tal que $X=0 \in \mathbb{R}^{n}$ é um ponto de equilíbrio $e$ o valor crítico do parâmetro de bifurcação $\mu$ é 0 . Se 
a) $F(0, \mu)=0$ para $\mu$ em um intervalo aberto contendo 0, e $0 \in \mathbb{R}^{n}$ é um ponto de equilibrio isolado de $F(\cdot, \mu)$,

b) F é analítica em $X$ e $\mu$ em uma vizinhança de $(0,0)$ em $\mathbb{R}^{n} \times \mathbb{R}^{1}$,

c) $A(\mu)=J_{X} F(0, \mu)$ tem um par de autovalores complexos conjugados $\lambda$ e $\bar{\lambda}$ tal que

$$
\lambda(\mu)=\alpha(\mu)+i \omega(\mu)
$$

onde $\omega(0)=\omega_{0}>0, \alpha(0)=0, \alpha^{\prime}(0) \neq 0$,

d) os $n-2$ autovalores restantes de $A(0)$ têm parte real estritamente negativa,

então o sistema (A.3) tem uma família de soluções periódicas: existe um $\varepsilon_{H}>0$ e uma função analítica

$$
\mu^{H}(\varepsilon)=\sum_{i=2}^{\infty} \mu_{i}^{H} \varepsilon^{i}, \quad\left(0<\varepsilon<\varepsilon_{H}\right),
$$

tal que para cada $\varepsilon \in] 0, \varepsilon_{H}$ [ existe uma solução $p_{\varepsilon}(t)$ periódica ocorrendo para $\mu=\mu^{H}(\varepsilon)$. Se $\mu^{H}(\varepsilon)$ não é identicamente nula, o primeiro coeficiente não nulo de $\mu_{i}^{H}$ tem índice par e existe um $\left.\left.\varepsilon_{1} \in\right] 0, \varepsilon_{H}\right]$ tal que $\mu^{H}(\varepsilon)$ é ou estritamente positivo ou estritamente negativo para $\varepsilon \in] 0, \varepsilon_{1}[$.

Para cada $L>2 \pi / \omega_{0}$ existe uma vizinhança $\Lambda$ de $X=0$ e um intervalo aberto $\mathcal{I}$ contendo 0 tal que para qualquer $\mu \in \mathcal{I}$ as únicas soluções periódicas não-constantes de (A.3) com periodos menores que L que estão contida em $\Lambda$ são membros da família $p_{\varepsilon}(t)$ para valores de $\varepsilon$ satisfazendo $\mu^{H}(\varepsilon)=\mu, \varepsilon \in$ ] $0, \varepsilon_{H}\left[\right.$. O período de $p_{\varepsilon}(t)$ é uma função analítica

$$
T^{H}(\varepsilon)=\frac{2 \pi}{\omega_{0}}\left[1+\sum_{i=2}^{\infty} \tau_{i}^{H} \varepsilon^{i}\right], \quad 0<\varepsilon<\varepsilon_{H} .
$$

Existe uma função analítica

$$
\beta^{H}(\varepsilon)=\sum_{i=2}^{\infty} \beta_{i}^{H} \varepsilon^{i}, \quad 0<\varepsilon<\varepsilon_{H},
$$

tal que a solução periódica $p_{\varepsilon}(t)$ é orbitalmente assintoticamente estável com fase assintótica se $\beta^{H}(\varepsilon)<0$, mas é instável se $\beta_{H}(\varepsilon)>0$. 


\section{Bibliografia}

[Abbas 2000] Abbas, A. K.; Lichtman, A. H.; Pober, J. S., Imunologia Celular 83 Molecular. Tradução de Raimundo Gesteira. Terceira edição. Livraria e Editora Revinter Ltda. Rio de Janeiro.

[Anderson 1993] Anderson, R. M.; May, R. M., Infectious Diseases of Humans. Dynamics and Control. Oxford University Press, Inc. New York.

[Barré-Sinoussi 2003] Barré-Sinoussi, F. The early years of HIV research: integrating clinical and basic research. Nature Medicine, Volume 9, Number 7 , pp. 844-846.

[Boyce 1992] Boyce, W. E.; Di Prima, R. C.,Elementary Differential Equations and Boundary Value Problems. John Wiley \& Sons Ltd., England.

[Callaway 2002] Callaway, D., Perelson, A. S., HIV-1 Infection and Low Steady State Viral Loads. Bulletin of Mathematical Biology, Vol. 64, pp. 29-64.

[Chun 1999] Chun, T. W. et al. Re-emergence of HIV-1 After Stopping Therapy. Nature, 401, pp. 874-875.

[Culshaw 2000] Culshaw, R. V.; Ruan, S., A Delay-Differential Equation Model of HIV Infection of $\mathrm{CD}^{+}{ }^{+}$-Cells. Mathematical Biosciences, 165, pp. 27-39.

[Farah 1997] Farah, S. B. DNA Segredos $\mathcal{3}$ Mistérios. São Paulo: Sarvier.

[Fauci 2003] Fauci, A. S. HIV and AIDS: 20 years of science. Nature Medicine, Volume 9, Number 7, pp. 839-843. 
[Finzi 1999] Finzi, D. et al. Latente Infection of $\mathrm{CD}^{+}$Cells Provides a Mechanism for Lifelong Persistence of HIV-1, even in Patients on Effective Combination Therapy. Nature Medicine, Volume 5, Number 5, pp. 512517 .

[Gautschi 1961] Gautschi, W., Numerical Integration of Ordinary Differential Equations Based on Trigonometric polynomials. Numer. Math., 3, 381-397.

[Gerald 1994] Gerald, C. F.; Wheatley, P. O., Applied Numerical Analysis. Fifth Edition. Addison Wesley Longman, Inc. Reading, Massachusetts.

[Guckenheimer 1983] Guckenheimer, P. H., Nonlinear Oscillations, Dynamical Systems and Bifurcations of Vector Fields. Applied Mathematical Sciences. Vol. 42. Springer-Verlag, New York.

[Guedes 2002] Guedes, C. L. C., Simulação Numérica de Modelos Determinísticos da Dinâmica do HIV. Dissertação de Mestrado, Instituto de Matemática e Estatística, Universidade de São Paulo, Brasil.

[Hale 1980] Hale, J., Ordinary Differential Equations. Robert E. Krieger Publishing Company, Inc. Malabar, Florida.

[Hale 1991] Hale, J.; Koçak, H., Dynamics and Bifurcations. SpringerVerlag, New York.

[Hassard 1981] Hassard,B. D.; Kazarinoff, N. D.; Wan, Y-H, Theory and Applications of Hopf Bifurcation. Cambridge University Press, Inc. Chelsea, Michigan.

[Ho 1995] Ho, D. D.; Newmann, A. U.; Perelson, A. S.; Chen, W.; Leonard, J. M.; Markowitz, M., Rapid Turnover of Plasma Virions and CD4 lymphocytes in HIV-1 infection. Nature, 373, pp. 123-126.

[Kepler 1998] Kepler, T. B.; Perelson, A. S., Drug Concentration heterogeneity Facilitates the Evolution of Drug Resistance. Proc. Natl. Acad. Sci, USA, 95, 11514-11519.

[Kirschner 1996] Kirschner, D., Webb, G. F., A Model for Treatment Strategy in the Chemotherapy of AIDS. Bulletin of Mathematical Biology, Vol. 58, Number 2, pp. 367-390. 
[Kirschner 1997] Kirschner, D., Webb, G. F., Understanding Drug Resistance for Monotherapy Treatment of HIV Infection. Bulletin of Mathematical Biology, Vol. 59, Number 4, pp. 763-785.

[ Knuth 1998] Knuth, D. E., The Art of Computer Programming. Third Edition. Seminumerical Algorithms. Vol. 2. Addison Wesley Longman, Inc. Reading, Massachusetts.

[Lambert 1962] Lambert, J. D.; Mitchell, A. R., On the Solution of $y^{\prime}=$ $f(x, y)$ by a Class of High Accuracy Difference Formulae of Low Order. Z. Angew. Math. Phys., 13, 223-232.

[Lambert 1973] Lambert, J. D., Computacional Methods in Ordinary Differential Equations. John Wiley \& Sons Ltd. Bristol, Great Britain.

[Lambert 1991] Lambert, J. D., Numerical Methods for Ordinary Differential Systems. The Inicial Value Problem. John Wiley \& Sons Ltd. Chichester, England.

[Letvin 2003] Letvin, N. L.; Walker, B. D. Immunopathogenesis and immunotherapy in AIDS virus infections. Nature Medicine, Volume 9 , Number 7, pp. 861-866.

[Lima 1996] Lima, A. L. L. M., HIV/AIDS. Perguntas e Respostas. Editora Atheneu, São Paulo.

[Lyne 1989] Lyne, S. P.; Spouge, J. L.; Dembo, M., Quantifying the Infectivity of HIV. Proc. Natl. Acad. Sci, USA, 86, 4644-4648.

[Markowitz 1996] Markowitz, M. et al. Triple Therapy with AZT, 3TC, and Ritonavir in 12 Subjects Newly Infected with HIV-1. XI International Conference on AIDS, Vancouver, 11 July 1996.

[Marsden 1976] Marsden, J. E.; McCracken, M., The Hopf Bifurcations and its Aplications.. Applied Mathematical Sciences. Vol. 19. SpringerVerlag, New York.

[Massad 1992] Massad, E., Modelos Matemáticos. In Forattini, O. P., editor, Ecologia, Epidemia e Sociedade. Editora Artes Médicas.

[Massad 1995] Massad, E., Mathematical and Computer Models in Epidemiology. Notas não publicadas. 
[McMichael 2003] McMichael, A. J.; Hanke, T. HIV vaccines 1983-2003. Nature Medicine, Volume 9, Number 7, pp. 874-880.

[Merrill 1987] Merrill, S., AIDS: Background and the Dynamics of the Decline of Immunocompetence. In Theorical Immunology, Part 2 , A. S. Perelson, Ed. Addison-Wesley, Redwood City, Calif, pp. 59-75.

[Merrill 1989] Merrill, S., Modeling the Interaction of HIV with Cells of the Immune Response. In Mathematical and Statistical Approaches to AIDS Epidemiology (Lec. Notes Biomath. Vol. 83), C. Castillo-Chavez, Ed., Springer-Verlag, New York, pp. 371-385. Addison-Wesley, Redwood City, Calif, pp. 59-75.

[Murray 1993] Murray, J. D., Mathematical Biology. Biomathematical Texts. Springer-Verlag. New York.

[Nelson 1998] Nelson, P. W. Mathematical Models of HIV Pathogenesis and Immunology. Tese de Doutorado, University of Washington, Seattle, Washington, Estados Unidos.

[Nelson 2000] Nelson, P. W.; Murray, J. D.; Perelson, A. S., A Model of HIV-1 Pathogenesis that Includes an Intracellular Delay. Mathematical Biosciences, 163, pp. 201-215.

[Perelson 1989] Perelson, A. S., Modeling the Interaction of the Immune System with HIV. In Mathematical and Statistical Approaches to AIDS Epidemiology (Lec. Notes Biomath. Vol. 83), C. Castillo-Chavez, Ed., Springer-Verlag, New York, pp. 350-368. Addison-Wesley, Redwood City, Calif, pp. 59-75.

[Perelson 1993] Perelson, A. S.; Kirschner, D. E.; Boer, R., Dynamics of HIV Infection of $\mathrm{CD4}^{+} \mathrm{T}$ cells. Mathematical Biosciences, Vol. 114, pp. 81-125.

[Perelson 1996] Perelson, A. S.; Neumann, A. U.; Markowitz, M.; Leonard, J. M.; Ho, D. D., HIV-1 dynamics in vivo: Virion clearance rate, infected cell life span, and viral generation time. Science, 271, pp. 1582-1586.

[Perelson 1997] Perelson, A. S.; Essunger, P.; Cao, Y.; Vesanen, M.; Hurley, A.; Saksela, K.; Markowitz, M.; Ho, D. D., Decay characteristics of 
HIV-1-infected compartments during combination therapy. Nature, 387, pp. 188-191.

[Perelson 1999] Perelson, A. S.; Nelson, P. W., Mathematical Analysis of HIV-1 Dynamics in Vivo. Society for Industrial and Applied Mathematics, Vol. 41, No. 1, pp. 3-44.

[Pomerantz 2003] Pomerantz, R. J.; Horn, D. L. Twenty years of therapy for HIV-1 infection. Nature Medicine, Volume 9, Number 7, pp. 867-873.

[Pontriaguine 1969] Pontriaguine, L., Équations Différentielles Ordinaires. Éditions Mir, Moscou.

[Pope 2003] Pope, M.; Haase A. T. Transmission, acute HIV-1 infection and the quest for strategies to prevent infection. Nature Medicine, Volume 9 , Number 7, pp. 847-852.

[Press 1989] Press, W. H.; Flannery, B. P.; Teukolsky, S. A.; Vetterling, W. T., Numerical Recipes in Pascal. The Art of Scientific Computing Cambridge University Press, Inc. New York.

[Rice 1993] Rice, J. R.,Numerical Methods, Software, and Analysis. Second Edition. Academic Press, Inc. San Diego.

[Rouche 1977] Rouche, N.; Habets, P.; Laloy, M.,Stability Theory by Liapunov's Direct Method. Applied Mathematical Sciences. Vol. 22. Springer-Verlag, New York.

[Sharkey 2000] Sharkey, M. E. et al. Persistence of Episomal HIV-1 Infection Intermediates in Patients on Highly Active Anti-retroviral Therapy. Nature Medicine, Volume 6, pp. 76-81.

[Simos 1995] Simos, T. E., An Explicit High Order Predictor-Corrector Method for Periodic Initial Value Problems. Mathematical Models and Methods in Applied Sciences, Vol. 5, Number 2, pp. 159-166.

[Sotomayor 1979] Sotomayor, J., Lições de Equações Diferenciais Ordinárias. Projeto Euclides, CNPq.

[Stevenson 2003] Stevenson, M. HIV-1 pathogenesis. Nature Medicine, Volume 9, Number 7, pp. 853-860. 
[Stites 1992] Stites, D. P.; Terr, A. I. Imunologia Básica. Tradução de José Mauro Peralta. Rio de Janeiro: Editora Prentice-Hall do Brasil Ltda.

[Struchiner 1994] Struchiner, C. J.; Massad, E.; Neto, R. A. N., Introdução à Dinâmica Populacional das Doenças Transmissiveis. Notas não publicadas.

[Tan 1997] Tan, W. Y.; Wu, H., Stochastic Modeling of the Dynamics of CD4 ${ }^{+}$T-Cell Infection by HIV and Some Monte Carlo Studies. Mathematical Biosciences, Vol. 147, pp. 173-205.

[Veronesi 1996] Veronesi, R., Tratado de Infectologia. Editora Atheneu, São Paulo.

[Waltkins 1995] Waltkins, B. A.; Klotman, M. E.; Gallo, R. C., Humam Immunodeficiency Viruses. In: Mandell, Douglas and Bennett's Principles and Pratice of Infectious Diseases. Gerald L. Mandell, John E. Bennet, Raphael Dolin eds - 4th ed. New York, Churchill Livingstone.

[Wei 1995] Wie, X. et al. Viral Dynamics in Human Immunodeficiency Virus Type 1 Infection. Nature, 373, pp. 117-122.

[Wiggins 1990] Wiggins, S., Introduction to Applied Nonlinear Dynamical Systems and Chaos. Texts in Applied Mathematics. Vol. 2. SpringerVerlag. New York. 